Florida International University FIU Digital Commons

$11-20-2001$

\title{
Titanium dioxide photocatalytic degradation of aliphatic ethers and their primary oxidation products
}

Vivian Cruz

Florida International University

DOI: $10.25148 /$ etd.FI14061553

Follow this and additional works at: https://digitalcommons.fiu.edu/etd

Part of the Chemistry Commons

\section{Recommended Citation}

Cruz, Vivian, "Titanium dioxide photocatalytic degradation of aliphatic ethers and their primary oxidation products" (2001). FIU Electronic Theses and Dissertations. 2677.

https://digitalcommons.fiu.edu/etd/2677 


\title{
FLORIDA INTERNATIONAL UNIVERSITY \\ Miami, Florida
}

\section{TITANIUM DIOXIDE PHOTOCATALYTIC DEGRADATION OF ALIPHATIC ETHERS AND THEIR PRIMARY OXIDATION PRODUCTS}

\author{
A thesis submitted in partial fulfillment of the \\ requirements for the degree of \\ MASTER OF SCIENCE \\ in
}

CHEMISTRY

by

Vivian Cruz

2002 
To: Dean Arthur W. Herriott

College of Arts and Sciences

This thesis, written by Vivian Cruz, and entitled Titanium Dioxide Photocatalytic Degradation of Aliphatic Ethers and their Primary Oxidation Products, having been approved in respect to style and intellectual content, is referred to you for judgment.

We have read this thesis and recommend that it be approved.

Stanislaw Wnuk

Ramón López de la Vega

William J. Cooper

Kevin E. O'Shea, Major Professor

Date of Defense: November 20, 2001

The thesis of Vivian Cruz is approved.

Dean Arthur W. Herriott College of Arts and Sciences

Dean Douglas Wartzok University Graduate School

Florida International University, 2002 
(C) Copyright 2002 by Vivian Cruz

All rights reserved. 


\section{ACKNOWLEDGMENTS}

All thanks to God.

I thank to my advisor, Dr. Kevin O'Shea, for his professional and enthusiastic guidance in the development and conclusion of the research project; and to the rest of the members of my committee for their support.

Special acknowledgments to my family, primarily to my husband, Ahmed Cruz, who has helped and inspired me with his optimism and perseverance. 
ABSTRACT OF THE THESIS

TITANIUM DIOXIDE PHOTOCATALYTIC DEGRADATION OF ALIPHATIC

ETHERS AND THEIR PRIMARY OXIDATION PRODUCTS

by

Vivian Cruz

Florida International University, 2002

Miami, Florida

Professor Kevin E. O'Shea, Major Professor

Two studies were performed to obtain fundamental mechanistic information on the $\mathrm{TiO}_{2}$ catalyzed degradation of organic substrates irradiated at $350 \mathrm{~nm}$ in dilute aqueous solutions under oxygenated conditions: (a) The photodecomposition of methyl tert-butyl ether (MTBE) and its intermediate products from $\beta$ - oxidation, 2-methoxy-2methylpropanol and 2-methoxy-2-methylpropanal. (b) The photodecomposition of two haloethers, bis-(2-chloroethyl) ether, and bis-(2-chloroisopropyl) ether. Controls were carried out throughout the two studies in the absence of light, and without the semiconductor in order to evaluate the role of photolysis.

The syntheses of proposed intermediate products, 2-methoxy-2-methylpropanol, 2methoxy-2-methylpropanal, 2-methoxy-2-methylpropanoic acid, 2-chloroethyl formate, and 1-chloro-2-propyl acetate, were performed. The formation of these products in the titanium dioxide photocatalytic oxidation of the substrates of interest was also confirmed. $\mathrm{TiO}_{2}$ photocatalysis is a very effective method for the mineralization of aliphatic ethers and their primary oxidation products. 
I INTRODUCTION

Water Decontamination - The Latest Technologies............................................ 1

Advanced Oxidation Processes (AOP) …......................................................... 1

Titanium Dioxide Photocatalysis ..................................................................... 4

Reactions of Peroxyl Radicals in Aqueous Solution .......................................... 7

II TITANIUM DIOXIDE PHOTOCATALYSIS OF

2-METHOXY-2-METHYL PROPANE (METHYL

tert-BUTYL ETHER, MTBE) .................................................................... 14

2-Methoxy-2-Methyl Propane (MTBE) - Introductory Remarks......................... 14

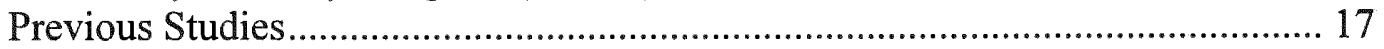

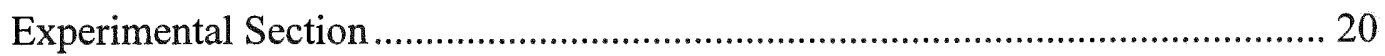

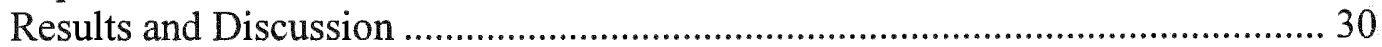

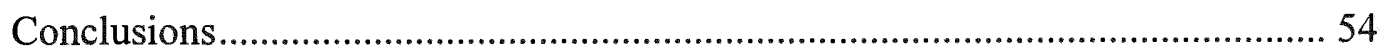

III TITANIUM DIOXIDE PHOTOCATALYZED

DEGRADATION OF HALO-ETHERS ……............................................... 58

Chloroalkyl Ethers - Introductory Remarks ........................................................ 58

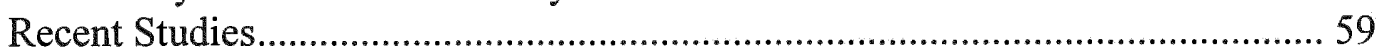

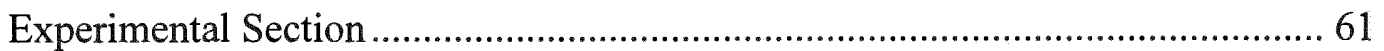

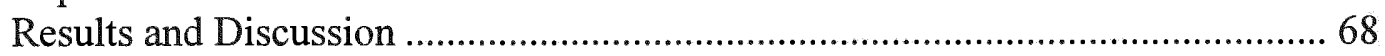

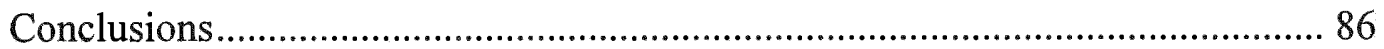

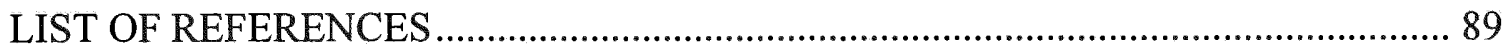

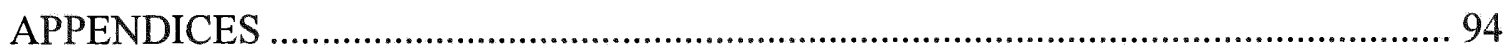




\section{LIST OF TABLES}

TABLE

PAGE

I. Oxidation Potential of Several Oxidants in Water.............................2

II. Rate Constants for $\mathrm{O}_{3}$ and $\bullet \mathrm{OH}$ Reactions with Organic

Compounds in Water...

III. Chemical Properties of MTBE.............................................16

IV. Chemical Data of MTBE Oxidation Products...................................19

V. Physical Constants of Aliphatic Haloethers..................................5

VI. Name and Structures of Aliphatic Haloethers in the Study ......................60

VII. Haloethers Derivatives. Chemical Data.....................................61 


\section{LIST OF FIGURES}

FIGURE

PAGE

I. Peroxyl Radicals. Monomolecular Reactions............................ 10

II. Peroxyl Radicals. Bimolecular Reactions..................................12

III. Oxyl Radical Reactions............................................... 13

IV. Degradation of Methyl tert-Butyl Ether (1.1 mM) in $\mathrm{TiO}_{2}$ Aqueous

Slurries. Air Saturated Solution.............................................32

V. Intermediate Products Profile in the $\mathrm{TiO}_{2}$ Degradation of MTBE at

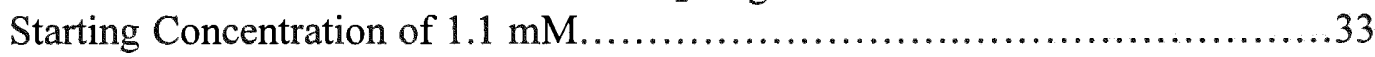

VI. Degradation of MTBE in $\mathrm{TiO}_{2}$ Slurries at Starting Concentration of

$5.0 \mathrm{mM}$. Air Saturated Solution.......................................... 36

VII. Intermediate Products Profile in the $\mathrm{TiO}_{2}$ Degradation of MTBE at

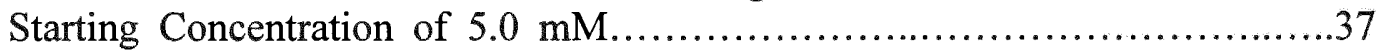

VIII. Degradation of an Air Saturated Solution of 2-Methoxy-2-Methylpropanol in $\mathrm{TiO}_{2}$ Slurries at Starting Concentration of $0.5 \mathrm{mM}$.

IX. Intermediate Products Profile in the $\mathrm{TiO}_{2}$ Photocatalyzed Oxidation of 2-Methoxy-2-Methylpropanol at Initial Concentration of $0.5 \mathrm{mM}$.

X. Degradation Profile of 2-Methoxy-2-Methylpropanal in $\mathrm{TiO}_{2}$

Slurries at Starting Concentration of $0.6 \mathrm{mM}$. Air Saturated Solution....

XI. Intermediate Products Profile in the Titanium Dioxide Photo-

Oxidation of 2-Methoxy-2-Methylpropanal at Starting

Concentration of $0.6 \mathrm{mM}$.

XII. Titanium Dioxide Photocatalyzed Degradation of MTBE.

Proposed Mechanism.

XIII. Proposed Mechanism for the Degradation of 2-Methoxy-2-

Methylpropanal. Formation of Acetone and Methyl Acetate.... 
XIV. Proposed Mechanism for the Degradation of 2-Methoxy-2-

Methylpropanal. Formation of 2-Methoxy-2-Methylpropanoic Acid.

XV. Proposed Mechanism for the $\mathrm{TiO}_{2}$ Photo-Induced Degradation of 2-Methoxy-2-Methylpropanol

XVI. Control Reactions and Titanium Dioxide Photocatalysis of Bis(2-chloroisopropyl) Ether. Initial Concentration $0.5 \mathrm{mM}$. Air Saturated Solution

XVII. Intermediate Products Profile in the Degradation of Bis(2-chloroisopropyl) Ether at Starting Concentration of $0.5 \mathrm{mM}$

XVIII. Titanium Dioxide Photocatalysis of 1-Chloro-2-Propyl Acetate at Starting Concentration of $0.5 \mathrm{mM}$. Air Saturated Solution. .74

XIX. Concentration of Chloroacetone as a function of Irradiation Time During the Titanium Dioxide Photolysis of 1-Chloro-2-Propyl Acetate (Initial Concentration $=0.5 \mathrm{mM}$ ).

XX. Control Reaction for Chloroacetone in the Dark at Starting Concentration of $0.6 \mathrm{mM}$. Air Saturated Solution.

XXI. Control Experiments and Titanium Dioxide Photo-Oxidation of Bis-(2-chloroethyl) Ether. Initial Concentration $0.7 \mathrm{mM}$.

Air Saturated Solution 78

XXII. Concentration of 2-Chloroethyl Formate and 2-Chloroethanol as a function of Irradiation Time During the $\mathrm{TiO}_{2}$ Photocatalyzed Degradation of Bis-(2-chloroethyl) Ether at Initial Concentration of $0.7 \mathrm{mM}$.

XXIII. Proposed Mechanism for the Degradation of Bis-(2-chloroisopropyl) Ether. Formation of 1-Chloro-2-Propyl Acetate and Chloroacetone.

XXIV. 1-Chloro-2-Propyl Acetate Photocatalyzed Degradation. Formation of Chloroacetone. Proposed Mechanism.

XXV. Formation of 2-Chloroethyl Formate During the $\mathrm{TiO}_{2}$ Photocatalysis of Bis-(2-chloroethyl) Ether. Proposed Mechanism

XXVI. Formation of 2-Chloroethanol During the $\mathrm{TiO}_{2}$ Photocatalysis of Bis-(2-chloroethyl) Ether. Proposed Mechanism. 


\section{INTRODUCTION.}

\subsection{WATER DECONTAMINATION - THE LATEST TECHNOLOGIES.}

The general presence of persistent organic chemicals as pollutants in wastewater effluents from industries and households is a serious environmental problem. Most of these compounds are toxic and difficult to treat using traditional wastewater facilities. Over the past two decades, environmental regulatory requirements have become more stringent because of increased awareness of the human health and ecological risks associated with environmental contaminants. In many cases, conventional treatment technologies, such as air stripping, carbon adsorption, biological treatment, and chemical oxidation using ozone $\left(\mathrm{O}_{3}\right)$ or hydrogen peroxide $\left(\mathrm{H}_{2} \mathrm{O}_{2}\right)$, have limitations. For example, stripping and adsorption merely transfer contaminants from one medium and to another, whereas biological treatment and conventional chemical oxidation have low removal rates for many environmental contaminants, including chlorinated organics. Therefore, various alternative treatment technologies have been developed over the last 10 to 15 years, in order to cost-effectively meet environmental regulatory requirements. One such group of technologies is commonly referred to as advanced oxidation processes. ${ }^{1,2}$

\subsection{ADVANCED OXIDATION PROCESSES (AOP).}

Advanced oxidation processes generally involve generation and use of powerful but relatively nonselective transient oxidizing species, primarily the hydroxyl radical $(\bullet \mathrm{OH}){ }^{1}$ In some vapor-phase advanced oxidation processes, singlet oxygen has also been identified as the dominant oxidizing species. ${ }^{3}$ Table I shows that $\bullet \mathrm{OH}$ has the highest 
thermodynamic oxidation potential, which is perhaps why $\bullet \mathrm{OH}$-based oxidation processes have received considerable attention as potential technologies for the treatment of chemical waste/pollutants.

TABLE I. Oxidation Potential of Several Oxidants in Water ${ }^{4}$

\begin{tabular}{|lc|}
\hline Oxidant & Oxidation Potential (eV) \\
\hline$\cdot \mathrm{OH}$ & 2.80 \\
$\mathrm{O}(1 \mathrm{D})$ & 2.42 \\
$\mathrm{O}_{3}$ & 2.07 \\
$\mathrm{H}_{2} \mathrm{O}_{2}$ & 1.77 \\
Perhydroxy radical & 1.70 \\
Peramnaganate ion & 1.67 \\
Chlorine dioxide & 1.50 \\
Chlorine & 1.36 \\
${ }^{\circ} \mathrm{O}_{2}$ & 1.23 \\
\hline
\end{tabular}

In addition, as shown in Table II, most environmental contaminants react $10^{6}$ to $10^{9}$ times faster with $\bullet \mathrm{OH}$ than with $\mathrm{O}_{3}$, which is currently used as a conventional oxidant. Hydroxyl radicals can be generated by photochemical or non-photochemical processes.

The typical mechanisms of reaction of hydroxyl radicals with organic substrates are:

1. $\cdot \mathrm{H}$ abstraction from the organic molecule by $\bullet \mathrm{OH}$ and the subsequent formation of $\mathrm{H}_{2} \mathrm{O}$ and the corresponding organic radical.

2. Addition of $\bullet \mathrm{OH}$ to the organic substrates.

3. Electron transfer from the substrate to $\bullet \mathrm{OH}$.

For aliphatic compounds, the most common mechanism is the hydrogen abstraction. 
TABLE II. Rate Constants for $\mathrm{O}_{3}$ and $\bullet \mathrm{OH}$ Reactions with Organic Compounds in Water $^{5}$

\begin{tabular}{|lll|}
\hline & \multicolumn{2}{c|}{ Rate Constant $\left(\mathrm{M}^{-15-1}\right)$} \\
\cline { 2 - 3 } Compound Type & $\mathrm{O}_{3}$ & $\cdot \mathrm{OH}$ \\
\hline Acetylenes & 50 & $10^{8}$ to $10^{9}$ \\
Alcohols & $10^{-2}$ to 1 & $10^{8}$ to $10^{9}$ \\
Alkanes & 10 & $10^{9}$ \\
Aromatics & $10^{-2}$ & $10^{6}$ to $10^{9}$ \\
Carboxylic acids & 1 to $10^{-2}$ & $10^{8}$ to $10^{10}$ \\
Chlorinated alkenes & $10^{-3}$ to $10^{-2}$ & $10^{7}$ to $10^{9}$ \\
Ketones & $10^{-1}$ to $10^{3}$ & $10^{9}$ to $10^{11}$ \\
Nitrogen-containing organics & 1 & $10^{9}$ to $10^{10}$ \\
Olefins & 1 to $10^{2}$ & $10^{8}$ to $10^{10}$ \\
Phenols & 1 to $450 \times 10^{3}$ & $10^{9}$ to $10^{11}$ \\
Sulfur-containing organics & $10^{3}$ & $10^{9}$ to $10^{10}$ \\
\hline
\end{tabular}

AOP technologies can be broadly divided into the following groups: ${ }^{1}$

1. Vacuum ultraviolet (VUV) photolysis. Contaminant degradation in water and in a relatively high-humidity air stream can be accomplished through oxidation by $\bullet \mathrm{OH}$ or reduction by $\mathrm{H} \bullet$, produced by the photolysis of water using UV radiation of a wavelength shorter than $190 \mathrm{~nm}$.

2. UV/oxidation processes. The generation of $\bullet \mathrm{OH}$ through $\mathrm{UV}$ photolysis of conventional oxidants, including hydrogen peroxide and ozone.

3. Photo-Fenton Process. The generation of hydroxyl radicals through the decomposition of $\mathrm{H}_{2} \mathrm{O}_{2}$ using ferrous iron (Fe(II)) or ferric iron (Fe(III)) under acidic 
conditions. The extent of mineralization can be improved by irradiation with near-UV radiation or visible light.

4. Sensitized AOP processes. They can be categorized as:

a. Dye-sensitized process. Dye molecules are excited by visible light. The excited state molecules can transfer their energy to other dissolved molecules, for example oxygen, which is converted to singlet oxygen, a powerful oxidant.

b. Semiconductor-sensitized AOP. Metal semiconductors are used to destroy environmental contaminants by means of light-induced redox reactions. These reactions involve generation of conduction band electrons and valence band holes by UV irradiation of semiconductor materials such as titanium dioxide $\left(\mathrm{TiO}_{2}\right)$.

5. Sonolysis. Ultrasonic waves, which consist of compression and rarefaction cycles, produce cavitation bubbles in liquid solution. After several compression cycles, the cavitation bubbles collapse violently and adiabatically with extremely high temperatures up to $5000 \mathrm{~K}$ and pressures of 975 bar. Under these extreme conditions, volatile chemical compounds are destroyed by direct photolysis reactions and indirectly by reactions with $\mathrm{H}^{\bullet}, \bullet \mathrm{OH}, \mathrm{O}^{\bullet-}$, and $\mathrm{H}_{2} \mathrm{O}_{2}{ }^{6}$

\subsection{TITANIUM DIOXIDE PHOTOCATALYSIS.}

Semiconductors are solids that have electrical conductivities between those of conductors and those of insulators. ${ }^{1}$ They are characterized by two separate energy bands: a low-energy valence band and a high-energy conduction band. Each band consists of a spectrum of energy levels in which electrons can reside. The energy separation between 
the valence and conduction band is called the band gap and consists of energy levels in which electrons can not reside. Light can be used to excite an electron from the valence band into the conduction band. A variety of semiconductors have been used in environmental applications, including titanium dioxide, ${ }^{7,8}$ strontium titanium trioxide, and zinc oxide. ${ }^{9} \mathrm{TiO}_{2}$ is a very attractive photocatalyst in several aspects. For example, it is relatively inexpensive, highly stable chemically, it has low toxicity, and the photogenerated holes are highly oxidizing. In addition, photogenerated electrons reduce oxygen to superoxide anion radical. ${ }^{10}$

Titanium dioxide is a semiconductor with an energy gap of $3.2 \mathrm{eV}$ between the valence band and the conduction band. For this semiconductor, the photon energy required to overcome the band gap energy and excite an electron from the valence band to the conduction band can be provided by light of a wavelength shorter than $387.5 \mathrm{~nm}$. When an electron in the valence band is excited into the conduction band, a vacancy or hole is left in the valence band. Such holes have the effect of a positive charge. The combination of the electron in the conduction band $\left(\mathrm{e}_{\mathrm{CB}}^{-}\right)$and the hole in the valence band $\left(\mathrm{h}^{+}{ }_{\mathrm{VB}}\right)$ is referred to as an electron-hole pair. In this stage, the electron is in an unstable excited state. That is why the electron-hole pair within a semiconductor band can undergo recombination to give the ground state semiconductor. However, the band gap inhibits this reversal long enough to allow excited electrons and holes near the surface of the semiconductor to participate in reactions at the surface. This creates the potential for both reduction and oxidation processes to occur. The positions of the valence and the conduction bands of antase $\mathrm{TiO}_{2}$ at $\mathrm{pH} 1$ (relative to SCE) are $-0.1 \mathrm{~V}$ and $+3.1 \mathrm{~V}$ respectively. ${ }^{11,12}$ 
The primary $\mathrm{TiO}_{2}$ photocatalytic mechanism is believed to proceed as follows: ${ }^{1}$

$$
\mathrm{TiO}_{2}+\mathrm{hv} \longrightarrow \mathrm{TiO}_{2}^{*}+\left(\mathrm{e}_{\mathrm{CB}}^{-}+\mathrm{h}^{+} \mathrm{vB}\right)
$$

Direct electron transfer from the substrate to the valence hole yields a radical cation, and electron transfer of the conduction band electron to the substrate produces a radical anion. Although direct electron transfer between substrate and photo-excited titanium dioxide is important, the predominant mechanisms for photo-oxidation of substrates in aqueous media appear to involve hydroxyl radicals, formed by electron transfer from water or hydroxide ion from water dissociation to the hole, at the $\mathrm{TiO}_{2}$ surface, ${ }^{1,13}$ as follows:

$$
\begin{aligned}
& \mathrm{h}^{+} \mathrm{VB}+\mathrm{H}_{2} \mathrm{O} \longrightarrow \cdot \mathrm{OH}+\mathrm{H}^{+} \\
& \mathrm{h}^{+}{ }_{\mathrm{VB}}+\mathrm{OH}^{-} \longrightarrow \cdot \mathrm{OH}
\end{aligned}
$$

Hydroxyl radical formation has been observed upon irradiation of titanium dioxide in the presence of water. ${ }^{14}$

Formation of hydroxyl radicals via reactions (2) and (3) is possible if the electronhole pair lasts long enough to allow oxidation of water molecules by the hole $\left(\mathrm{h}^{+}{ }_{\mathrm{VB}}\right)$. If the electron in the conduction band reacts with $\mathrm{O}_{2}$ to form superoxide ions, the lifetime of $\mathrm{h}^{+}{ }_{\mathrm{VB}}$ is prolonged dramatically, ${ }^{1}$ increasing the production of $\cdot \mathrm{OH}$ via oxidation of $\mathrm{H}_{2} \mathrm{O}$.

$$
\mathrm{e}_{\mathrm{CB}}^{-}+\mathrm{O}_{2} \longrightarrow \mathrm{O}_{2}{ }^{--}
$$

The $\mathrm{O}_{2}{ }^{*-}$ can then react with $\mathrm{H}_{2} \mathrm{O}$ to provide additional $\cdot \mathrm{OH}, \mathrm{OH}^{-}$, and $\mathrm{O}_{2}{ }^{\mathrm{I}}$, as follows:

$$
\begin{aligned}
& 2 \mathrm{O}_{2}{ }^{\circ-}+2 \mathrm{H}_{2} \mathrm{O} \longrightarrow \mathrm{H}_{2} \mathrm{O}_{2}+2 \mathrm{OH}^{-}+\mathrm{O}_{2} \\
& \mathrm{H}_{2} \mathrm{O}_{2}+\mathrm{e}_{\mathrm{CB}}^{-} \longrightarrow \mathrm{OH}^{-}+\cdot \mathrm{OH}
\end{aligned}
$$


The efficiency of the photooxidation process is related to the adsorption/partitioning of substrates on the surface of the photocatalyst and the reaction rates between substrate and the reactive species generated at the surface. Although it has been reported that adsorption is critical for the degradation of reactive intermediates, there is still uncertainty as to the role that adsorption plays and how it ultimately affects the reaction pathways. ${ }^{15,16}$

The redox potential for photogenerated holes on the $\mathrm{TiO}_{2}$ surface at $\mathrm{pH} 7$ is $+2.53 \mathrm{~V}$ (versus the standard hydrogen electrode (SHE)). Upon reaction with water or hydroxide anions, these holes can produce hydroxyl radicals. The redox potential for conduction band electrons is $-0.52 \mathrm{~V}$, which is in principle negative enough to evolve hydrogen from water, but the electrons can become trapped and lose some of their reducing power. However, even after trapping, a significant number are still able to reduce dioxygen to superoxide $\left(\mathrm{O}_{2}{ }^{-}\right)$or to hydrogen peroxide $\left(\mathrm{H}_{2} \mathrm{O}_{2}\right)$. Depending upon the conditions, the holes, hydroxyl radicals, $\mathrm{O}_{2}{ }^{--}, \mathrm{H}_{2} \mathrm{O}_{2}$, and $\mathrm{O}_{2}$ can all play important roles in the photocatalytic reaction mechanisms. ${ }^{10}$

One of the most important aspects of $\mathrm{TiO}_{2}$ photocatalysis is that, like the photoelectric effect, it depends upon the energy of the incident photons but, to a first approximation, not on their intensity. Thus, even if there are just few photons of the required energy, they can induce photocatalysis. ${ }^{10}$

\subsection{REACTIONS OF PEROXYL RADICALS IN AQUEOUS SOLUTION.}

Whenever free radicals are formed, independent of whether this occurs thermally, is induced by UV or ionizing irradiation, takes place in redox reactions, or it is a result of 
- H abstraction, they are converted rapidily into the corresponding peroxyl radicals in the presence of oxygen. $^{17}$

The peroxyl radicals formed can undergo monomolecular and bimolecular reactions. A number of peroxyl radicals are able to eliminate $\mathrm{O}_{2}{ }^{--}$, as shown in Figure I. In order for the rate of this reaction to be measurable, the positive charge must be stabilized by a heteroatom (reaction I). The influence of the substituents is much more pronounced in charge stabilization than in the stabilization of radical centers ${ }^{18}$. An alkoxy group situated next to the peroxyl radical function $(A, X=0)$ does not suffice to make the reaction much faster than $1 \mathrm{~s}^{-1},{ }^{19}$ while two alkoxy groups $\left(\mathrm{A}, \mathrm{X}=\mathrm{O}, \mathrm{R}^{\prime}=\mathrm{OR}\right)$ accelerate the reaction to almost $10^{5} \mathrm{~s}^{-1} ;{ }^{20}$ with a dimethylamino group as the stabilizer of the positive charge $(B, X=N R)$ the reaction is so fast that the intermediate peroxyl radical can no longer be detected. ${ }^{21}$ The rapid formation of $\mathrm{HO}_{2}{ }^{\bullet} / \mathrm{O}_{2}{ }^{--}$from the peroxyl radicals of the aldehyde hydrates $(\mathbf{C}, \mathrm{R}=\mathrm{H})$ and hemiacetals $\mathbf{C},{ }^{22,23,24}$ may also involve an elimination of $\mathrm{O}_{2}{ }^{\bullet-}$, although in these cases the proton is split off in a concerted manner together with $\mathrm{O}_{2}{ }^{\bullet-}$ (reaction II). The $\mathrm{HO}_{2}{ }^{\bullet-}$-elimination reactions starting from $\alpha$-hydroxyalkylperoxyl radicals $\mathbf{E}$ (reaction III) are mechanistically different, and a five-membered transition state has been assumed to be involved. ${ }^{25}$ This type of reaction possibly also includes the formation of $\mathrm{HO}_{2}{ }^{\bullet}$ from cyclohexadienylperoxyl radicals $\mathbf{H}$ (reaction V). ${ }^{26}$ In this case, the driving force would be the increase in conjugation energy as the aromatic product I is formed. A deprotonation of the $\alpha$-hydroxyalkylperoxyl radicals $\mathbf{E}$ leads to their anions $\mathbf{G}$, which very rapidly eliminate $\mathrm{O}_{2}{ }^{--}$(reaction IV). ${ }^{27,28}$ 
If weakly bonded hydrogen atoms are in a suitable position $(\mathbf{J}$, six-membered ring as the transition state) intramolecular hydrogen transfer reactions can become important (reaction VI). ${ }^{19,29}$ Peroxyl radicals of type $\mathbf{L}$ can also add intramolecularly to double bonds. $^{30}$

Peroxyl radicals (A) undergo a head-to-head termination reaction ${ }^{31}$ to form intermediate tetroxides $\mathbf{B}$, which are in equilibrium with the peroxyl radicals at low temperatures in organic solvents, as shown in Figure II. Tetroxides lead to different products through a series of reactions. The best known is the Russell reaction, in which two primary or secondary peroxyl radicals undergo an electrocyclic reaction to give molecular oxygen, a product with a $\mathrm{C}=\mathrm{O}$ function, and one with an $\mathrm{OH}$ function (reaction I). ${ }^{32}$ A six-membered transition state has been postulated. A further electrocyclic process leads to the formation of $\mathrm{H}_{2} \mathrm{O}_{2}$ and two carbonyl compounds (reaction II). The transition state could involve two five-membered rings. ${ }^{32}$ 
FIGURE I. Peroxyl Radicals. Monomolecular Reactions
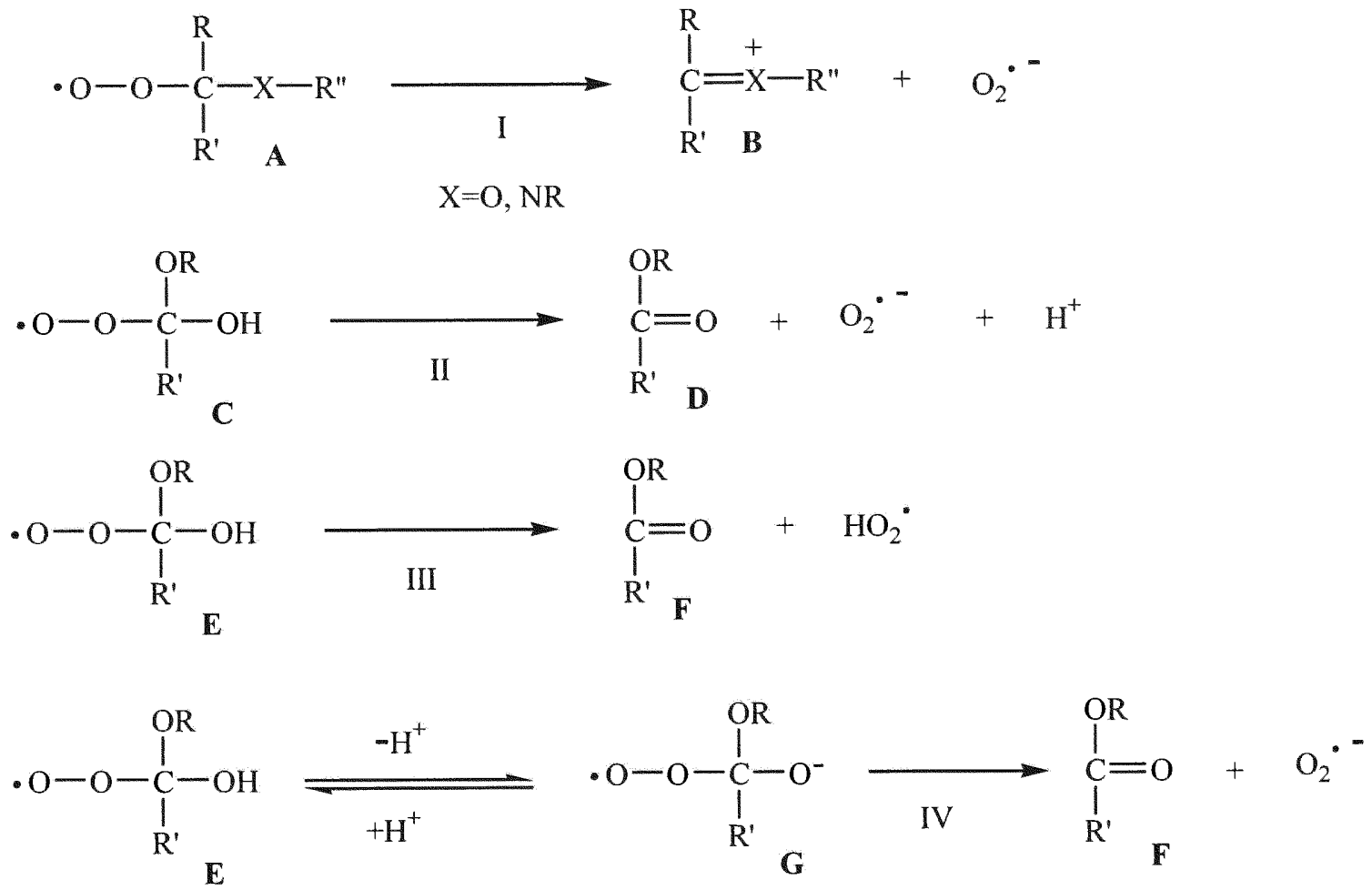<smiles>[O-]OC1C=CC=CC1</smiles><smiles></smiles><smiles>[R]C([R])([R])OC([R])([R])O[O-]</smiles><smiles>[R]OC([R])([R])O[C]([R])[R]</smiles><smiles>[R]C([R])=C([R])C([R])([R])O[O-]</smiles>

$\mathbf{L}$<smiles>[R]C1C([R])([R])OOC1([R])[R]</smiles>

M 
The decomposition of peroxyl radicals to give molecular oxygen and two oxyl radicals C (reaction IV) is a well established reaction pathway. ${ }^{33}$

As shown in figure III, a disproportionation of the oxyl radicals in the solvent cage (reaction I) leads to the same products as the Russell mechanism, so that these two processes can be difficult to distinguish. ${ }^{34} \mathrm{~A}$ recombination of two oxyl radicals to give peroxides $\mathbf{E}$ (reaction IV) is not of great importance in aqueous solution, ${ }^{35,36}$ since reaction IV, figure II, probably leads preferentially to ${ }^{3} \mathrm{O}_{2}$ and a triplet oxyl radical pair, thus the probability of recombination in the solvent cage is reduced. The water-catalyzed rearrangement of an oxyl radical $\mathbf{C}$ to the tautomeric $\alpha$-hydroxyalkyl radical $\mathbf{D}$ is also possible (reaction II). ${ }^{37,38,39}$

In the case of primary and secondary oxyl radicals $\mathbf{C}, 1,2-\mathrm{H}$ shift is generally so fast that it can take precedence over the long-known $\beta$-fragmentation of the oxyl radicals $\mathbf{C}$ (reaction III). In the case of tertiary oxyl radicals, the latter is however the typical decomposition pathway. ${ }^{40,41,42}$ 
FIGURE II. Peroxyl Radicals. Bimolecular Reactions<smiles>[R]C([R])OOOC([R])[R]</smiles><smiles>[R]C([R])OOOC([R])[R]</smiles>

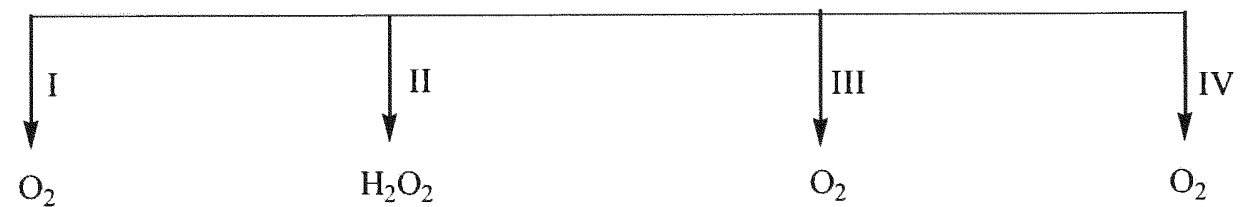

$\underbrace{\mathrm{R}_{2} \mathrm{CHOH}} \quad \underbrace{2 \mathrm{R}_{2} \mathrm{C}=\mathrm{O}}_{\begin{array}{c}\text { Five-membered } \\ \text { transition state }\end{array}} \quad 2 \mathrm{RCHO}$

Russell Reaction

Russell Reaction<smiles></smiles>

$\mathrm{O}_{2}+\mathrm{R}_{2} \mathrm{C}=\mathrm{O}+\mathrm{R}_{2} \mathrm{CHOH}$ 
FIGURE III. Oxyl Radical Reactions
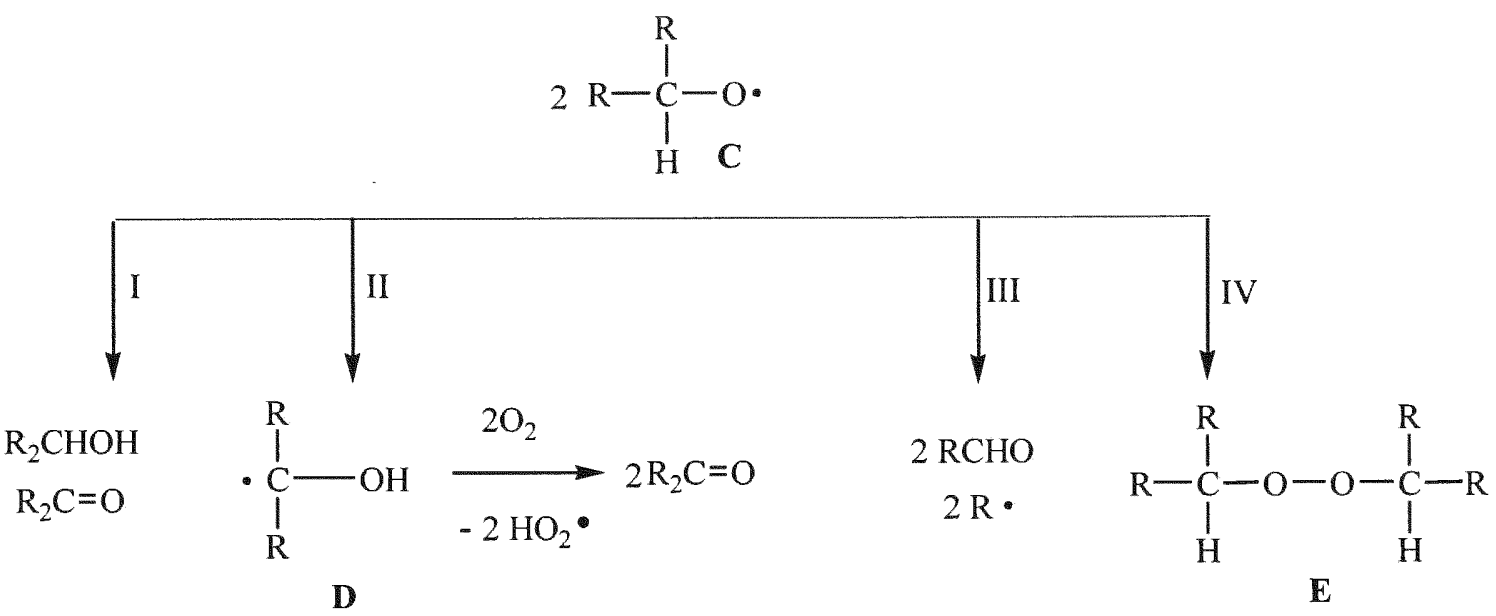
II. TITANIUM DIOXIDE PHOTOCATALYSIS OF 2-METHOXY-2-METHYLPROPANE (METHYL tert-BUTYL ETHER, MTBE).

\subsection{2-METHOXY-2-METHYL PROPANE (METHYL tert-BUTYL ETHER) - INTRODUCTORY REMARKS.}

Contamination of ground and surface waters by motor vehicle fuels and fuel additives is not a new problem, given the history and pervasive use of fuels in the $20^{\text {th }}$ century. ${ }^{43}$ Over a million underground fuel storage tanks exist in the United States, and leaks from these tanks have been the focus of major programs to prevent or clean up such releases. ${ }^{44}$ Transport of fuels via pipelines and in bulk containers also presents the potential for accidental releases and consequent environmental contamination.

Against this background with fuel-related contamination of ground and surface waters, recent events have focused attention on what appear to be somewhat different characteristics associated with fuels containing chemicals known as oxygenates. Oxygenates are added to fuel to increase its oxygen content and thereby reduce certain emissions from use of the fuel. ${ }^{45}$

Beginning in the late 1970s, methyl tert-butyl ether (MTBE) was used to increase the octane value of gasoline in the United States, as well as oxygenate to improve the air quality. The 1990 Clean Air Act Amendments created two fuel programs to reduce the carbon monoxide ( $\mathrm{CO}$ ) emissions from vehicle engines, and increase the level of oxygen in gasoline, ${ }^{46}$ which contributes to reduce emissions of ozone precursors and certain toxic organic pollutants. As a result, greater amounts of MTBE (up to $15 \%$-vol) were added to gasoline to achieve the specified oxygen content requirements. 
Unfortunately, the use of MTBE in gasoline has created a serious environmental problem because of leakage from storage tanks or petroleum pipelines. There has been serious and significant concern over the increase of MTBE-contaminated waters. ${ }^{47}$ Recently, monitoring of groundwater quality by the U.S. Geological Survey (USGS) indicates that MTBE has become detectable in shallow groundwater samples, in certain urban areas, with concentration ranging from $0.2 \mu \mathrm{g} / \mathrm{L}$ to over $20,000 \mu \mathrm{g} / \mathrm{L}{ }^{48,49}$ Reports of point-source MTBE contamination of drinking water sources at well over $100 \mu \mathrm{g} / \mathrm{L}$, raise several important questions about potential environmental and public health impacts of oxygenated fuels.

Oxygenates in the atmosphere degrade with a half-life as short as 3 days. However, MTBE is soluble in water and, because of its relatively low Henry's Law Constant, partitions readily from air to rainfall and snowfall. Table III shows the physical characteristics of MTBE. 
TABLE III Chemical Properties of MTBE ${ }^{43}$

\begin{tabular}{ll}
\hline Chemical Name & Methyl Tertiary Butyl Ether \\
\hline CAS Registry No. & $1634-04-4$ \\
\hline Molecular Weight $(\mathrm{g} / \mathrm{mol})$ & 88.15 \\
\hline Molecular Formula & $\mathrm{C}_{5} \mathrm{H}_{12} \mathrm{O}$ \\
\hline Structural Formula & $\mathrm{CH}_{3} \mathrm{OC}\left(\mathrm{CH}_{3}\right)_{3}$ \\
\hline Boiling Point (at $760 \mathrm{~mm} \mathrm{Hg})$ & $55.2{ }^{\circ} \mathrm{C}$ \\
\hline Vapor Pressure $\left(\mathrm{mm} \mathrm{Hg}\right.$ at $\left.20^{\circ} \mathrm{C}\right)$ & 240 \\
\hline Vapor Density $($ air $=1)$ & 3.1 \\
\hline Density $\left(\mathrm{g} / \mathrm{mL}\right.$ at $\left.20{ }^{\circ} \mathrm{C}\right)$ & 0.74 \\
\hline Solubility $(\mathrm{g} / 100 \mathrm{~g}$ water $)$ & 4.8 \\
\hline Henry's Law Constant $\left(\mathrm{Atm}-\mathrm{m}^{3}\right) /(\mathrm{g}-\mathrm{mole})$ & $5.28 \mathrm{E}-4$ to $3 \mathrm{E}-3$ \\
\hline Log KoC & 0.55 to 0.91 \\
\hline Log Kow & 0.94 to 1.30 \\
\hline
\end{tabular}

Some studies have been conducted to determine a reliable, fast, and affordable method for the remediation of MTBE contaminated drinking water. Results from field studies of the natural biodegradation of MTBE in ground water show that the processes involved generally take place at very slow rates or with long lag time, and depend on sitespecific geochemical conditions. ${ }^{50}$ Granular activated carbon (GAC) adsorption is a frequently used treatment process for organic contaminants. However, because of its limited adsorption capacity for MTBE, GAC is generally not cost effective for the removal of this contaminant. ${ }^{51}$ On the other hand, Fenton's reagent, a hydroxyl radical treatment, has been shown to be effective for MTBE. However, because of secondary effects, it is unlikely that Fenton's reagent would be used in a drinking water facility. ${ }^{52}$ 
Biofiltration processes that utilize the addition of primary substrates should not be conducted for drinking water treatment, because primary substrates are problematic.

It has been reported that advanced oxidation technologies are among the most costeffective methods for oxygenate destruction. For that reason, the United States Environmental Protection Agency (EPA) set, as a top priority, the evaluation of candidate technologies for removing oxygenate contaminants from water under various conditions. Among some other proposed methods for drinking-water contaminant removal process, such as ozone/peroxide, ozone/UV, peroxide/UV, ozone/sonication; the titanium dioxide photocatalytic degradation is a very promising method for MTBE degradation. ${ }^{43}$

\subsection{PREVIOUS STUDIES.}

Recently, a number of reports have proposed the formation of 2-methoxy-2methylpropanal (MMP), 2-methoxy-2-methylpropanol (MMP-OH), and 2-methoxy-2methylpropanoic acid (MMP-COOH) as important intermediates in the $\bullet \mathrm{OH}$-mediated oxidation of MTBE. The application of the $\mathrm{UV} / \mathrm{H}_{2} \mathrm{O}_{2}$ process to the degradation of methyl tert-butyl ether (MTBE) in diluted aqueous solution reportedly resulted in the generation of tert-butyl formate (TBF), formaldehyde, acetone, tert-butyl alcohol (TBA),

and methyl acetate as primary byproducts. ${ }^{53}$ MMP was identified and quantified by using trimethylacetaldehyde as a reference compound, because of their similar steric configurations and close molecular weights. Neo-pentyl alcohol was used as a surrogate for $\mathrm{MMP}-\mathrm{OH}$ identification, given their similar structures, since $\mathrm{MMP}-\mathrm{OH}$ is not commercially available. In this case, MMP-OH was not found to be one of the intermediates, although it has been suggested. While MMP is tentatively identified, the 
proposed reaction pathways suggested that the formation of methyl acetate and acetone are independent of the reactions involving MMP. ${ }^{53}$ Barreto et al. ${ }^{54}$ found tert-butyl formate (TBF), and tert-butyl alcohol (TBA) as primary by-products in the $\mathrm{TiO}_{2}$ photocatalytic degradation of MTBE. Although they suggested and tentatively identified $\left(\mathrm{CH}_{3}\right)_{3} \mathrm{COCH}_{2} \mathrm{OOH}$ (HperMTBE) as the primary intermediate, which is proposed to lead to $\mathrm{TBF}$ by hydrolysis, it is unlikely that $\mathrm{ROOH}$ survive the $\mathrm{GC}$ conditions reported for the analysis. Also, $\mathrm{ROOH}$ would react relatively fast with the $\bullet \mathrm{OH}$ present in the reaction media, leading to different intermediate products. The proposed mechanism also involves the formation of formic acid and TBA from the hydrolysis of TBF, while TBA leads to isobutene and acetone. While the proposed conversions are possible, these processes are typically very slow at neutral $\mathrm{pH}$ and the ambient temperature employed.

Although MMP has been implicated as a low-level primary degradation product of the MTBE photocatalytic degradation, conclusive identification has not been reported. In an attempt to confirm the formation of MMP, and to further study its reactivity, the synthesis of this compound was performed using standard synthetic methods.

The formation of 2-methoxy-2-methylpropanol is clearly expected from the $\mathrm{TiO}_{2}$ photocatalytic degradation of MTBE, based on the general reactions of hydroxyl radicals with organic substrates. Preparation and study of authentic samples of MMP-OH has been confirmed by our studies

The third cited compound, 2-methoxy-2-methylpropanoic acid, is likely an intermediate in MTBE photooxidation, which degrades upon reaction with hydroxyl radicals, and generates some of the identified final products. In order to confirm its 
involvement, the comparison of the compounds in the reaction mixture with an authentic sample of the carboxylic acid is essential.

The chemical name, molecular and structural formula and molecular weight of the MTBE derivatives studied in this chapter are summarized in Table IV.

TABLE IV. Chemical Data of MTBE Oxidation Products

Chemical

Name
Molecular Formula Structural Formula
Molecular

Weight $(\mathrm{g} / \mathrm{mol})$

2-methoxy-2-methyl

propanal

$\mathrm{C}_{5} \mathrm{H}_{10} \mathrm{O}_{2}$

$\left(\mathrm{CH}_{3}\right)_{2} \mathrm{C}\left(\mathrm{OCH}_{3}\right) \mathrm{CHO}$

102

2-methoxy-2-methyl

propanol

$\mathrm{C}_{5} \mathrm{H}_{12} \mathrm{O}_{2}$

$\left(\mathrm{CH}_{3}\right)_{2} \mathrm{C}\left(\mathrm{OCH}_{3}\right) \mathrm{CH}_{2} \mathrm{OH}$

104

2-methoxy-2-methyl

propanoic acid

$\mathrm{C}_{5} \mathrm{H}_{10} \mathrm{O}_{3}$

$\left(\mathrm{CH}_{3}\right)_{2} \mathrm{C}\left(\mathrm{OCH}_{3}\right) \mathrm{COOH}$

118

propanoic acid

acetone

$\mathrm{C}_{3} \mathrm{H}_{6} \mathrm{O}$

$\mathrm{CH}_{3} \mathrm{COCH}_{3}$

58

methyl acetate

$\mathrm{C}_{3} \mathrm{H}_{6} \mathrm{O}_{2}$

$\mathrm{CH}_{3} \mathrm{COOCH}_{3}$

74 


\subsection{EXPERIMENTAL SECTION.}

2.3.1 Reagents and Materials.

Isobutylene Oxide was purchased from TCI America ( $97 \%$ purity), pyridinium chlorochromate was purchased from Aldrich Chemicals ( $98 \%$ purity). Both were used in the synthesis processes. Sulfuric acid, hydrochloric acid, methanol, dichloromethane, anhydrous ethyl ether, potassium permanganate, obtained from Fisher Scientific, were used as received in the synthesis processes. The internal standards, n-butanol $(99.9 \%$ purity), n-hexanol ( $99.9 \%$ purity); $\mathrm{Na}_{2} \mathrm{~B}_{4} \mathrm{O}_{7}$ (sodium tetraborate, $99.99 \%$ purity), used for the preparation of the buffer solution in the ion chromatography analysis; MTBE $(99.9 \%$ purity), were purchased from Fisher Scientific. The photocatalyst used was titanium dioxide, Degussa P25 lot\# RV 2186 (surface area $50 \mathrm{~m}^{2} / \mathrm{g}$, avg. primary particle size 30 $\mathrm{n}, \mathrm{X}$-Ray structure primarily anatase). Ultrapure water was employed throughout these investigations.

\subsubsection{Apparatus.}

The UV irradiation experiments were carried out in a Rayonet Photochemical Reactor, Model RPR-100 (manufactured by The Southern New England Ultraviolet Company, Branford, USA). The lamps intensity was $1.29 \times 10^{16}$ photon/sec $\mathrm{x} \mathrm{mL}$, and the wavelength was $350 \mathrm{~nm}$. 


\subsubsection{Analytical Methods.}

The GC-Head Space-FID and Ion Chromatography methods were applied to confirm the identity of the compounds as well as to develop the quantitation methods. Authentic samples (standards) for all the analyzed compounds were used.

\subsubsection{Analysis of 2-methoxy-2-methylpropanal.}

GC-Head Space-FID. 2-methoxy-2-methylpropanal, acetone and methyl acetate were analyzed by a HP 5890 series II gas chromatography system equipped with a HP 19395A head space system, a HP 19395A autosampler, and a HP 3396 series II integrator. A RTx-BAC1 (fused silica) column (ID $30 \mathrm{~m}$ X $0.53 \mathrm{~mm}, 3 \mu \mathrm{m}$ film thickness) by Restek Corporation in connection with a flame ionization detector (FID) was used. The FID detector was set at $200{ }^{\circ} \mathrm{C}$. The oven temperature was programmed at $30{ }^{\circ} \mathrm{C}$ for $3 \mathrm{~min}$, then ramped up to $90{ }^{\circ} \mathrm{C}$ at a rate of $15{ }^{\circ} \mathrm{C} / \mathrm{min}$, and held at $90{ }^{\circ} \mathrm{C}$ for $1 \mathrm{~min}$; helium was the carrier gas. The injector port temperature was $180{ }^{\circ} \mathrm{C}$, and the samples were injected using headspace technique, the bath temperature was $40{ }^{\circ} \mathrm{C}$, the loop temperature was 55 ${ }^{\circ} \mathrm{C}$, and the equilibration time was 1 min. A calibration curve of each compound was prepared by the following procedure. Stock solutions of 2-methoxy-2-methylpropanal (59.2 ppm), acetone $(101.2 \mathrm{ppm})$, and methyl acetate $(100.6 \mathrm{ppm})$ were prepared. Standard mixtures of acetone and methyl acetate were prepared in a range of concentrations from $2.0 \mathrm{ppm}$ to $24.3 \mathrm{ppm}$. MMP was analyzed separately in a range of concentrations from $7.1 \mathrm{ppm}$ to $59.2 \mathrm{ppm}$. A $5.0 \mathrm{mLs}$ aliquot of each standard mixture was placed in $20 \mathrm{mLs}$ vials fitted with an aluminum seal and a PTFE septum. For the 
calibration curves, $200 \mu \mathrm{Ls}$ of 1-butanol solution (internal standard, $810 \mathrm{ppm}$ ) were added to each standard mixture.

2.3.3.2 Analysis of 2-methoxy-2-methylpropanol.

GC-Head Space-FID. 2-methoxy-2-methylpropanol, 2-methoxy-2-methylpropanal, acetone and methyl acetate were analyzed by the same equipment and conditions described in 2.3.3.1. In this case the bath temperature was $70{ }^{\circ} \mathrm{C}$, and the loop temperature was $85{ }^{\circ} \mathrm{C}$. Calibration curves were prepared from stock solutions of 2methoxy-2-methylpropanol (344.0 ppm), 2-methoxy-2-methylpropanal (278.6 ppm), acetone $(45.0 \mathrm{ppm})$, and methyl acetate $(45.0 \mathrm{ppm})$. Standard mixtures were prepared in concentration ranges from $17.2 \mathrm{ppm}$ to $114.7 \mathrm{ppm}$ for 2-methoxy-2-methylpropanol, 9.3 $\mathrm{ppm}$ to $27.8 \mathrm{ppm}$ for 2-methoxy-2-methylpropanal, $2.2 \mathrm{ppm}$ to $11.2 \mathrm{ppm}$ for methyl acetate and acetone. A $6.0 \mathrm{mLs}$ aliquot of each standard mixture was placed in a $20 \mathrm{mLs}$ vial fitted with an aluminum seal and a PTFE septum. For the calibration curves, $50 \mu \mathrm{Ls}$ of 1-butanol solution (internal standard, $810 \mathrm{ppm}$ ) were added to each standard mixture.

\subsubsection{Analysis of methyl tert-butyl ether (MTBE).}

GC-Head Space-FID. 2-methoxy-2-methylpropanol, 2-methoxy-2-methylpropanal, acetone and methyl acetate were analyzed by GC-Head Space. In this case the bath temperature was $70^{\circ} \mathrm{C}$, and the loop temperature was $85^{\circ} \mathrm{C}$. The oven temperature was programmed at $35^{\circ} \mathrm{C}$ for $3 \mathrm{~min}$, then ramped up to $120^{\circ} \mathrm{C}$ at a rate of $15^{\circ} \mathrm{C} / \mathrm{min}$, and held at $120{ }^{\circ} \mathrm{C}$ for $1 \mathrm{~min}$. For methyl tert-butyl ether (MTBE) analysis, the bath temperature was $40^{\circ} \mathrm{C}$, and the loop temperature was $55^{\circ} \mathrm{C}$. The column temperature was 
programmed at $35{ }^{\circ} \mathrm{C}$ for $3 \mathrm{~min}$, then ramped up to $120{ }^{\circ} \mathrm{C}$ at a rate of $15{ }^{\circ} \mathrm{C} / \mathrm{min}$, and held at $120^{\circ} \mathrm{C}$ for $1 \mathrm{~min}$. The equipment and the rest of the conditions were described in 2.3.3.1. Calibration curves were prepared by the following procedures. Stock solutions of 2-methoxy-2-methylpropanol (668.0 ppm), 2-methoxy-2-methylpropanal (774.0 ppm), acetone $(66.0 \mathrm{ppm})$, and methyl acetate $(66.0 \mathrm{ppm})$ were prepared. Standard mixtures were prepared in ranges of concentration from $5.1 \mathrm{ppm}$ to $111.3 \mathrm{ppm}$ for 2-methoxy-2methylpropanol, $1.3 \mathrm{ppm}$ to $31.0 \mathrm{ppm}$ for 2-methoxy-2-methylpropanal, $1.0 \mathrm{ppm}$ to 11.0 ppm for methyl acetate and acetone. A stock solution of MTBE (622.0 ppm) was prepared. The range of concentration for the standards was from $1.0 \mathrm{ppm}$ to $31.0 \mathrm{ppm}$. A $6.0 \mathrm{mLs}$ aliquot of each standard mixture (each standard in the case of MTBE) was placed in a $20 \mathrm{mLs}$ vial fitted with an aluminum seal and a PTFE septum. For the calibration curves, $20 \mu \mathrm{Ls}$ of 1-hexanol solution (internal standard, $814 \mathrm{ppm}$ ) for the standard mixtures, and $100 \mu \mathrm{Ls}$ for MTBE standards were added to each vial.

Ion Chromatography. 2-methoxy-2-methylpropanoic acid was analyzed by conductivity detection with a Dionex DX-100 ion chromatograph equipped with an ion self-regenerating suppressor ASRN and E-Lab software program. An ion exchange column AS4A-SC, 4 X $250 \mathrm{~mm}$, and an IonPac AS4 guard column were used for the analysis of 2-methoxy-2-methylpropanoic acid with $1.8 \mathrm{mM} \mathrm{Na}_{2} \mathrm{~B}_{4} \mathrm{O}_{7}$ solution as the eluent (isocratic flow of $1 \mathrm{~mL} \min ^{-1}$ ). A calibration curve was prepared. Using concentrations from $4 \mathrm{ppm}$ to $80 \mathrm{ppm}$. Plastic vials fitted with a plastic seal were filled with the standard solutions to be run in the Ion Chromatograph. 


\subsubsection{Photolysis experiment}

In a typical photolysis experiment, $100 \mathrm{mLs}$ aliquot of a given concentration solution of the studied compound was placed in a $120 \mathrm{mLs}$ reactor vessel ( 7 inch long $\mathrm{x} 0.25$ inch diameter) equipped with a screw top Teflon cap. Titanium dioxide Degussa P25 (15 mg) and $8 \times 13 \mathrm{~mm}$ Teflon stirring bar were added to the reaction vessel, and the suspension was sonicated for $15 \mathrm{~min}$ at room temperature, $43 \mathrm{KHz}$, in a solid state/ultrasonic FS-14. To match the temperature inside the photoreactor, the temperature of the solution was equilibrated to $42{ }^{\circ} \mathrm{C}$ using a water bath, and the vessel was covered prior to irradiation with aluminum foil. The reaction vessel was then placed in the Photochemical Reactor and irradiated for specific time intervals. Samples were taken at specific times for analysis.

\subsubsection{MTBE. Photolysis.}

For the photolysis experiments of MTBE the general procedure described in 2.3.4.1 was followed. In this case the starting solution concentration was $100 \mathrm{ppm}(1.1 \mathrm{mM})$. Two $6.0 \mathrm{mLs}$ aliquots were taken at given time intervals, one for MTBE and one for MMP, acetone and methyl acetate analysis. Each sample was transferred to a $20 \mathrm{mLs}$ vial fitted with an aluminum seal and a PTFE septum. An aliquot of stock solution (1hexanol, $814 \mathrm{ppm}$ ) of internal standard (100 $\mu \mathrm{Ls}$ for MTBE, and $20 \mu \mathrm{Ls}$ for other compounds analysis) was added to each vial. The samples were analyzed by the procedure used to obtain the calibration curves as described in 2.3.3.3. 
In an attempt to identify minor reaction products, a second UV irradiation experiment was performed. In this case, the starting concentration of MTBE solution was $438.0 \mathrm{ppm}$ $(5.0 \mathrm{mM})$ and the procedure was the same as described above. Three aliquots were taken (one for MTBE, $6.0 \mathrm{mLs}$; one for MMP and MMP-OH, $6.0 \mathrm{mLs}$; and one for MMP$\mathrm{COOH}, 10 \mathrm{mLs}$ analysis) at given time intervals. The $6.0 \mathrm{mLs}$ aliquots were transferred to a $20 \mathrm{mLs}$ vial fitted with an aluminum seal and a PTFE septum. An aliquot of stock solution (1-hexanol, $814 \mathrm{ppm}$ ) of internal standard (100 $\mu \mathrm{Ls}$ for MTBE, and $20 \mu \mathrm{Ls}$ for MMP and MMP-OH analysis) was added to each vial. These samples were analyzed as described in 2.3.3.3. The $10.0 \mathrm{mLs}$ aliquot was transferred to a plastic vial fitted with a plastic seal for IC analysis. These samples were analyzed by the conditions described in 2.3.3.3.

2.3.4.3 2-methoxy-2-methylpropanal (MMP), and 2-methoxy-2-methylpropanol (MMP$\mathrm{OH})$. Photolysis.

Control reactions were run following the procedure described in 2.3.4.1 with some variations. The initial concentration for MMP was $60.4 \mathrm{ppm}$, and for MMP-OH, 51.0 and $58.2 \mathrm{ppm}$. For Control Reaction I, the reaction vessel was covered with aluminum foil and placed in a water bath instead of the photoreactor, keeping the reaction temperature at $42{ }^{\circ} \mathrm{C}$. For Control Reaction II no $\mathrm{TiO}_{2}$ was added to the solution.

For the UV irradiation experiment of MMP, the typical photolysis experiment procedure described in 2.3.4.1 was followed. In this case, the starting concentration of 2methoxy-2-methylpropanal was $60.4 \mathrm{ppm}$. A $5.0 \mathrm{mLs}$ aliquot was taken for analysis at given time intervals. Each sample was transferred to a $20 \mathrm{mLs}$ vial fitted with an 
aluminum seal and a PTFE septum. 1-butanol (200 $\mu \mathrm{Ls}, 810 \mathrm{ppm}$ solution) was added to each vial as internal standard. These were analyzed as described in Section 2.3.3.1. A second (10 mLs) aliquot was taken for analysis at given time intervals. In this case, the samples were transferred to a plastic vial fitted with a plastic seal for IC analysis. These were analyzed by the conditions described in 2.3.3.3.

MMP-OH was irradiated following the same procedure as MMP. The stock solution used for the analysis of 2-methoxy-2-methylpropanol had a concentration of $54.1 \mathrm{ppm}$. A $6.0 \mathrm{mLs}$ aliquot was taken for analysis every time. Each aliquot was transferred to a 20 $\mathrm{mL}$ vial fitted with an aluminum seal and a PTFE septum. Internal standard (1-butanol, $810 \mathrm{ppm}, 50 \mu \mathrm{L})$ was added to each vial. These samples were analyzed as described in 2.3.3.2. A second ( $10 \mathrm{mLs})$ aliquot was taken for analysis at given time intervals. In this case, the samples were transferred to a plastic vial fitted with a plastic seal for IC analysis. These were analyzed by the conditions described in 2.3.3.3.

\subsubsection{Synthesis}

A number of reports have appeared which propose the presence of MMP, MMP-OH, and MMP-COOH. These reports involve spectral comparison with surrogate compounds and/or incomplete characterization. We have successfully synthesized and characterized these compounds.

The synthesis of 2-methoxy-2-methylpropanol was achieved by following the general procedure for the synthesis of alcohols from epoxides. ${ }^{55}$ The oxidation of 2-methoxy-2methylpropanol with pyridinium chlorocromate in anhydrous methylene chloride to yield 
the correspondent aldehyde is a known procedure for mild oxidation of alcohols to aldehydes. $^{56}$

The standard oxidation of an alcohol to the corresponding carboxylic acid using potassium permanganate $e^{57}$ in aqueous solution was used for the synthesis of 2-methoxy2-methylpropanoic acid (MMP-COOH). This compound had been previously synthesized by the reaction of 2-butene with $\alpha$-peroxy lactone in a 1:1 mixture of $\mathrm{CH}_{3} \mathrm{CCl}_{3} / \mathrm{CH}_{3} \mathrm{OH}$ at $-20{ }^{\circ} \mathrm{C}$ for $24 \mathrm{~h},{ }^{58}$ and has been partially characterized previously, ${ }^{58}$ based on a characteristic singlet at $\delta 3.3 \mathrm{ppm}$ in the ${ }^{1} \mathrm{H}$ NMR spectrum.

Detailed descriptions of the synthesis and characterization are provided in the following section.

2.3.5.1 Synthesis of 2-methoxy-2-methylpropanol.

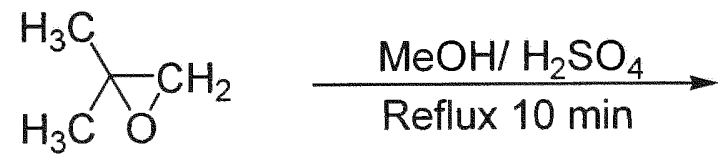

Isobutylene Oxide<smiles>COC(C)(C)CO</smiles>

2-methoxy-2-methyl propanol (MMP-OH)

Isobutylene oxide $(1 \mathrm{~mL}, 0.01 \mathrm{~mol})$ was added dropwise to a $5 \mathrm{~mL}$ of a solution of concentrated sulfuric acid ( 2 drops) in $100 \mathrm{~mL}$ of methanol. The resulting mixture was heated to reflux for $10 \mathrm{~min}$. A solution of potassium hydroxide (one pellet in $100 \mathrm{~mL}$ of methanol) was used to adjust the solution to $\mathrm{pH} \sim 8$. The solvent was removed and the product purified by distillation to yield 2-methoxy-2-methylpropanol as a colorless liquid $(0.73 \mathrm{~g}, 63 \%)$ : bp $142-144{ }^{0} \mathrm{C} ;{ }^{1} \mathrm{H}$ NMR $\left(400 \mathrm{MHz}, \mathrm{CDCl}_{3}\right) \delta 1.16(\mathrm{~s}, 6 \mathrm{H}), 3.24(\mathrm{~s}, 3 \mathrm{H})$, 
$3.43(\mathrm{~s}, 2 \mathrm{H}) ;{ }^{13} \mathrm{C}$ NMR $(100 \mathrm{MHz}, \mathrm{CDCl} 3) \delta 21.3,49.4,69.2,75.0 . \mathrm{MS} \mathrm{m} / \mathrm{z}$ (relative intensity) $104\left(\mathrm{M}^{+}, 0.05\right), 87(32), 73$ (100), 55 (26).

2.3.5.2 Synthesis of 2-methoxy-2-methylpropanal.

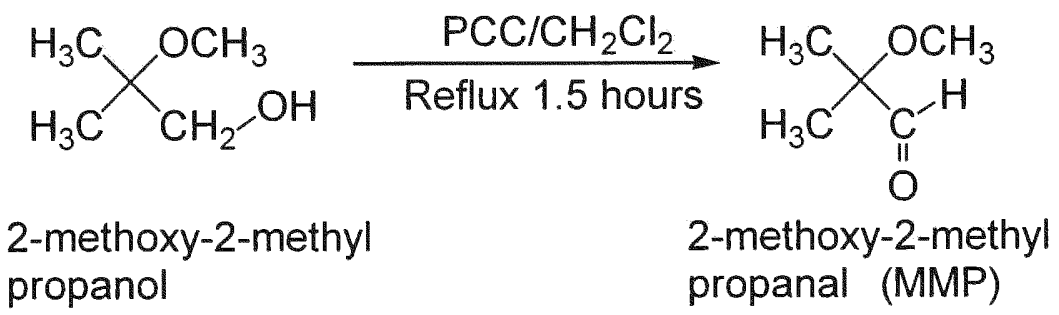

Pyridinium chlorochromate $(16.1 \mathrm{~g}, 0.075 \mathrm{~mol})$ was suspended in anhydrous methylene chloride $(100 \mathrm{~mL})$, and combined with 2-methoxy-2-methylpropanol (4.1 g, $0.04 \mathrm{~mol})$ in dry methylene chloride $(10 \mathrm{~mL})$ in a $250 \mathrm{~mL}$ round bottom flask. The reaction vessel was equipped with a reflux condenser and the resulting solution heated to reflux for 1.5 hours. The resultant reaction mixture was extracted with dry diethyl ether $(100 \mathrm{~mL})$ and the supernatant liquid was decanted from the dark residue. The residue was washed with three $25 \mathrm{~mL}$ portions of dry diethyl ether. The combined organic phase was passed through a silica gel (200-400 Mesh) plug using diethyl ether. The solvent was removed by simple distillation and the product purified by fractional distillation. The final product, 2-methoxy-2-methylpropanal is a colorless liquid $(1.79 \mathrm{~g}, 45 \%)$ : ${ }^{1} \mathrm{H}$ NMR $\left(400 \mathrm{MHz}, \mathrm{CDCl}_{3}\right) \delta 1.27(\mathrm{~s}, 6 \mathrm{H}), 3.30(\mathrm{~s}, 3 \mathrm{H}), 9.58(\mathrm{~s}, 1 \mathrm{H}),{ }^{13} \mathrm{C} \mathrm{NMR}(100 \mathrm{MHz}$, $\left.\mathrm{CDCl}_{3}\right) \delta 20.2,51.9,80.1,204.5$. IR (film) $v_{\max } 2690,1742 \mathrm{~cm}^{-1} . \mathrm{MS} \mathrm{m} / \mathrm{z}$ (relative intensity) $102\left(\mathrm{M}^{+}\right.$, not observed), 87 (43), 73 (100), 55 (40). 
2.3.5.3 Synthesis of 2-methoxy-2-methylpropanoic acid.<smiles>COC(C)(C)CO</smiles>

2-methoxy-2-methyl propanol (MMP-OH)

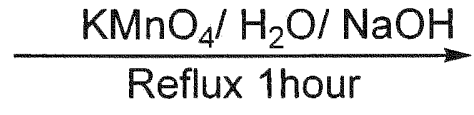

$\underset{\mathrm{H}}{\mathrm{H}_{3} \mathrm{C}} \underset{\substack{\mathrm{O} \\ \mathrm{H}}}{\mathrm{H}-\mathrm{OH}}$

2-methoxy-2-methyl propanoic acid (MMP-COOH)

2-methoxy-2-methylpropanol $(7.0 \mathrm{~g}, 0.06 \mathrm{~mol})$ was placed in a $500 \mathrm{~mL}$ round bottomed flask. Deionized water $(200 \mathrm{~mL})$, potassium permanganate $(32 \mathrm{~g}, 0.2025 \mathrm{~mol})$ and 10 pellets of sodium hydroxide were added. The reaction vessel was equipped with a reflux condenser and the mixture was heated to reflux for 1 hour. The resultant reaction mixture was allowed to cool, and small amounts of sodium bisulfite ( $10 \%$ solution) were added until the total disappearance of the purple color. The reaction mixture was filtered through a cake of filter aid ( $2 \mathrm{~g})$. The cake was washed twice with hot water, and the filtrate and washings were combined. Concentrated hydrochloric acid $(10 \mathrm{~mL})$ was then added to the filtrate, while stirring. The aqueous solution was extracted with $100 \mathrm{~mL}$ of dichloromethane three times. The extracts were combined and dried over anhydrous magnesium sulfate. The extract was roto-evaporated to yield 2-methoxy-2methylpropanoic acid $(0.66 \mathrm{~g}, 8 \%)$ as an oil: ${ }^{1} \mathrm{H}$ NMR $\left(400 \mathrm{MHz}, \mathrm{CDCl}_{3}\right) \delta 1.47(\mathrm{~s}, 6 \mathrm{H})$, $3.35(\mathrm{~s}, 3 \mathrm{H}) ;{ }^{13} \mathrm{C} \mathrm{NMR}\left(100 \mathrm{MHz}, \mathrm{CDCl}_{3}\right) \delta 23.4,51.8,77.6,178.4$. 


\subsection{RESULTS AND DISCUSSION.}

A sample of $1.1 \mathrm{mM}$ of MTBE in an aqueous slurry of $\mathrm{TiO}_{2}$ was subject to irradiation at $350 \mathrm{~nm}$. Control reactions $\left(\mathrm{TiO}_{2}-\mathrm{no} \mathrm{h} \nu\right.$, and no $\left.\mathrm{TiO}_{2}-\mathrm{h} \nu-\lambda=350 \mathrm{~nm}\right)$ run in previous studies $^{54}$, showed that no losses take place due to direct photolysis of MTBE or degradation of this substrate in titanium dioxide without the incidence of light. Data describing the photocatalytic degradation of MTBE in aqueous slurries of $\mathrm{TiO}_{2}$ at a starting concentration of $1.1 \mathrm{mM}$ is shown in Figure IV. Within approximately 1 hour, $25 \%$ of the MTBE has degraded, while at approximately 3 hours, $50 \%$ of the starting material was converted to products. At 10 hours, MTBE was no longer detected in the reaction solution under our experimental conditions.

As mentioned previously, tert-butyl alcohol and tert-butyl formate have been established as the primary intermediate products in the titanium dioxide photocatalyzed degradation of $\mathrm{MTBE}^{53,54}$. With this in mind, three intermediate products of the photocatalytic degradation of MTBE were monitored by GC-head space under the previous reaction conditions (Figure V). MMP and methyl acetate appeared rapidly and remain at a low concentration over the reaction. Acetone also appeared rapidly but is present in a significantly higher concentration. Acetone reached a maximum concentration at 6 hours, corresponding to $36 \%$ of MTBE starting concentration. Methyl acetate reached the maximum at 4 hours ( $9 \%$ of MTBE starting concentration), and the concentration remained steady for an additional 2 hours. After 6 hours, the concentrations gradually decreased until their complete disappearance at 10 hours. MMP reached a maximum concentration at 3 hours, which represents $2.2 \%$ of MTBE starting concentration, and it was not detectable under our experimental conditions at 6 hours. 
<smiles></smiles>

MTBE<smiles>CC(C)=O</smiles>

acetone<smiles>COC(C)=O</smiles>

methyl acetate<smiles>COC(C)(C)C=O</smiles>

MMP 


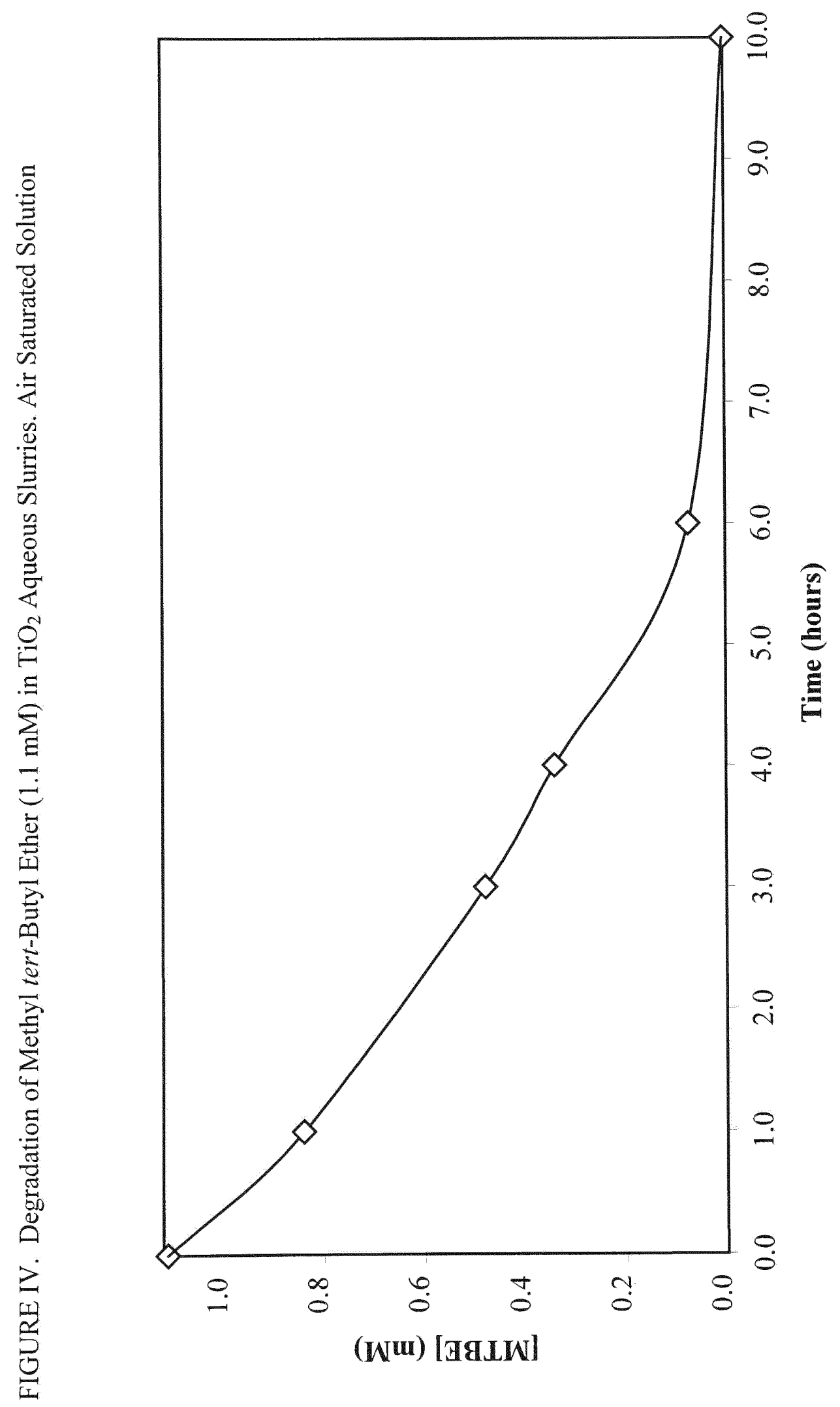




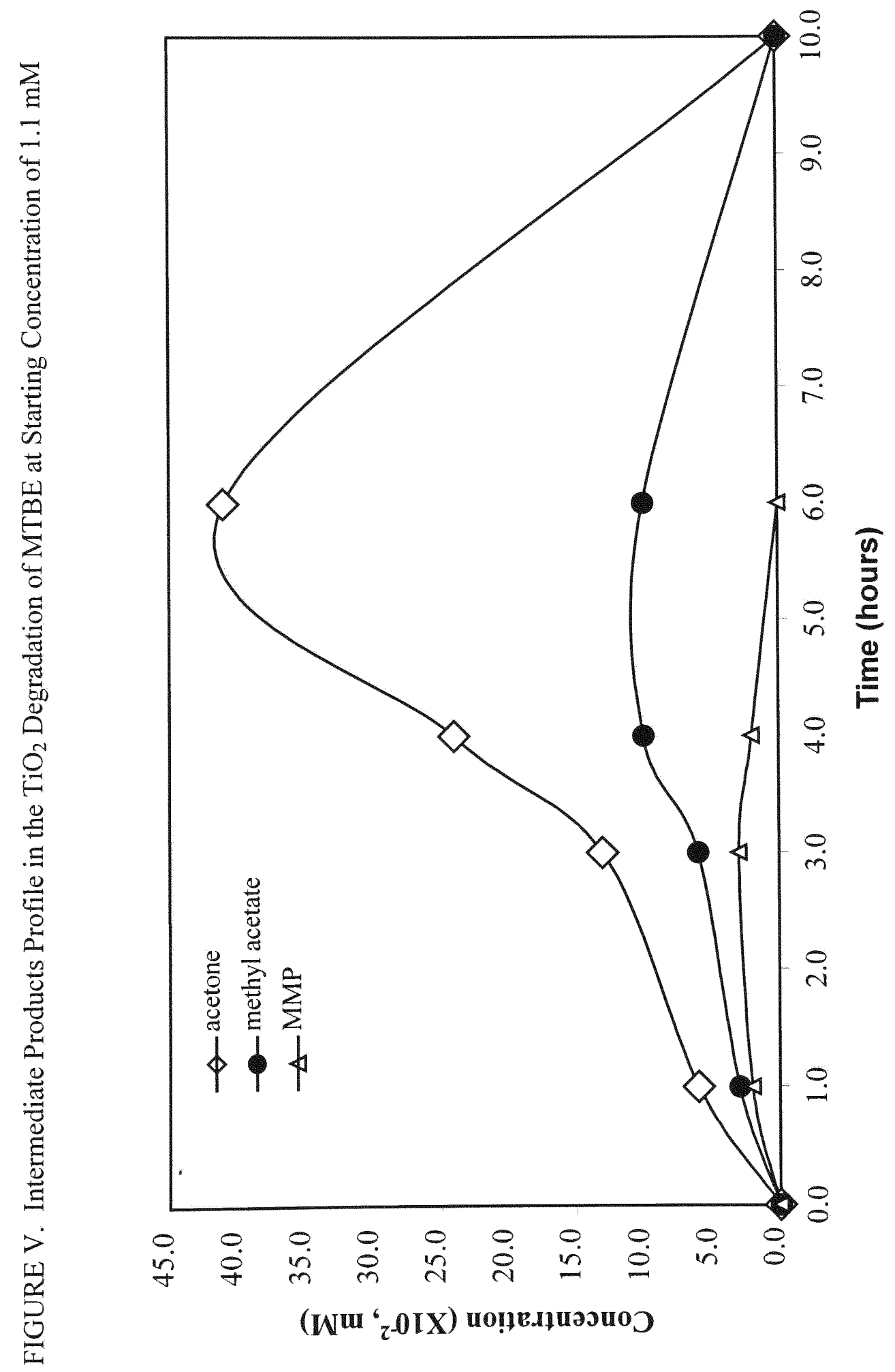


The photocatalytic degradation of MTBE in aqueous slurries of $\mathrm{TiO}_{2}$ at a starting concentration of $5.0 \mathrm{mM}$ is shown in Figure VI. The reaction was slower at increased MTBE concentration, since the concentration of titanium dioxide remained constant, and the "active sites" of $\mathrm{TiO}_{2}$ surface were a limiting factor. The reaction rate decreased after 4 hours, due to the formation of reaction intermediate products competing with MTBE for the active sites on titanium dioxide surface. After 18 hours of irradiation, MTBE is not detected in the reaction solution under our experimental conditions.

By increasing the starting concentration of MTBE to $5.0 \mathrm{mM}$, we were able to identify two previously unreported intermediate products by comparison with authentic samples, and using GC-head Space and Ion Chromatography (Fig. VII). MMP-OH (2methoxy-2-methylpropanol) and MMP-COOH (2-methoxy-2-methylpropanoic acid) were formed, but present at very low concentrations. The maximum concentration of MMP-OH is 3.5 times higher than MMP-COOH maximum concentration. The formation of MMP (2-methoxy-2-methylpropanal) was also investigated when increasing MTBE concentration. Under these conditions, MMP remained in the reaction solution longer. Although the starting concentration of MTBE was increased 5 times, the MMP maximum concentration increased only 2.5 times, compared with the maximum concentration of this compound in previous experiments (MTBE starting concentration of $1.1 \mathrm{mM}$ ). The formation of detectable levels of other intermediate products indicates that some competing reactions are taking place, which might be the reason why the increase in MMP concentration is not proportional with the increase in MTBE starting concentration. 
<smiles>COC(C)(C)C</smiles>

MTBE<smiles>COC(C)(C)CO</smiles>

$\mathrm{MMP}-\mathrm{OH}$<smiles>COC(C)(C)C=O</smiles>

MMP<smiles>COC(C)(C)C(=O)O</smiles>

MMP-COOH 
<smiles>C1CCCCC1</smiles> 


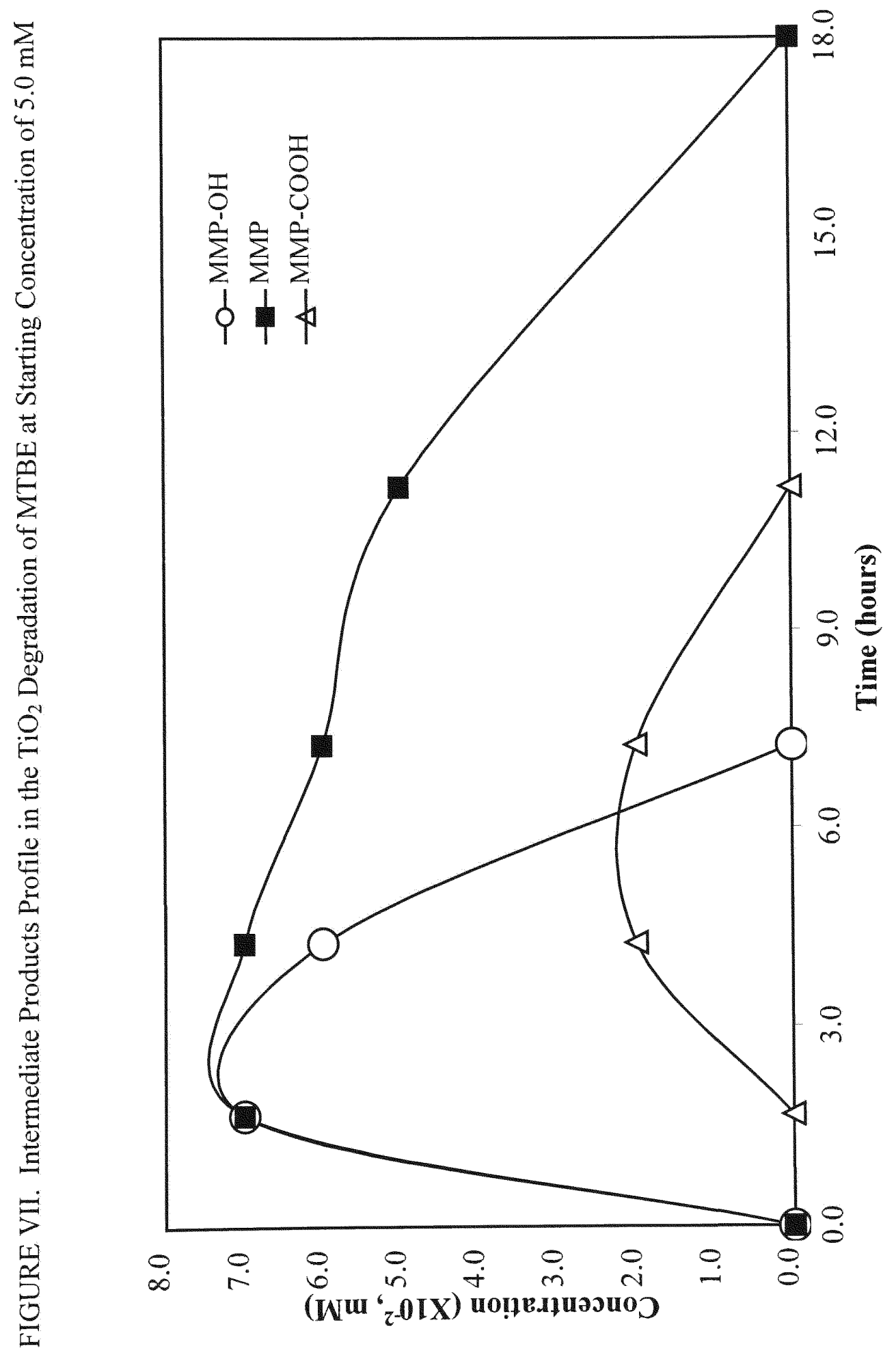


During the titanium dioxide photo-catalyzed degradation of 2-methoxy-2methylpropanol (MMP-OH) negligible losses were observed under control reactions (no $\mathrm{TiO}_{2}-42{ }^{\circ} \mathrm{C}, \mathrm{TiO}_{2}$ - no light), therefore, direct photolysis of MMP-OH did not occur under these reaction conditions (Figure VIII).

The photocatalytic degradation of $\mathrm{MMP}-\mathrm{OH}$ in aqueous slurries of $\mathrm{TiO}_{2}$ is also shown in Figure VIII. During the first 0.6 hours, $50 \%$ of the MMP-OH has disappeared, while at 7.5 hours MMP-OH was no longer detected in the reaction solution under our experimental conditions.

Acetone, methyl acetate, and 2-methoxy-2-methylpropanal (MMP) were identified by GC-head space (Figure IX). 2-Methoxy-2-methylpropanoic acid (MMP-COOH) was identified by Ion Chromatography. MMP, acetone and methyl acetate appeared rapidly, but remained at relatively low concentrations over the reaction. While MMP and MMP$\mathrm{COOH}$ were not longer detectable under our experimental conditions after 8.3 hours of irradiation, acetone and methyl acetate required 13.4 hours of irradiation for removal. MMP-COOH is formed in a extremely low concentration.

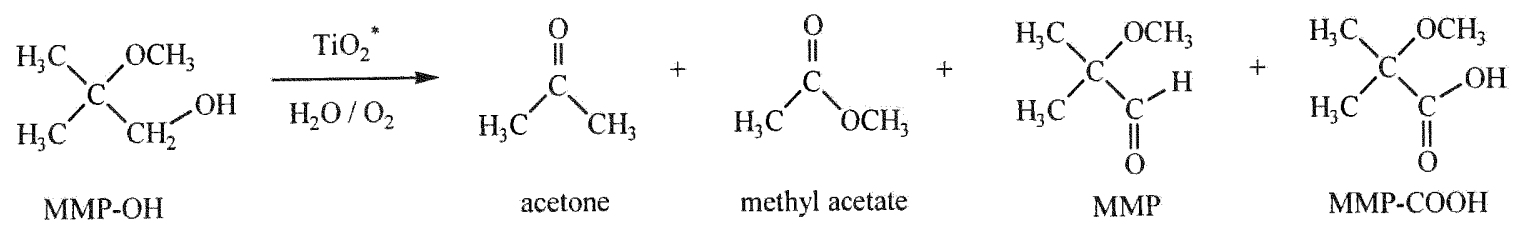


葛

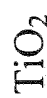

.



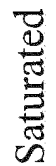

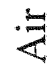

ส

4

总

๑ั n

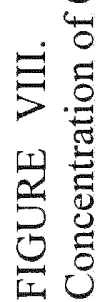

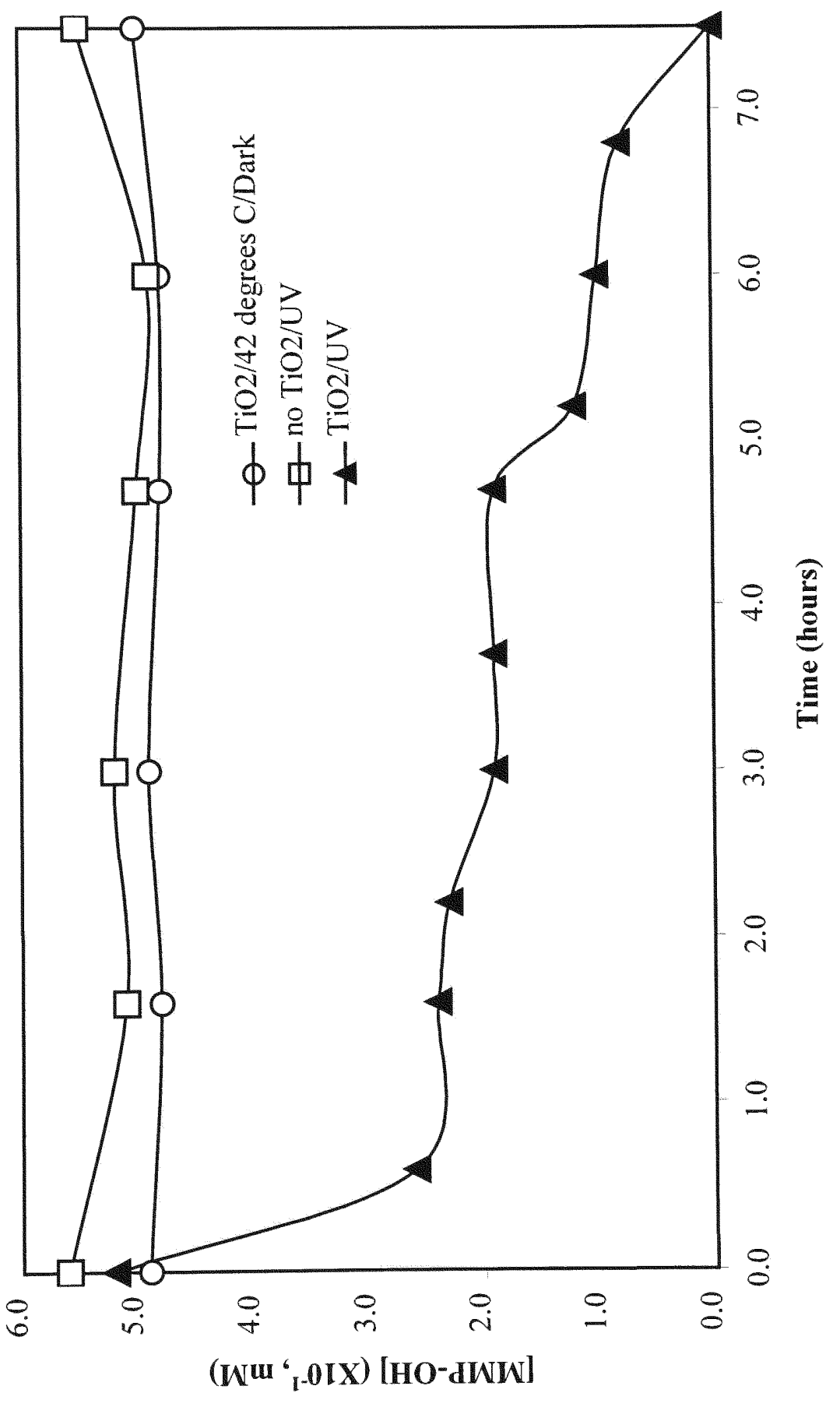




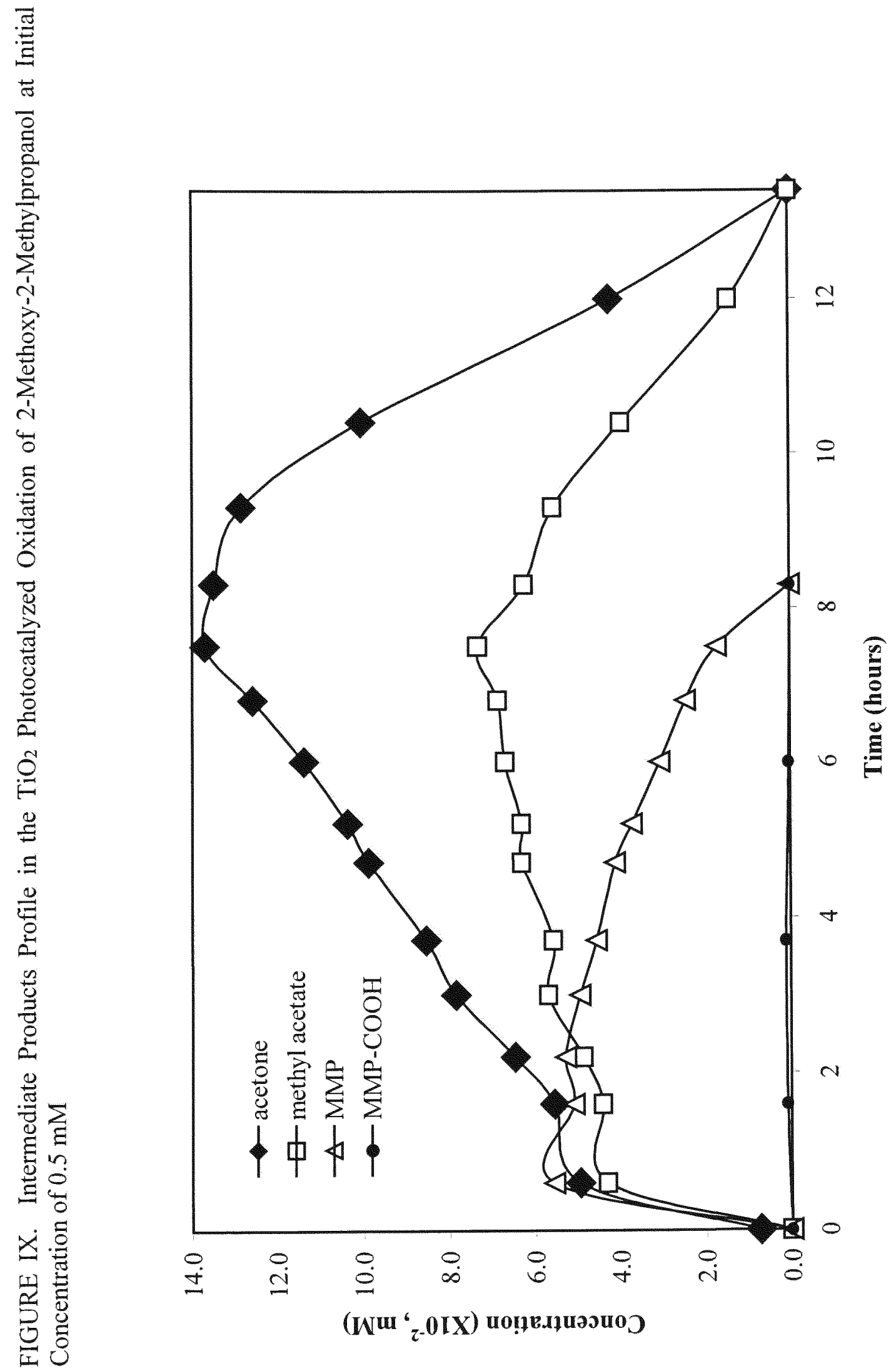


No losses were observed during the dark control reactions in the titanium dioxide photocatalyzed degradation of 2-methoxy-2-methylpropanal, i.e. the starting concentration of the substrate remained constant (Figure X). On the contrary, very slow degradation was observed when the reaction mixture was place in the photochemical reactor $(\lambda=350 \mathrm{~nm})$ and no $\mathrm{TiO}_{2}$ was added, indicating that some direct photolysis of the substrate might have occurred. The photocatalytic degradation of MMP in aqueous slurries of $\mathrm{TiO}_{2}$ is also shown in Figure X. Within the first 0.75 hours, $26 \%$ of the MMP had disappeared. After 3.3 hours, $46 \%$ of the MMP was degraded and at 9 hours, MMP was not longer detected in the reaction solution.

Acetone and Methyl Acetate were identified as intermediate products of the photocatalytic degradation of MMP by GC-head space (Figure XI). Both products appeared rapidly, but remained at a relatively low concentration throughout the reaction, reaching a maximum concentration at 7.6 hours, where the concentration started decreasing. MMP-COOH was identified and monitored by Ion Chromatography. Again, the concentration of MMP-COOH is very low through the reaction, compared with the other two identified intermediates. It was not longer detectable under our experimental conditions at 8 hours.<smiles>COC(C)(C)C=O</smiles>

MMP

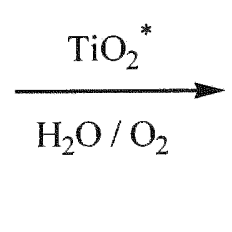

acetone<smiles>CC(C)=O</smiles><smiles>COC(C)=O</smiles>

methyl acetate<smiles>COC(C)(C)C(=O)O</smiles>

$\mathrm{MMP}-\mathrm{COOH}$ 


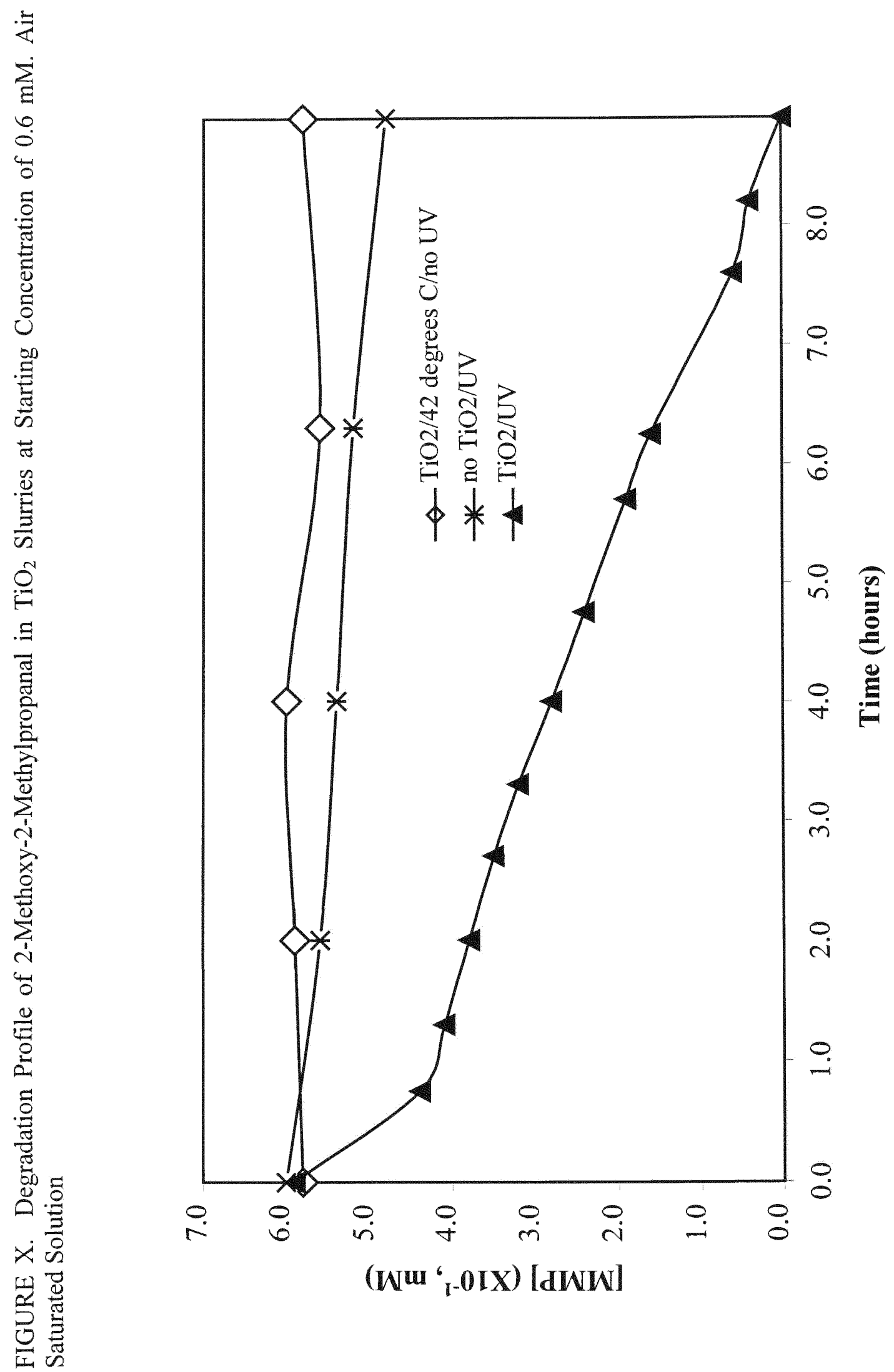




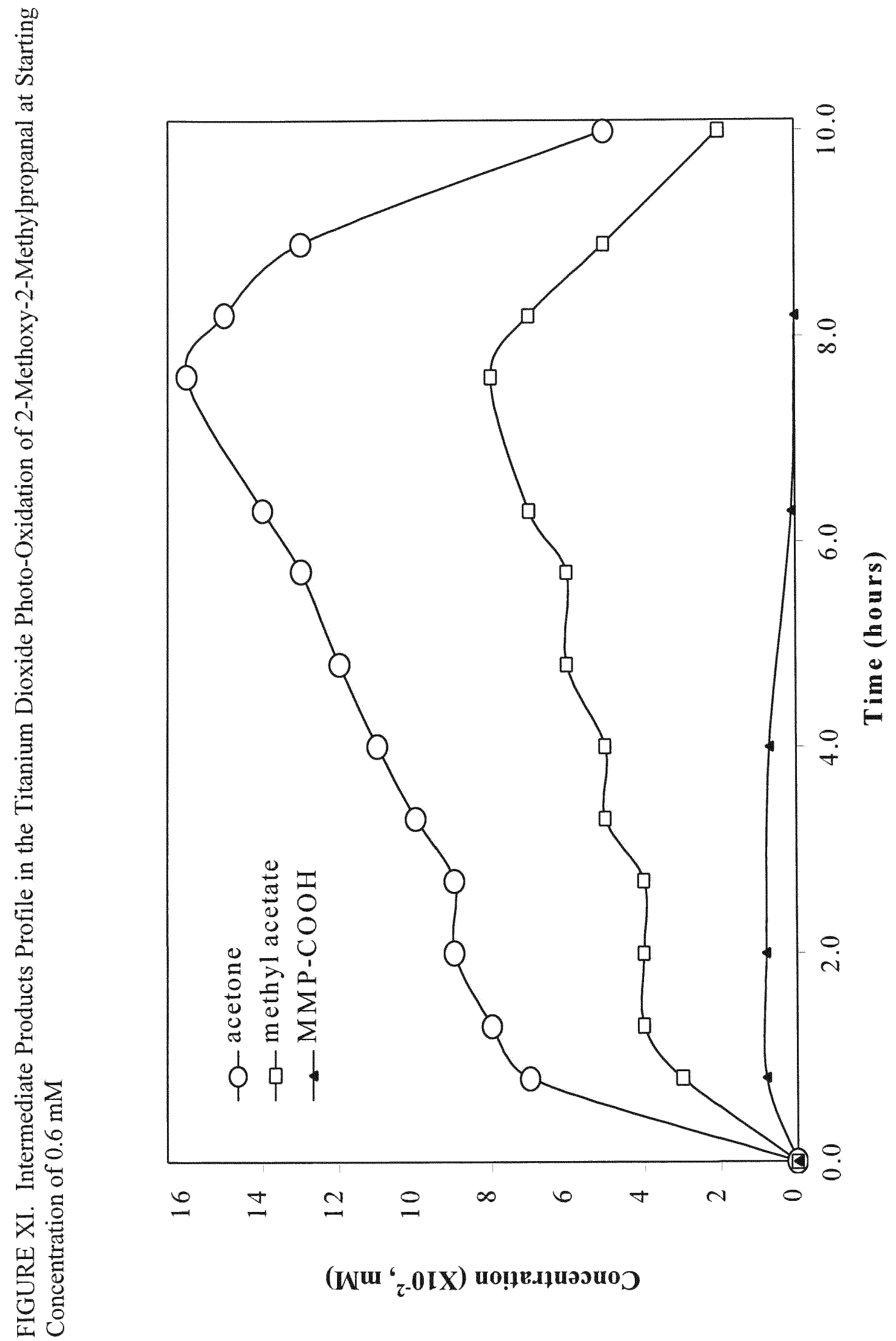


It is well accepted that the oxidative degradation by $\mathrm{TiO}_{2}$ photocatalysis $\left(\mathrm{TiO}_{2}, \mathrm{O}_{2}\right.$, $h v)$, predominantly involves the hydroxyl radicals. These are formed mainly by electron transfer from water or hydroxide ion to the valence band hole. The hole is created by the promotion of an electron from the balance band to the conduction band, when titanium dioxide is irradiated at an appropriated wavelength. ${ }^{1,59}$ Serpone and co-workers provided convincing evidence that hydroxyl radicals are formed in such systems using pulseradiolysis techniques. ${ }^{60}$ The $\bullet \mathrm{OH}$ radicals readily react with a variety of organic substrates. The reaction of the $\mathrm{H} \cdot$ atoms and in many cases also of the solvated electrons with organic substrates is slower. ${ }^{61}$ The presence of oxygen is very important in these kinds of reactions. Studies showed that when free radicals are formed, in this case by the reaction of $\bullet \mathrm{OH}$ with organic substrates, they are converted rapidly into the corresponding peroxyl radicals $\left(\mathrm{R}-\mathrm{O}_{2} \bullet\right.$ ) in the presence of $\mathrm{O}_{2}{ }^{62}$ The rate constants for reactions of a variety of radicals with oxygen are such that the reaction is virtually diffusion-controlled, and the formation of peroxyl radicals is practically irreversible. ${ }^{62}$ The role of $\mathrm{O}_{2}$ was also confirmed in previous studies, and the $\mathrm{TiO}_{2}$ photocatalytic reactions are typically not observed when oxygen is not present in the reaction media. ${ }^{54}$ Oxygen also reacts with electrons in the conduction band in the titanium dioxide surface forming superoxide anion $\left(\mathrm{O}_{2}{ }^{-}\right)$, thus leading the holes to react with water and $\mathrm{OH}^{-}$to form hydroxyl radicals.

Peroxyl radicals undergo head-to-head termination reactions ${ }^{63}$ to form intermediate tetroxides (R-O-O-O-O-R'). Tetroxides undergo a series of competing processes to lead to stable final products. Among those processes, loss of oxygen molecule by the elimination of the terminal oxygen atom from each peroxyl radical in the tetroxide 
molecule (R-O-[O-O]-O-R'), ${ }^{33}$ has been used in isotopic labeling studies to confirm the presence of tetroxides. ${ }^{63}$

Previous studies have demonstrated the formation of primary intermediates in the hydroxyl radical mediated degradation of $\mathrm{MTBE}^{53,54}$. Tert-butyl formate (TBF), tertbutyl alcohol (TBA), acetone, methyl acetate, and formaldehyde have been identified, while the formation of MMP, MMP-OH, and MMP-COOH has been widely suggested. In order to achieve a detailed understanding of each process, the hydroxyl radical mediated degradation was also applied individually to some of the most significant byproducts, namely TBF and TBA. ${ }^{54}$ Although it has been proposed the formation of acetone directly from $\alpha$ and $\beta$ oxidation of $\mathrm{MTBE},{ }^{53}$ other results showed that acetone is also a primary product in the TBA degradation. ${ }^{54}$ Barreto et al. also found TBA as a product during the photocatalytic transformation of TBF, although it has been suggested the hydrolysis of hydroxymethyl tert-butyl ether (from $\alpha$ oxidation of MTBE) as a pathway in the formation of TBA. ${ }^{53}$

Based on our experimental results, and the previous data, a series of mechanisms for the degradation of MTBE, MMP, and MMP-OH has been proposed.

The proposed mechanism for the hydroxyl mediated degradation of MTBE involves $\alpha$ and $\beta$ hydrogen abstraction. The $\beta$-hydrogen abstraction of MTBE leads to carboncentered radical (1) as shown in Figure XII. Subsequent reaction with oxygen to form ROO•, followed by head to head termination, and loss of $\mathrm{O}_{2}$ leads to the alkoxy radical (2). This radical can undergo $(1,2)$ intramolecular hydrogen shift to form the carboncentered radical (3), which is stabilized due the overlapping of the non-paired electron with the oxygen non-bonding orbitals, and upon reaction with oxygen, and loss of $\mathrm{HO}_{2}$ • 
(hydroperoxyl radical), leads to MMP. A competing pathway includes two units of the alkoxy radicals undergoing disproportionation to form MMP and MMP-OH. Loss of formaldehyde from the alkoxy radical (2) leads to a carbon-centered radical (4), which can eliminate a methyl radical to form acetone. Alternatively, (4) can undergo a series of steps $\left(\mathrm{O}_{2}\right.$ trap, termination, loss of oxygen) to form a new alkoxy radical (ㅁ), which loses either methyl radical or methoxyl radical to form methyl acetate or acetone respectively. 
FIGURE XII. Titanium Dioxide Photocatalyzed Degradation of MTBE. Proposed Mechanism

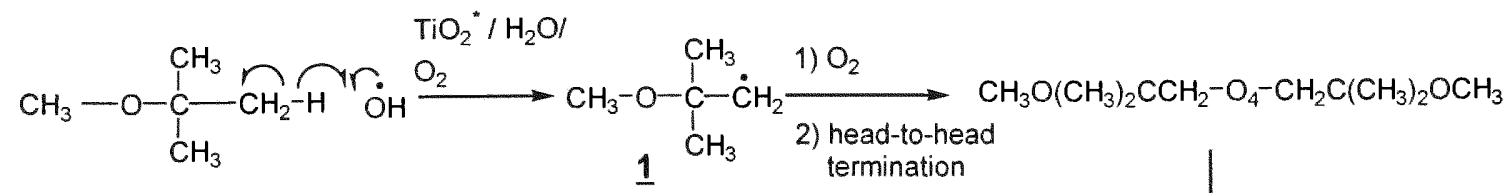<smiles>COC(C)(C)C=O</smiles><smiles>O=[N+]([O-])[O-]</smiles>
1<smiles>COC(C)(C)C=O</smiles><smiles>COC(C)(C)CO</smiles>
disproportionation<smiles>COC(C)(C)C(=O)CCCCCCO</smiles>
$-\mathrm{O}_{2}$<smiles>COC(C)(C)[C@H](O)[18OH]</smiles>

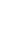<smiles>COC(C)(C)CO</smiles><smiles>CC1CCCCC1</smiles><smiles>[Y]C(C)C=O</smiles><smiles>C=C(C)OC</smiles><smiles>CCC</smiles><smiles>CCCC(C)(C)OC</smiles><smiles>CCCC</smiles>

$\underline{6}$<smiles>CC1(C)CCCCC1(C)O</smiles>

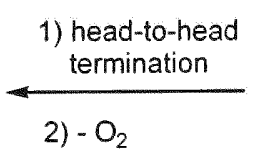<smiles>COC(C)(C)OC</smiles><smiles>CCOC(C)CC</smiles>

5

$\mathrm{O}_{2}$

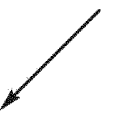
$-\stackrel{\circ}{-} \mathrm{CH}_{3}$

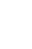<smiles>COC(C)=O</smiles><smiles>CC(C)=O</smiles><smiles>CC(C)=O</smiles> 
The $\mathrm{TiO}_{2}$ photocatalytic degradation of MMP leads to acetone and methyl acetate. Fig. XIII shows the proposed mechanism for this process. The first step is the generation of the acyl radical (7) from the aldehyde (MMP) reaction with hydroxyl radicals (abstraction of the aldehydic hydrogen). Reaction with oxygen leads to the formation of peroxyl radicals, which undergo head to head termination to form tetroxide. Loss of $\mathrm{O}_{2}$ and carbon dioxide generates the carbon centered radical ( 8$)$, which is stabilized by the overlapping of the electron in carbon "p" orbital with the oxygen non-bonding orbitals. This carbon centered radical could either lead to acetone by losing methyl radical, or react with $\mathrm{O}_{2}$ to form peroxyl radical, which undergoes head-to-head termination leading to the tetroxide. The loss of $\mathrm{O}_{2}$ generates an oxygen centered radical (9), which can either lead to methyl acetate by losing methyl radical or acetone by losing methoxyl radical. 
FIGURE XIII. Proposed Mechanism for the Degradation of 2-Methoxy-2Methylpropanal. Formation of Acetone and Methyl Acetate.
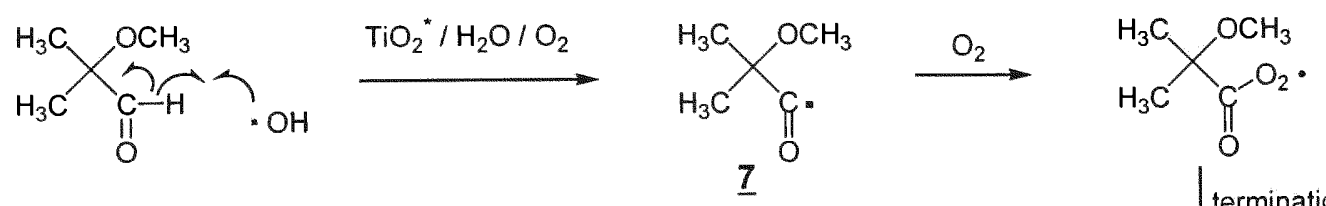<smiles>COC(C)(C)C</smiles><smiles>COC(=O)C(C)(C)OCC=O</smiles><smiles>COC(=O)OCOCOC(=O)C(C)(C)OC</smiles><smiles>COC(C)(C)CCCOc1cc(C)cc(C)c1C</smiles>

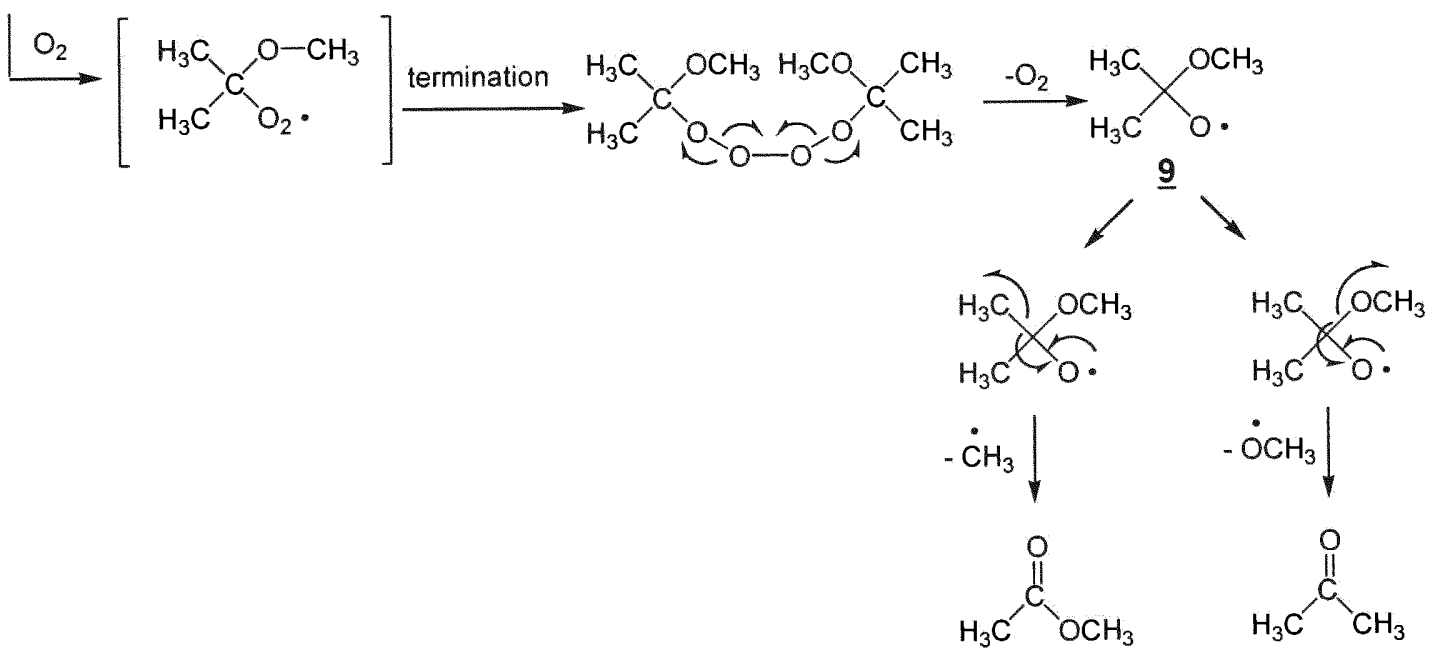


Bolton et al. proposed the formation of MMP-COOH from the titanium dioxide photocatalytic degradation of MMP, since the oxidation of aldehydes to carboxylic acid in $\mathrm{TiO}_{2}$ slurries has been previously reported. ${ }^{53}$ This reaction pathway has not been investigated in previous reports, since no authentic samples of MMP and MMP-COOH were available.

The proposed mechanism for the formation of 2-methoxy-2-methylpropanoic acid is illustrated in Figure XIV. Aldehydes in aqueous solution are normally in equilibrium with their corresponding acetals. Hydrogen abstraction from the acetal (in equilibrium with MMP) by hydroxyl radicals leads to a carbon-centered radical (stabilized by overlapping of the non-pair electron with the oxygen non-bonding orbitals). This radical can react with oxygen leading to the corresponding peroxyl radical. Subsequent elimination of $\mathrm{HO}_{2}{ }^{\circ-}$ from $\alpha$-hydroxyalkylperoxyl radicals is common (as explained earlier). The elimination involves a five-membered transition state, ${ }^{25}$ and leads to a carbonyl compound, in this case, 2-methoxy-2-methylpropanoic acid. 
FIGURE XIV. Proposed Mechanism for the Degradation of 2-Methoxy-2Methylpropanal. Formation of 2-Methoxy-2-Methylpropanoic Acid<smiles>COC(C)(C)C=O</smiles><smiles>COC(C)(C)C(O)O</smiles>

Acetal

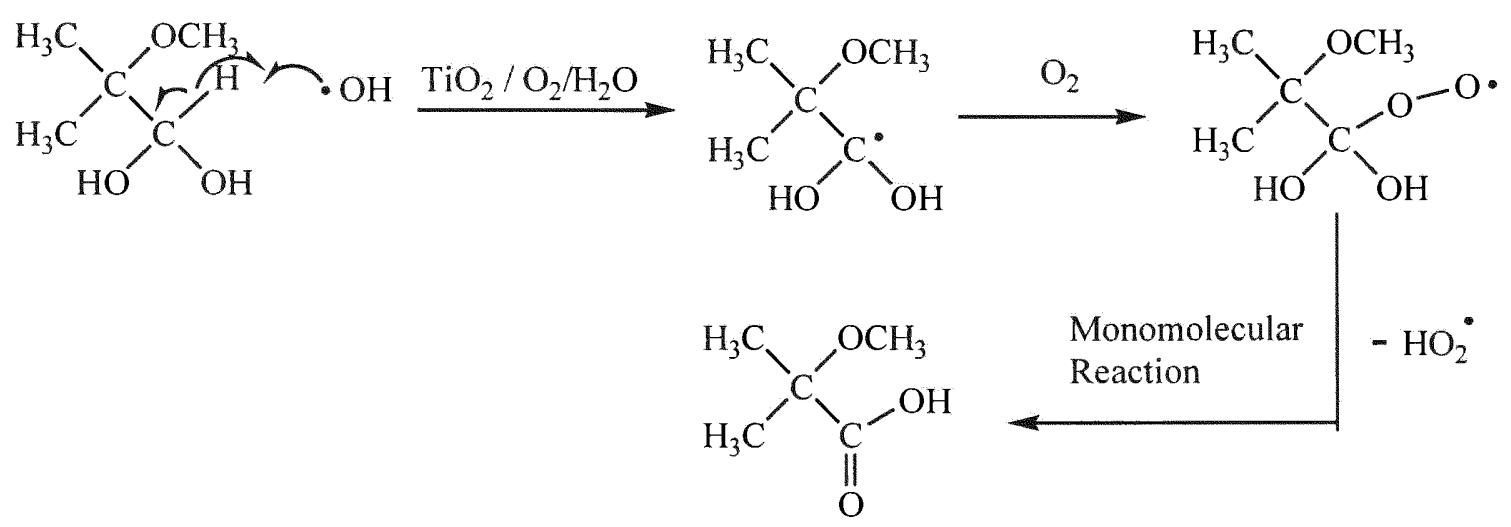

The formation of acetone and methyl acetate in the photocatalytic degradation of MMP-OH and MMP, (figures IX and XI) is similar, suggesting that acetone and methyl acetate are formed by similar or identical processes from the titanium dioxide photocatalyzed degradation of MMP and MMP-OH. The starting concentration of 2 methoxy-2-methylpropanal during its degradation experiments (figure XI) was approximately $0.6 \mathrm{mM}$, while it was ten times less in the degradation of 2-methoxy-2methylpropanol (based on the initial concentration of MMP-OH and rate of degradation of MMP during the first 30 minutes). Despite that difference, the amounts of acetone and methyl acetate in both reactions were very similar, suggesting that they are formed from $\mathrm{MMP}-\mathrm{OH}$ as well. In addition, the concentration ratio of MMP-COOH in the titanium dioxide photocatalytic degradations of MMP-OH and MMP is 1/10 (figures IX and XI). 
As explained before, the starting concentrations of MMP in both reactions (titanium dioxide photocatalytic degradations of MMP-OH and MMP) have the same ratio (1/10 respectively). This suggests either that 2-methoxy-2-methylpropanoic acid is formed only from the photocatalytic degradation of MMP, or that the rate of formation of MMP$\mathrm{COOH}$ from MMP is much greater than the correspondent rate from MMP-OH.

The proposed mechanism for the degradation of MMP-OH is shown in Fig. XV. The first step is the hydrogen abstraction by hydroxyl radicals to generate a carbon-centered radical (10). Reaction with oxygen leads to peroxyl radical (11), which loses $\mathrm{HO}_{2}{ }^{\bullet-}$, generating 2-methoxy-2-methylpropanal. Alternatively, peroxyl radical (11) can undergo head-to-head termination, followed by loss of oxygen to lead to the oxygen-centered radical (12), which in turn can lose H• to form 2-methoxy-2-methylpropanoic acid (13). Oxidation of the acid (13) by $\mathrm{OH} \bullet$ can lead to the oxygen-centered radical (14). This radical (14) can eliminate carbon dioxide, to yield the carbon-centered radical (8), which, through a series of steps (reaction with oxygen, head-to-head termination, loss of oxygen) leads to the oxygen-centered radical (9). Elimination of $\bullet \mathrm{CH}_{3}$ from (9) leads to methyl acetate, while loss of $\bullet \mathrm{OCH}_{3}$ yields acetone. 
FIGURE XV. Proposed Mechanism for the $\mathrm{TiO}_{2}$ Photo-induced Degradation of 2Methoxy-2-Methylpropanol
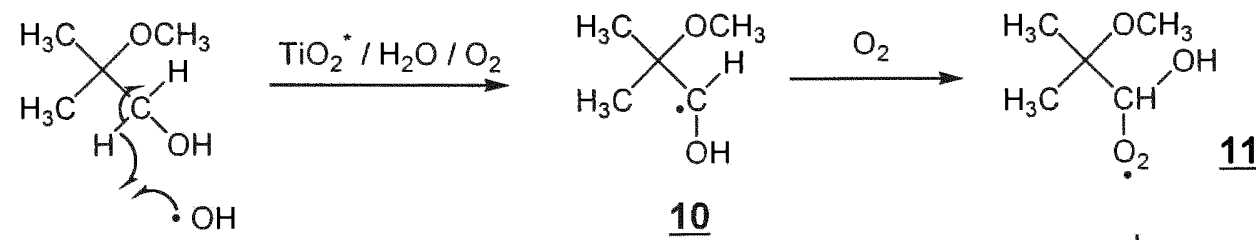

10<smiles>CC(C)(C)C=O</smiles><smiles>COC(C)(C)C(O)O</smiles>
11<smiles>COC(C)(C)C(=O)O</smiles><smiles>COC(=O)C(C)(C)C(=O)OCO</smiles>

12<smiles>COC(C)(C)O</smiles>

1) $\mathrm{O}_{2}$

2) Termination<smiles>CO[C+](C)C</smiles><smiles>CC1CCCCC1C</smiles><smiles>CCCC</smiles><smiles>CCOC</smiles>
3) $-\mathrm{O}_{2}$

$\underline{8}$<smiles>COC(=O)C(C)(C)OC</smiles><smiles>COC(C)=O</smiles><smiles>CC(C)=O</smiles> 


\subsection{CONCLUSIONS.}

The elucidation of the reaction pathway in the titanium dioxide photocatalytic degradation of MTBE is a very important task in the search for a reliable, fast, and affordable method of water decontamination. Although some progress has been achieved in the identification of intermediate products, as well as in the understanding of the reaction mechanisms leading to their formation and degradation, more research is needed in order to confirm the effectiveness of the advanced oxidation processes in the complete mineralization of organic pollutants.

Our studies were focused in the $\beta$-oxidation of MTBE, since $\alpha$-oxidation has been widely studied previously. As a result of our studies, a series of reaction pathways has been established, and a better fundamental understanding of the reactions of hydroxyl radicals, produced in the reaction media, with aliphatic ethers, which can be extended to a variety of organic substrates, has been achieved.

The most important goal of these studies was to confirm, by comparison with authentic samples, the formation of 2-methoxy-2-methylpropanal (MMP), 2-methoxy-2methylpropanol (MMP-OH), and 2-methoxy-2-methylpropanoic acid (MMP-COOH) as intermediate products during the titanium dioxide photocatalytic degradation of MTBE. In an attempt to confirm the effectiveness of this method in the complete mineralization of organic pollutants, and their primary intermediate products, a further study of the $\mathrm{TiO}_{2}$ -mediated photo-oxidation of MMP, MMP-OH, and MMP-COOH was proposed. 
Equation 1 shows the products that were monitored in our study of the degradation of MTBE. Based on the well known mechanisms of hydroxyl radicals mediated degradation of organics compounds, we were able to proposed a series of steps leading to acetone, methyl acetate, MMP, and MMP-OH directly from the $\beta$-oxidation of MTBE (Figure XII).

MMP-OH

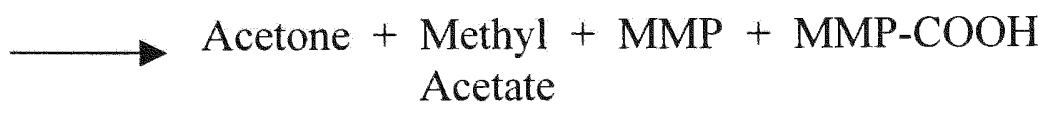

The monitored products in the titanium dioxide photocatalytic degradation of MMP$\mathrm{OH}$ were acetone, methyl acetate, MMP and MMP-COOH (equation 2). There is sufficient evidence in our work to support the formation of these intermediate products, and the proposed mechanisms for these transformations are summarized in Figure XV.

$\mathrm{MMP} \longrightarrow$ Acetone + Methyl Acetate $+\mathrm{MMP}-\mathrm{COOH}$

The $\mathrm{TiO}_{2}$-mediated photo-oxidation of MMP leads to some confirmed and monitored intermediate products, acetone, methyl acetate, and MMP-COOH. Oxidation of aldehydes to their corresponding carboxylic acids in titanium dioxide slurries is expected and was previously reported. ${ }^{53}$ The mechanism proposing the hydroxyl radicalmediated oxidation of the corresponding acetal (in equilibrium with MMP in aqueous solution) is shown in Figure XIV. Based on the fundamental understanding of reactions of hydroxyl radicals with organic substrates we were able to propose the mechanism of 
formation of acetone and methyl acetate from MMP. These mechanisms are summarized in Figure XIII.

In previous studies, the formation of acetone and methyl acetate has been proposed to be directly from $\alpha$ and $\beta$-oxidation of MTBE. ${ }^{53}$ Our studies confirm the formation of these two intermediates products from MMP and $\mathrm{MMP}-\mathrm{OH}$, and along with the previous results, provide important mechanistic information about specific reaction pathways.

Although the formation of MMP during the titanium dioxide photocatalytic degradation of MMP-OH is confirmed, this intermediate product appears to be formed also directly from $\beta$-oxidation of MTBE, as proposed in previous studies. ${ }^{53}$ Our conclusions are consistent with the analysis of the intermediate products profile, and the proposed mechanism for the $\mathrm{TiO}_{2}$ photocatalytic degradation of MTBE (Figures VII and XII). During the first hour of irradiation similar concentrations of MMP and MMP-OH are formed, suggesting the formation of these two intermediate products initially from the disproportionation of the alkoxy radical $\mathrm{CH}_{3} \mathrm{O}\left(\mathrm{CH}_{3}\right)_{2} \mathrm{CCH}_{2} \mathrm{O}$, which is an intermediate in the degradation of MTBE (Figure XII). Further irradiation of the substrate leads to a rapid degradation of $\mathrm{MMP}-\mathrm{OH}$, while relatively high concentrations, compared with the initial amounts, of MMP remains in the reaction media, indicating that MMP is also being formed from the titanium dioxide photo-induced oxidation of MMP-OH.

The analysis of the $\mathrm{TiO}_{2}$ photocatalyzed degradation of MMP-COOH may provide very important information in the elucidation of the reaction pathways, as well as determining the effectiveness of the method in the treatment of organic pollutants in water. 
In general, titanium dioxide photocatalytic oxidation is a very effective method for the mineralization of MTBE, as well as its intermediate products. The fundamental information obtained from these studies is useful in developing predictive models for potential water treatment applications. 


\section{TITANIUM DIOXIDE PHOTOCATALYZED DEGRADATION OF HALO- ETHERS.}

\subsection{CHLOROALKYL ETHERS - INTRODUCTORY REMARKS.}

Chloroalkyl ethers, a subclass of haloethers, are commonly used as industrial solvents and have been found in the aquatic environment. A number of these substrates are potent carcinogens. Among the haloethers, bis-(2-chloroethyl) (BCEE) ether, bis-(2chloroisopropyl) ether (BCIE), bis-(chloromethyl) ether (BCME), and chloromethyl methyl ether (CMME) have received the greatest attention because of their potential health hazards. ${ }^{64,65,66}$ Chloroalkyl ethers do not occur naturally, hence their occurrence is entirely anthropogenic. Discharges from industrial and manufacturing processes represent the major sources of these organic pollutants in the aquatic environment. ${ }^{67}$

A number of reports have concluded that $\alpha$-chloroalkyl ethers (BCME, CMME) have extremely short lifetimes in aqueous solutions because they are susceptible to rapid hydrolysis, therefore they are present in aqueous media for short period of time. ${ }^{68,69}$ In contrast, the $\beta$-chloroalkyl ethers are much more stable, ${ }^{69}$ and their occurrence in river and finished drinking water, has been reported. ${ }^{70} \mathrm{BCEE}$ and $\mathrm{BCIE}$ have been consistently detected and quantitatively determined in specific areas of the country. ${ }^{71}$

The water quality criterion for BCEE has been established by the EPA. This data is based on the induction of hepatomas in male mice (strain $\mathrm{C} 57 \mathrm{BL} / 6 \mathrm{X} \mathrm{C} 3 \mathrm{H} / \mathrm{Anf}) \mathrm{F}_{1}$ ) given a daily oral dose of $300 \mathrm{ppm}$ for 80 weeks. The water concentration of BCEE calculated to keep individual lifetime cancer risk below $10^{-5}$ was $0.30 \mu \mathrm{g} / \mathrm{L} .^{67}$ 
Although there is not empirical evidence that $\mathrm{BCIE}$ is carcinogenic, given its mutagenic activity and close structural similarities to BCEE, which the studies have shown to be carcinogenic in mice, the possible carcinogenicity of BCIE is a matter of concern, as expressed on the EPA reports. ${ }^{67}$

Table V summarizes the main physical constants of the aliphatic haloethers treated by $\mathrm{TiO}_{2}$ photocatalysis. These properties may influence the relative reactivity of substrates toward titanium dioxide photocatalysis. A limited number of reports have appeared on the photochemical and oxidative reactions of this important class of compounds. ${ }^{72,73}$

TABLE V Physical Constants of Aliphatic Haloethers ${ }^{74}$

\begin{tabular}{lcccccc}
\hline Compound & $\begin{array}{c}\mathrm{MW} \\
(\mathrm{g} / \mathrm{mol})\end{array}$ & $\begin{array}{l}\mathrm{BP} \\
\left({ }^{\circ} \mathrm{C}\right)\end{array}$ & $\begin{array}{l}\rho \\
(\mathrm{g} / \mathrm{mL})\end{array}$ & $\begin{array}{l}\text { Solubility } \\
\text { in water } \\
(\mathrm{g} / \mathrm{L})\end{array}$ & $\begin{array}{l}\text { Vapor } \\
\text { Pressure } \\
(\text { Torr })\end{array}$ & $\mathrm{K}_{\mathrm{OW}}$ \\
\hline $\begin{array}{l}\text { Bis-(2-chloro- } \\
\text { ethyl) ether }\end{array}$ & 143.01 & 65 & 1.220 & $10.2^{75}$ & $0.71^{75}$ & $38.0^{76}$ \\
\hline $\begin{array}{l}\text { Bis-(2-cloro- } \\
\text { isopropyl) ether }\end{array}$ & 171.07 & 189 & 1.114 & $1.70^{75}$ & $0.85^{75}$ & $380.2^{76}$ \\
\hline
\end{tabular}

\subsection{RECENT STUDIES.}

Previous works in the $\mathrm{TiO}_{2}$ photocatalytic degradation of bis-(2-chloroethyl) ether have shown the formation of 2-chloroethanol, chloroacetaldehyde, and chloroacetic acid as stable intermediates. ${ }^{74}$ A number of intermediate products were also identified during titanium dioxide photocatalysis of bis-(2-chloroisopropyl) ether, including 1-chloro-2propanol, and chloroacetone. ${ }^{74}$ 
In an attempt to develop a better understanding of the mechanisms and reaction pathways in the $\mathrm{TiO}_{2}$ photocatalysis of this class of compounds, studies were carried out. $\mathrm{TiO}_{2}$ induced photo-oxidations of bis-(2-chloroethyl) ether and bis-(2-chloroisopropyl) ether, structures provided in Table VI, were performed. In addition to previously reported products, 2-chloroethyl formate, and 1-chloro-2-propyl acetate, are observed as intermediate products. The identity of these intermediate compounds was confirmed by chromatographic comparison with independently synthesized samples.

TABLE VI Name and Structures of Aliphatic Haloethers in the Study

Name / Chemical Abstract \#

Structure

Bis-(2-chloroethyl) ether

$\mathrm{Cl}-\mathrm{CH}_{2}-\mathrm{CH}_{2}-\mathrm{O}-\mathrm{CH}_{2}-\mathrm{CH}_{2}-\mathrm{Cl}$

CAS\# 111-44-4

Bis-(2-chloroisopropyl) ether

$\mathrm{Cl}-\mathrm{CH}_{2}-\mathrm{CH}\left(\mathrm{CH}_{3}\right)-\mathrm{O}-\mathrm{CH}\left(\mathrm{CH}_{3}\right)-\mathrm{CH}_{2}-\mathrm{Cl}$

CAS\# 108-60-1

The name, molecular and structural formulas, as well as the molecular weight of the titanium dioxide photocatalyzed degradation derivatives of the haloethers studied in this chapter are presented in Table VII. 
TABLE VII Haloethers Derivatives. Chemical Data

Chemical

Name
Molecular

Formula
Structural Formula

$\mathrm{CH}_{3} \mathrm{COOCH}\left(\mathrm{CH}_{3}\right)\left(\mathrm{CH}_{2} \mathrm{Cl}\right)$

136.5
Molecular

Weight $(\mathrm{g} / \mathrm{mol})$

1-chloro-2-propyl

$\mathrm{C}_{5} \mathrm{H}_{9} \mathrm{O}_{2} \mathrm{Cl}$

acetate

chloroacetone

$\mathrm{C}_{3} \mathrm{H}_{5} \mathrm{OCl}$

$\mathrm{ClCH}_{2} \mathrm{COCH}_{3}$

92.5

2-chloroethyl

$\mathrm{C}_{3} \mathrm{H}_{5} \mathrm{O}_{2} \mathrm{Cl}$

$\mathrm{HCOOCH}_{2} \mathrm{CH}_{2} \mathrm{Cl}$

108.5

formate

2-chloroethanol

$\mathrm{C}_{2} \mathrm{H}_{5} \mathrm{OCl}$

$\mathrm{ClCH}_{2} \mathrm{CH}_{2} \mathrm{OH}$

80.5

\subsection{EXPERIMENTAL SECTION.}

\subsubsection{Reagents and Materials.}

Formic acid ( $90 \%$ water solution), anhydrous ethyl ether ( $99.9 \%$ purity), dichloromethane, methanol, acetic anhydride, dimethyl-amino pyridine, sulfuric acid, anhydrous magnesium sulfate, were used for the synthesis processes; n-butanol ( $99.9 \%$ purity), nhexanol $(99.9 \%$ purity), were used as internal standards. These reagents were purchased from Fisher Scientific. Chloroacetone (95\% purity), bis-(2-chloroethyl) ether (99\% purity), bis-(2-chloroisopropyl) ether (99\% purity), 1-chloro-2-propanol (70\% purity), 2- 
chloroethanol (99\% purity) were purchased from Aldrich Chemicals, and used as standards for the study of the reactions. The photocatalyst used was titanium dioxide, Degussa P25 lot\# RV 2186 (surface area $50 \mathrm{~m}^{2} / \mathrm{g}$, avg. primary particle size $30 \mathrm{n}, \mathrm{X}$-Ray structure primarily anatase). Ultrapure water was employed throughout these investigations.

\subsubsection{Apparatus.}

The UV irradiation experiments were carried out in a Rayonet Photochemical Reactor, Model RPR-100 (manufactured by The Southern New England Ultraviolet Company, Branford, USA). The lamps intensity is $1.29 \times 10^{16}$ photon/sec $\mathrm{x} \mathrm{mL}$, and the wavelength was $350 \mathrm{~nm}$.

\subsubsection{Analytical Methods.}

The GC-Head Space - FID methods were applied to confirm the identity of the compounds as well as to develop the quantification procedures. The GC-Head Space-MS methods were applied to confirm the identity of the compounds (qualitative analysis). Authentic samples (standards) of all the analyzed compounds were used.

\subsubsection{Analysis of bis-(2-chloroisopropyl) ether.}

GC-Head Space-FID. Bis-(2-chloroisopropyl) ether, chloroacetone, 1-chloro-2propanol, and 1-chloro-2-propyl acetate were analyzed by a HP 5890 series II gas chromatography system equipped with a HP 19395A head space system, a HP 19395A autosampler, and a HP 3396 series II integrator. A RTx-BAC1 (fused silica) column (ID 
$30 \times 0.53 \mathrm{~mm}, 3 \mu \mathrm{m}$ film thickness) by Restek Corporation was used in connection with a flame ionization detector (FID). The FID detector was set at $200{ }^{\circ} \mathrm{C}$. The column temperature was programmed at $40{ }^{\circ} \mathrm{C}$ for $1 \mathrm{~min}$, then ramped up to $142{ }^{\circ} \mathrm{C}$ at a rate of 9 ${ }^{\circ} \mathrm{C} / \mathrm{min}$, and held at $142{ }^{\circ} \mathrm{C}$ for $0.2 \mathrm{~min}$; helium was the carrier gas. The injector port temperature was $180{ }^{\circ} \mathrm{C}$, and the samples were injected using headspace technique. The bath temperature was $60^{\circ} \mathrm{C}$, the loop temperature was $75^{\circ} \mathrm{C}$, and the equilibration time was 1 min. Calibration curves were prepared using the following procedure. Stock solutions of 2-chloroisopropyl ether (274.0 ppm), 1-chloro-2-propyl acetate (336.0 ppm), chloroacetone (486.0 ppm), and 1-chloro-2-propanol (456.0 ppm) were prepared. Standard mixtures were prepared in a range of concentration from $0.9 \mathrm{ppm}$ to $137.0 \mathrm{ppm}$ for 2-chloroisopropyl ether, $2.1 \mathrm{ppm}$ to $105.8 \mathrm{ppm}$ for 1-chloro-2-propyl acetate, $4.9 \mathrm{ppm}$ to $81.0 \mathrm{ppm}$ for chloroacetone, and $15.2 \mathrm{ppm}$ to $152 \mathrm{ppm}$ for 1-chloro-2-propanol. A 6.0 mLs aliquot of each standard mixture was placed in $20 \mathrm{mLs}$ vials fitted with an aluminum seal and a PTFE septum. For the calibration curves, $50 \mu \mathrm{Ls}$ of n-butanol solution (internal standard, $810 \mathrm{ppm}$ ) were added to each standard.

GC-Head Space-MSD. Bis-(2-chloroisopropyl) ether, chloroacetone, 1-chloro-2propanol, and 1-chloro-2-propyl acetate were analyzed by a HP 6890 gas chromatography system equipped with a HP 7694 head space system, and a HP 5973 mass selective detector (MSD). A RTX-5 (60m X 0.53mm, $3 \mu \mathrm{m})$ by Restek Corporation in connection with the MSD was used. The column temperature was programmed at 40 ${ }^{\circ} \mathrm{C}$ for 0 min, ramped up to $86{ }^{\circ} \mathrm{C}$ at a rate of $2{ }^{\circ} \mathrm{C} / \mathrm{min}$, held at $86{ }^{\circ} \mathrm{C}$ for $5 \mathrm{~min}$, then ramped up to $250^{\circ} \mathrm{C}$ at a rate of $20^{\circ} \mathrm{C} / \mathrm{min}$, then held at $250{ }^{\circ} \mathrm{C}$ for $5 \mathrm{~min}$. Helium was the carrier gas, and the total flow rate was $15.0 \mathrm{~mL} / \mathrm{min}$. The bath temperature was $70^{\circ} \mathrm{C}$, 
the MSD temperature was $280^{\circ} \mathrm{C}$. Splitless injection mode was used, with an injection volume of $1.0 \mu \mathrm{L}$.

\subsubsection{Analysis of bis-(2-chloroethyl) ether.}

GC-Head Space-FID. Bis-(2-chloroethyl) ether, 2-chloroethanol, and 2-chloroethyl formate were analyzed by the same equipment as described in 3.3.3.1 (section I). For the analysis of 2-chloroethanol, the bath temperature was $80^{\circ} \mathrm{C}$, the loop temperature was 95 ${ }^{\circ} \mathrm{C}$. The oven temperature was programmed at $40{ }^{\circ} \mathrm{C}$ for $1.5 \mathrm{~min}$, then ramped up to 135 ${ }^{\circ} \mathrm{C}$ at a rate of $15^{\circ} \mathrm{C} / \mathrm{min}$, and held at $135^{\circ} \mathrm{C}$ for $1.5 \mathrm{~min}$. For the analysis of 2-chloroethyl formate, the bath temperature was $40{ }^{\circ} \mathrm{C}$, the loop temperature was $55{ }^{\circ} \mathrm{C}$; and for 2 chloroethyl ether, the bath temperature was $80{ }^{\circ} \mathrm{C}$, the loop temperature was $95{ }^{\circ} \mathrm{C}$. The oven temperature was programmed at $50{ }^{\circ} \mathrm{C}$ for $1 \mathrm{~min}$, then ramped up to $135^{\circ} \mathrm{C}$ at a rate of $19^{\circ} \mathrm{C} / \mathrm{min}$, and held at $135^{\circ} \mathrm{C}$ for $1 \mathrm{~min}$ for both compounds. Standard solutions were prepared in ranges of concentration from $6.0 \mathrm{ppm}$ to $30.0 \mathrm{ppm}$ for 2-chloroethanol, 20.1 ppm to $96.4 \mathrm{ppm}$ for 2-chloroethyl formate, and $2.0 \mathrm{ppm}$ to $59.0 \mathrm{ppm}$ for 2-chloroethyl ether. A $6.0 \mathrm{mLs}$ aliquot of each standard was placed in a $20 \mathrm{mLs}$ vial fitted with an aluminum seal and a PTFE septum. For the calibration curves, $20 \mu$ Ls of n-hexanol solution (internal standard, $814 \mathrm{ppm}$ ) were added to 2-chloroethanol and 2-chloroethyl ether standards, and $100 \mu \mathrm{Ls}$ of the same internal standard were added to the 2chloroethyl formate standards.

GC-Head Space-MSD. Bis-(2-chloroethyl) ether, 2-chloroethanol, and 2-chloroethyl formate were analyzed by the same equipment as described in 3.3.3.1. The oven 
temperature was programmed at $80^{\circ} \mathrm{C}$ for $4 \mathrm{~min}$, ramped up to $180^{\circ} \mathrm{C}$ at a rate of 10 ${ }^{\circ} \mathrm{C} / \mathrm{min}$, then ramped up to $250^{\circ} \mathrm{C}$ at a rate of $30^{\circ} \mathrm{C} / \mathrm{min}$.

\subsubsection{Photolysis.}

3.3.4.1 2-chloroisopropyl ether, and 2-chloroethyl ether control reactions.

Control reactions were run for 2-chloroisopropyl ether (initial concentration of 86.0 $\mathrm{ppm}$ ), and 2-chloroethyl ether (initial concentration of $100 \mathrm{ppm}$ ). For Control Reaction I the procedure was the same as described in 2.3.4.1, except the reaction vessel was covered with aluminum foil and placed in a water bath instead of the photoreactor, keeping the reaction temperature at $42{ }^{\circ} \mathrm{C}$. For Control Reaction II the procedure was the same described in 2.3.4.1, but no $\mathrm{TiO}_{2}$ was added to the solution. Samples were taken at given time intervals, and analyzed by the procedures described in 3.3.3.1 and 3.3.3.2.

\subsubsection{Control reaction for chloroacetone.}

A stock solution (59.1 ppm) was prepared. The followed procedure was the same as described in 3.3.4.1 for Control Reaction I.

3.3.4.3 Bis-(2-chloroisopropyl) ether, bis-(2-chloroethyl) ether, and 1-chloro-2-propyl acetate. Photolysis.

For the UV irradiation experiment $100 \mathrm{mLs}$ aliquot of $86.0 \mathrm{ppm}$ solution of 2chloroisopropyl ether, $100.0 \mathrm{ppm}$ solution of 2-chloroethyl ether, $73.0 \mathrm{ppm}$ solution of 1chloro-2-propyl acetate, were placed in three $120 \mathrm{mLs}$ reactor vessels ( 7 inch long $\mathrm{X}$ 
0.25 inch diameter) equipped with a screw top Teflon caps. The followed procedure was the same as described in 2.3.4.1. Aliquots $(6.0 \mathrm{mLs})$ were taken for analysis every time. Each sample was transferred to a $20 \mathrm{~mL}$ vial fitted with an aluminum seal and a PTFE septum. The samples were analyzed as described in 3.3.3.1 and 3.3.3.2

\subsubsection{Synthesis}

3.3.5.1 Synthesis of 1-chloro-2-propyl acetate.

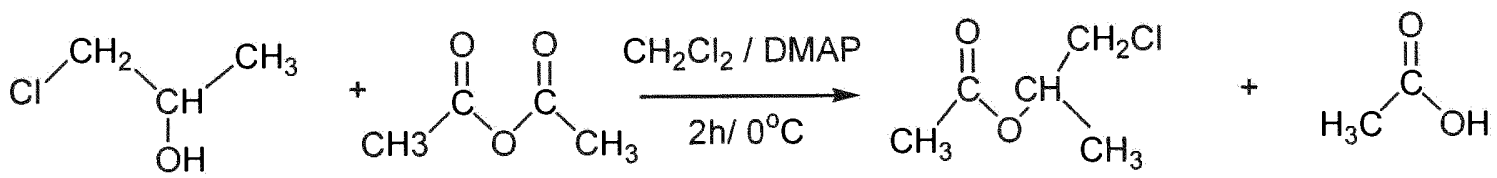

1-chloro-2-propanol acetic anhydride

1-chloro-2-propyl acetate acetic acid

General procedure as described in Results and Discussion Section.

In a $100 \mathrm{mLs}$ round-bottom flask, $5 \mathrm{mLs}$ of dry methylene chloride $\left(0^{\circ} \mathrm{C}\right)$ were magnetically stirred. A mixture $76 \%$ of 1-chloro-2-propanol / $24 \%$ of 2-chloro-1propanol $(5 \mathrm{mmol}, 0.42 \mathrm{~g})$, acetic anhydride $(1 \mathrm{~mL})$, and dimethyl-amino pyridine $(5$ mmol, $0.6 \mathrm{~g}$ ), were added. The reaction was stirred at $0{ }^{\circ} \mathrm{C}$ for $2.0 \mathrm{~h}$, followed by the addition of methanol $(5 \mathrm{mLs})$, and stirring at room temperature for $2.0 \mathrm{~h}$. The resulting mixture was extracted with water, followed by a saturated solution of sodium chloride. The organic layer was dried over anhydrous magnesium sulfate, and then transferred to a $25 \mathrm{mLs}$ round-bottom flask equipped for distillation. The solution was carefully distilled 
to yield a mixture of 1-chloro-2-propyl acetate and 2-chloro-1-propyl acetate. The interest compound 1-chloro-2-propyl acetate was characterized: $(0.17 \mathrm{~g}, 24.6 \%),{ }^{1} \mathrm{H}$ NMR (400 $\left.\mathrm{MHz}, \mathrm{d}_{4}-\mathrm{MeOH}\right) \delta(\mathrm{ppm}) 5.00(\mathrm{~m}, 1 \mathrm{H}), 3.60(\mathrm{~d}$ of d, J $=4.53 \mathrm{~Hz}, \mathrm{~J}=11.60 \mathrm{~Hz}, 1 \mathrm{H})$, $3.54(\mathrm{~d}$ of d, J $=5.92 \mathrm{~Hz}, \mathrm{~J}=11.60 \mathrm{~Hz}, 1 \mathrm{H}), 1.98(\mathrm{~s}, 3 \mathrm{H}), 1.24(\mathrm{~d}, \mathrm{~J}=6.38 \mathrm{~Hz}, 3 \mathrm{H}) ;{ }^{13} \mathrm{C}$ NMR (100 MHz, d $\left.\mathrm{d}_{4}-\mathrm{MeOH}\right) \quad \delta(\mathrm{ppm}) 18.0,21.5,47.3,70.0,170.7$. MS $\mathrm{m} / z$ (relative intensity) $136\left(\mathrm{M}^{+}\right.$, not observed), $87(39), 76(6), 61(12), 43(100)$.

3.3.5.2 Synthesis of 2-chloroethyl formate.

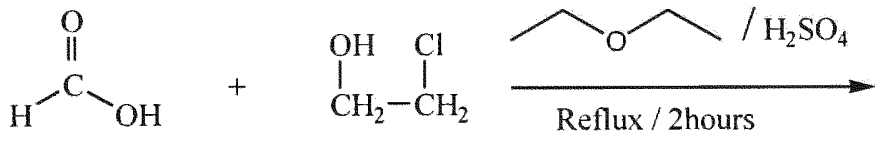

formic acid<smiles>O=COCCCl</smiles>

2-chloroethyl formate

General procedure as described in Results and Discussion Section.

To $350 \mathrm{mLs}$ of anhydrous diethyl ether (magnetically stirred) 3 drops of concentrated sulfuric acid, formic acid (0.2 mol, $9 \mathrm{~g})$, and 2-chloroethanol $(0.22 \mathrm{~mol}, 15 \mathrm{mLs})$ were added in a $500 \mathrm{mLs}$ round-bottom flask. The reaction was heated to reflux for $2.0 \mathrm{~h}$ in a water bath $\left(50^{\circ} \mathrm{C}\right)$. The resulting reaction mixture was distilled and approximately 200 mLs of the solvent was collected. The residue was transferred to a separatory funnel, and a saturated solution of sodium bicarbonate was added until the $\mathrm{pH}$ was neutralized $(\sim 7)$. The organic layer, separated from the aqueous phase, was washed with water, a saturated solution of sodium chloride, and then dried over anhydrous magnesium sulfate. The residue was transferred to a $250 \mathrm{mLs}$ round-bottom flask and careful distillation was 
performed to yield 2-chloroethyl formate $(2.04 \mathrm{~g}, 9.7 \%)$ : bp $123-125{ }^{\circ} \mathrm{C} / 760 \mathrm{~mm} ;{ }^{1} \mathrm{H}$ NMR (400 MHz, $\left.\mathrm{CDCl}_{3}\right) \delta(\mathrm{ppm}) 3.73(\mathrm{t}, \mathrm{J}=5.7 \mathrm{~Hz}, 2 \mathrm{H}), 4.44(\mathrm{t}, \mathrm{J}=5.7 \mathrm{~Hz}, 2 \mathrm{H}), 8.11$ (s, 1H); ${ }^{13} \mathrm{C}$ NMR $\left(100 \mathrm{MHz}, \mathrm{CDCl}_{3}\right) \delta(\mathrm{ppm}) 41.2,63.4,160.4$. IR (film) $v_{\max } 1723.64$ $\mathrm{cm}^{-1}(\mathrm{CO}) . \mathrm{MS} \mathrm{m} / \mathrm{z}$ (relative intensity) $108\left(\mathrm{M}^{+}, 0.03\right), 64(28), 62(86), 51(4), 49(9), 45$ $(5), 43(16), 31(100)$.

\subsection{RESULTS AND DISCUSSION.}

The synthesis of 1-chloro-2-propyl acetate was performed by using a standard esterification procedure. ${ }^{77}$ Acetic anhydride reacts with 1-chloro-2-propanol to lead to the corresponding ester and acetic acid. Methanol is added to react with the excess of acetic anhydride leading to methyl acetate and acetic acid. Dimethyl-amino pyridine, is protonated by acid-base reaction with acetic acid, making it easier to remove the acid (non-protonated form) simply by extracting the reaction mixture with water.

Werner et al. proposed the synthesis of formic acid-derivated esters by the reaction of the correspondent alcohol with formic acid. ${ }^{78}$ Since formic acid is not stable when treated with mineral acids, diisopropyl ether is used as solvent, to remove the excess of water (azeotropic mixture containing $2.6 \%$ water), and drive the esterification equilibrium toward the formation of the ester. Following this procedure was followed, a number of by-products were obtained in the reaction mixture, which were very difficult to separate from the desired product, 2-chloroethyl formate. The procedure was modified by employing a more volatile solvent, diethyl ether, which reduces the refluxing temperature. In addition, a low concentrated mineral acid was used ( 3 drops of sulfuric acid were added to $350 \mathrm{mLs}$ of the solvent) as a catalyst. 
Cort and Pearson ${ }^{79}$ prepared 2-chloroethyl formate from chlorination of 1,3-dioxolan, and characterized it as follows: b.p. $131-132{ }^{\circ} \mathrm{C} / 763 \mathrm{~mm}, n_{\mathrm{D}}{ }^{25}$ 1.4251. Elementary analysis. Found: $\mathrm{C}, 33.2 ; \mathrm{H}, 4.6 ; \mathrm{Cl}, 32.6$. Calc. for $\mathrm{C}_{3} \mathrm{H}_{5} \mathrm{O}_{2} \mathrm{Cl}: \mathrm{C}, 33.2 ; \mathrm{H}, 4.6 ; \mathrm{Cl}$, 32.7\%. 2-Chloroethyl formate, prepared according to the method of Cotardi and Ercoli ${ }^{79}$ from formic acid and ethylene chlorohydrin $\left(60 \%\right.$ yield), had b.p. $131-132{ }^{\circ} \mathrm{C} / 764 \mathrm{~mm}$, $n_{\mathrm{D}}{ }^{25} 1.4251$. Elementary analysis. Found $\mathrm{Cl}, 33.1 \%$. Infrared spectrum shows strong absorption at $1723 \mathrm{~cm}^{-1}$, which is coincident with our results.

Data describing the photocatalytic degradation of bis-(2-chloroisopropyl) ether in aqueous slurries of $\mathrm{TiO}_{2}$ is shown in Figure XVI. Slow disappearance of the starting material is observed under control conditions $\left(\mathrm{TiO}_{2}-42{ }^{\circ} \mathrm{C} /\right.$ no light, no $\mathrm{TiO}_{2}-\mathrm{UV}$ light, $\lambda=350 \mathrm{~nm}$ ). Since both control reactions give similar rates of disappearance, it may suggest that hydrolysis leads to relative slow degradation at $42{ }^{\circ} \mathrm{C}$. (approximately $30 \%$ in 7 hours).

Under $\mathrm{TiO}_{2}$ photocatalysis conditions, within 60 minutes, $50 \%$ of the ether is degraded (Figure XVI), while at 4 hours, more than $90 \%$ of the substrate has been degraded. A significant decrease in the rate of degradation is observed after 4 hours, undoubtedly due to competition from intermediate products for the active sites in the $\mathrm{TiO}_{2}$ surface, leading to a slow decrease of the ether concentration, until it was not longer detectable under our experimental conditions at 7 hours. 

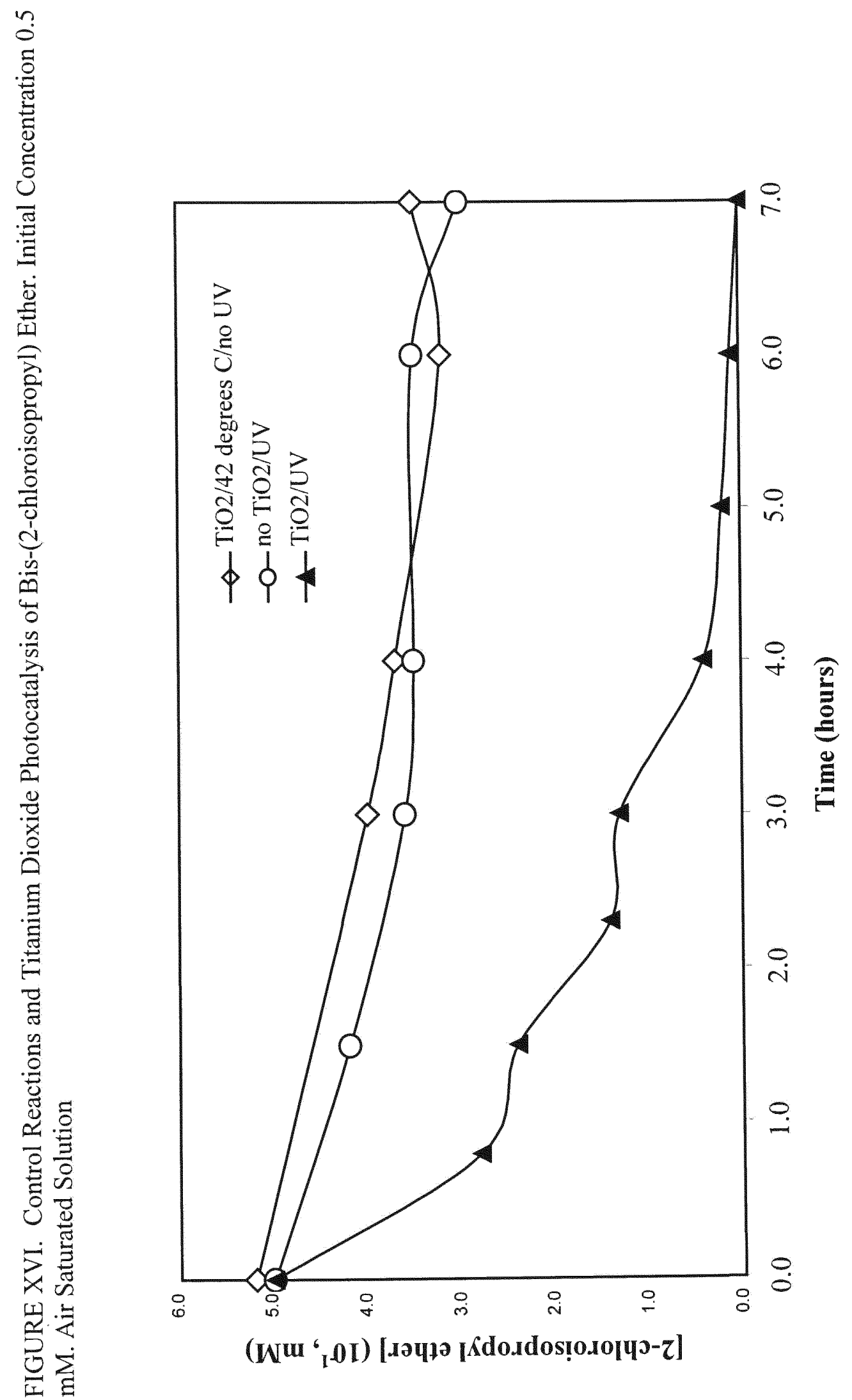
Two products of the photocatalytic degradation of bis-(2-chloroisopropyl) ether were identified by GC-head space-FID, chloroacetone and 1-chloro-2-propyl acetate, which was confirmed by GC-Head Space-Mass Spectroscopy (Figure XVII). The chloroacetone concentration was relatively constant throughout the reaction, reaching a maximum at 1.5 hours, which represented approximately $6 \%$ of the ether starting concentration. After 7 hours of irradiation, the concentration started to decrease to non-detectable levels at 8.8 hours. The by-product, 1-chloro-2-propyl acetate was formed at significantly higher concentrations during the initial hour of irradiation, and remained relatively constant during the first 6 hours of the reaction. 1-Chloro-2-propyl acetate reached a maximum concentration, representing $26 \%$ of the ether initial concentration, at 3 hours. Continued irradiation resulted in a decrease in the concentration, and it was not longer detectable in the solution at 8.8 hours.<smiles>CCC(C)OC(C)CCl</smiles>

bis (2-chloroisopropyl) ether

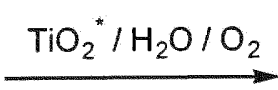<smiles>CC(=O)OC(C)CCl</smiles>

1-chloro-2-propyl acetate<smiles>CCC(C)=O</smiles>

chloroacetone 


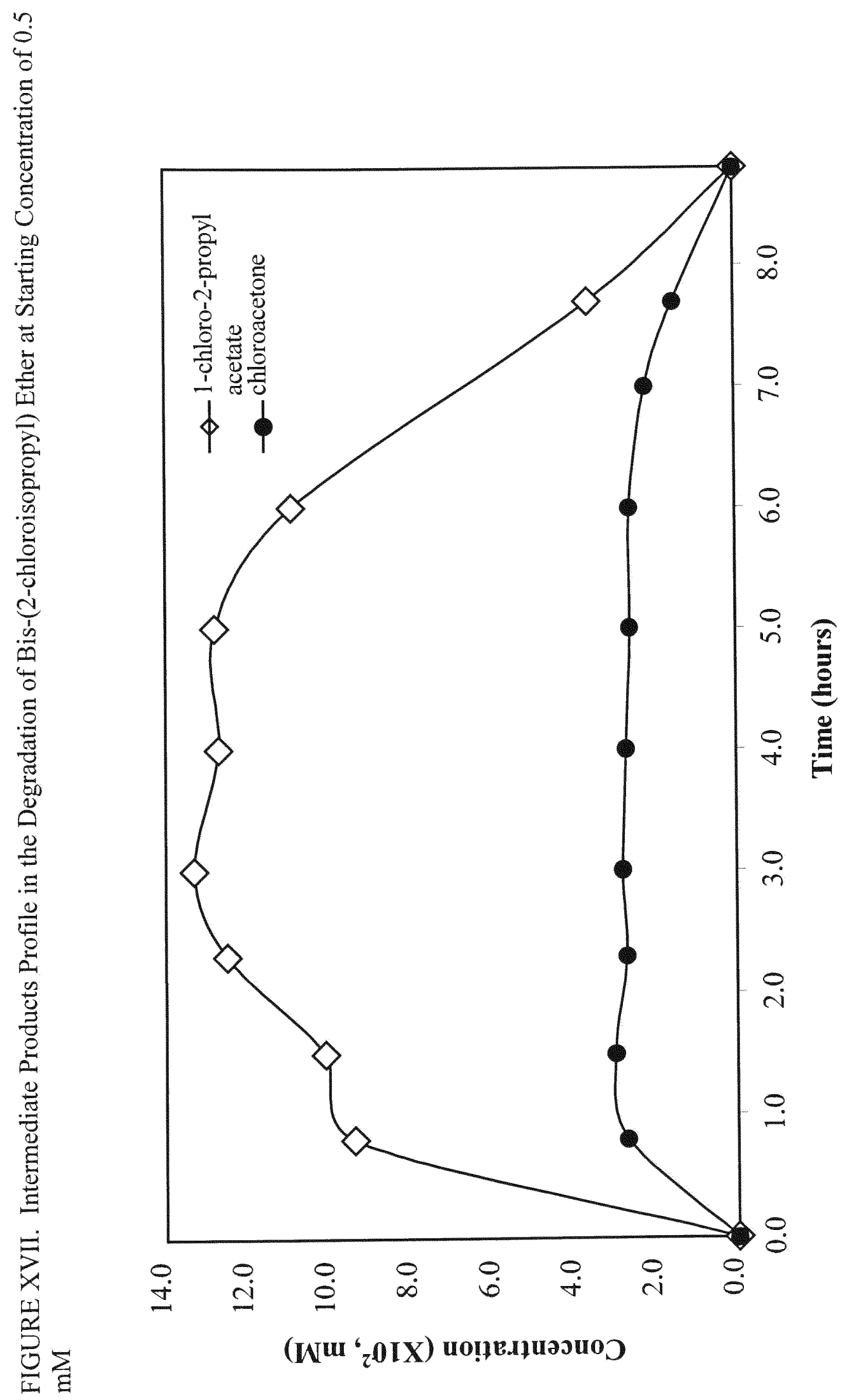


We studied the photocatalytic degradation of the major product, 1-chloro-2-propyl acetate in aqueous slurries of $\mathrm{TiO}_{2}$, as shown in Fig. XVIII. Within the first 50 minutes, $27 \%$ of compound has disappeared, while at 5 hours, $60 \%$ of the initial amount has been degraded. At 8.8 hours, 1-chloro-2-propyl acetate was no longer detected in the reaction solution under our experiment conditions. This compound is readily hydrolyzed in aqueous solution and in titanium dioxide slurries at $60{ }^{\circ} \mathrm{C}$. In a period of approximately 200 minutes (3.3 hours), different concentrations of aqueous solutions of 1-chloro-2propyl acetate (from 2.1 to $105.8 \mathrm{ppm}$ ) at $60{ }^{\circ} \mathrm{C}$ hydrolyzed approximately $18.2 \%$ as an average. Similar results were found when the same concentration solutions were added $\mathrm{TiO}_{2}(0.1 \mathrm{mg} / \mathrm{mLs})$ and kept at the same temperature during the same period of time.

Although a number of products are likely formed, we were only able to identify chloroacetone during the photocatalytic degradation of 1-chloro-2-propyl acetate by using GC-Head Space analysis. Chloroacetone appeared during the initial stages of the reaction and the concentration remained almost constant over the first 7.0 hours, followed by a decrease until it is no longer detectable at 8.8 hours (Figure XIX). 


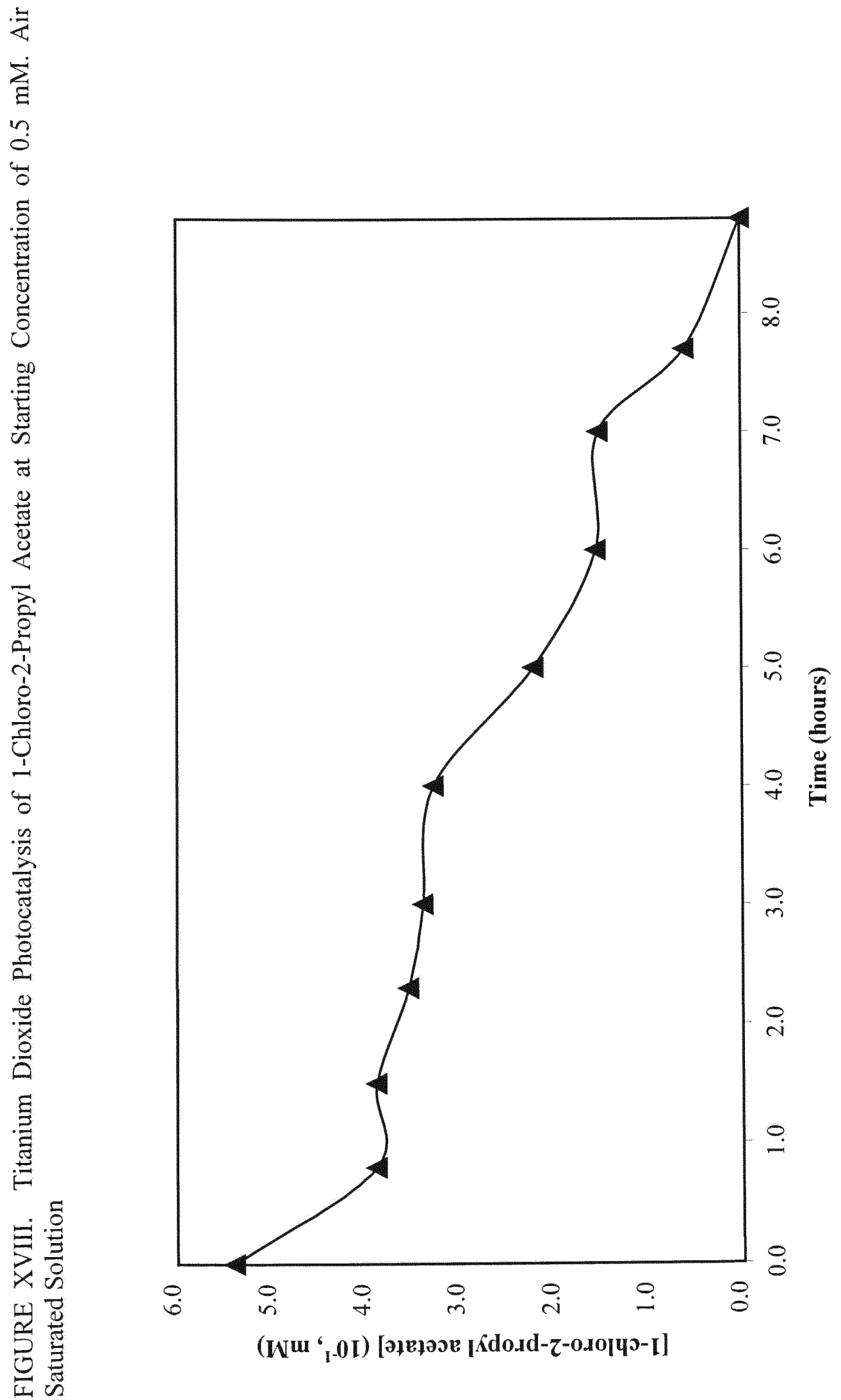




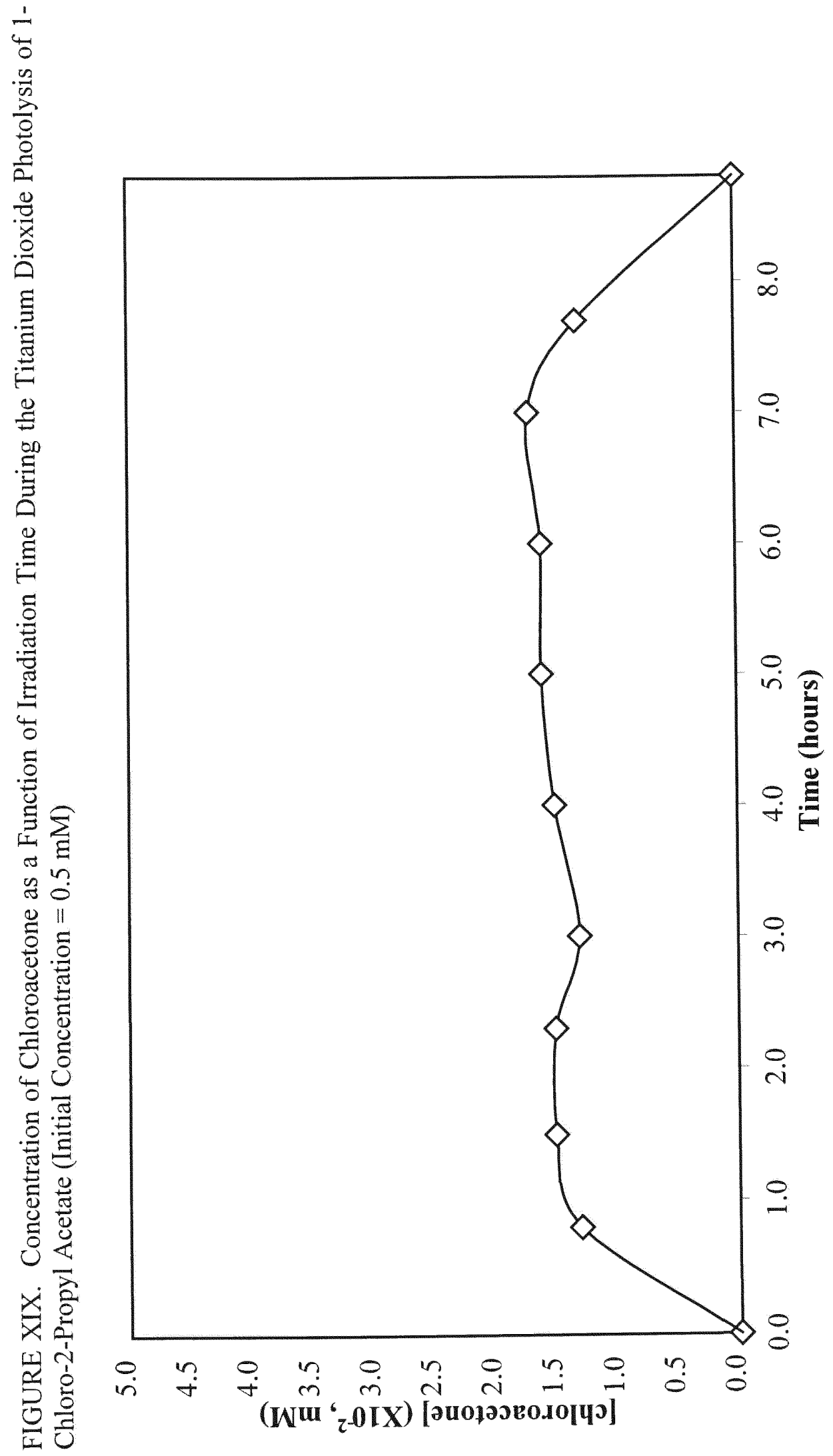


The control experiments for chloroacetone illustrate that this substrate in the presence of titanium dioxide at $42{ }^{\circ} \mathrm{C}$ over considerable period of time, is not reactive. This indicates that loses do to adsorption onto the $\mathrm{TiO}_{2}$ surface are insignificant, and chloroacetone is relative stable to hydrolysis or other surface catalyzed (non-hv) reactions at this temperature (Figure $\mathrm{XX}$ ).

The photocatalytic degradation of bis-(2-chloroethyl) ether in aqueous slurries of $\mathrm{TiO}_{2}$ at a starting concentration of $100.0 \mathrm{ppm}$ was carried out, and control reactions were run. No losses of starting material were observed during control experiments (no $\mathrm{TiO}_{2}-$ $42{ }^{\circ} \mathrm{C}, \mathrm{TiO}_{2}-$ no light), indicating that direct photolysis, hydrolysis, or adsorption of this substrate onto the titanium dioxide surface did not occur appreciably. Within 1 hour, 19\% of 2-chloroethyl ether has disappeared, while at 8 hours, $48 \%$ of the starting material was converted to products, as shown in figure XXI. 2-Chloroethyl ether was no longer detectable after 12 hours of irradiation. 


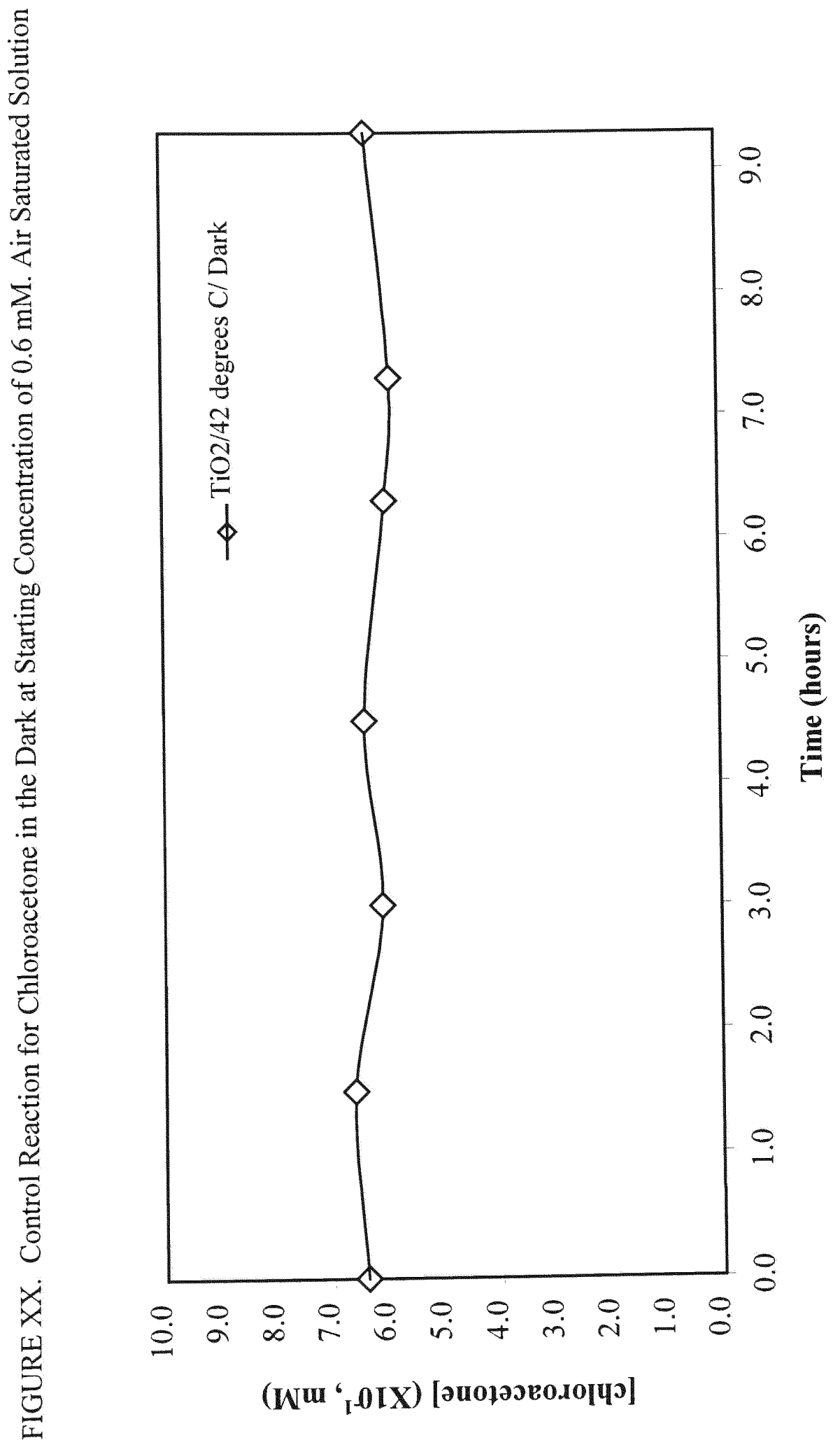




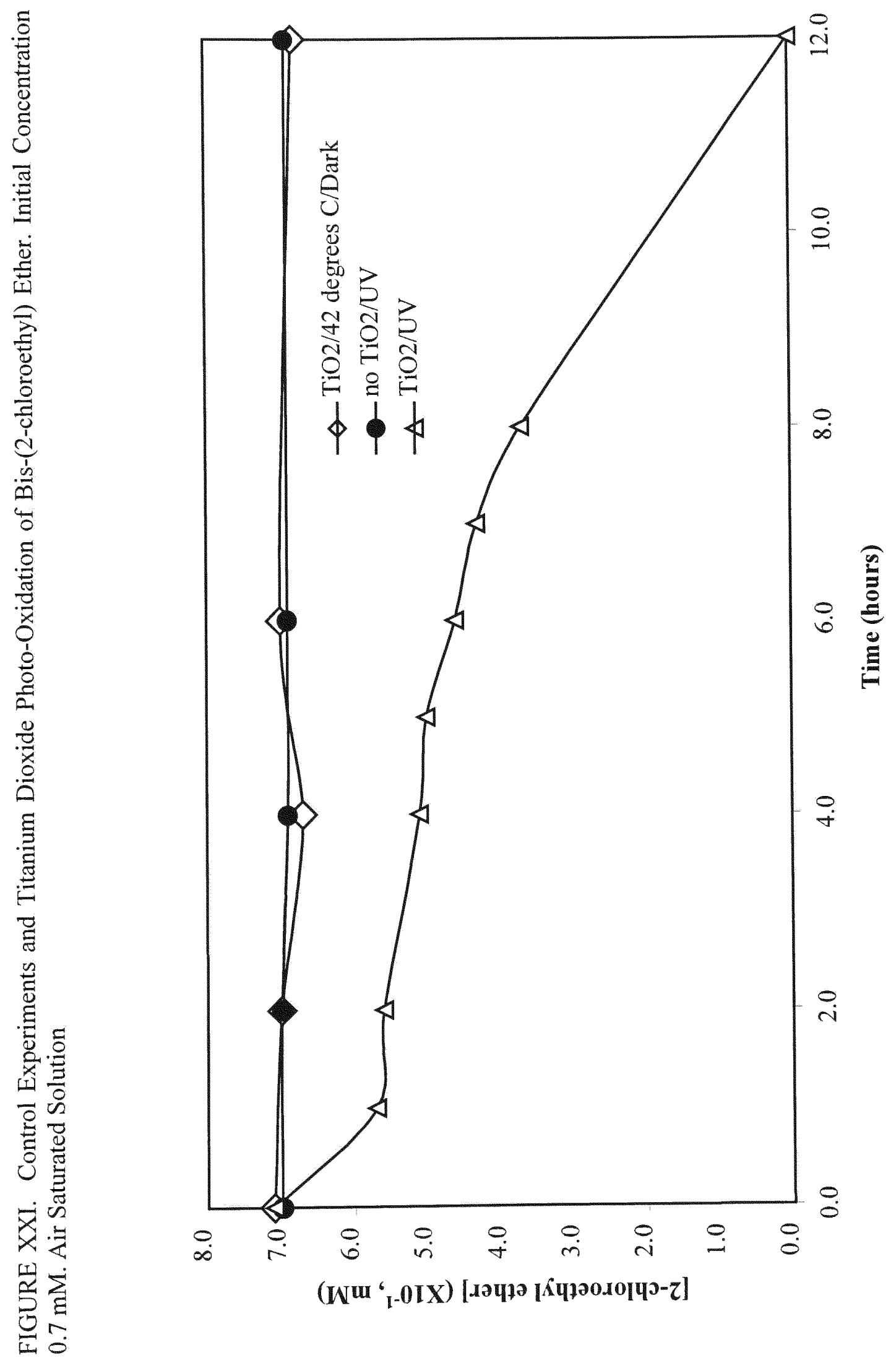



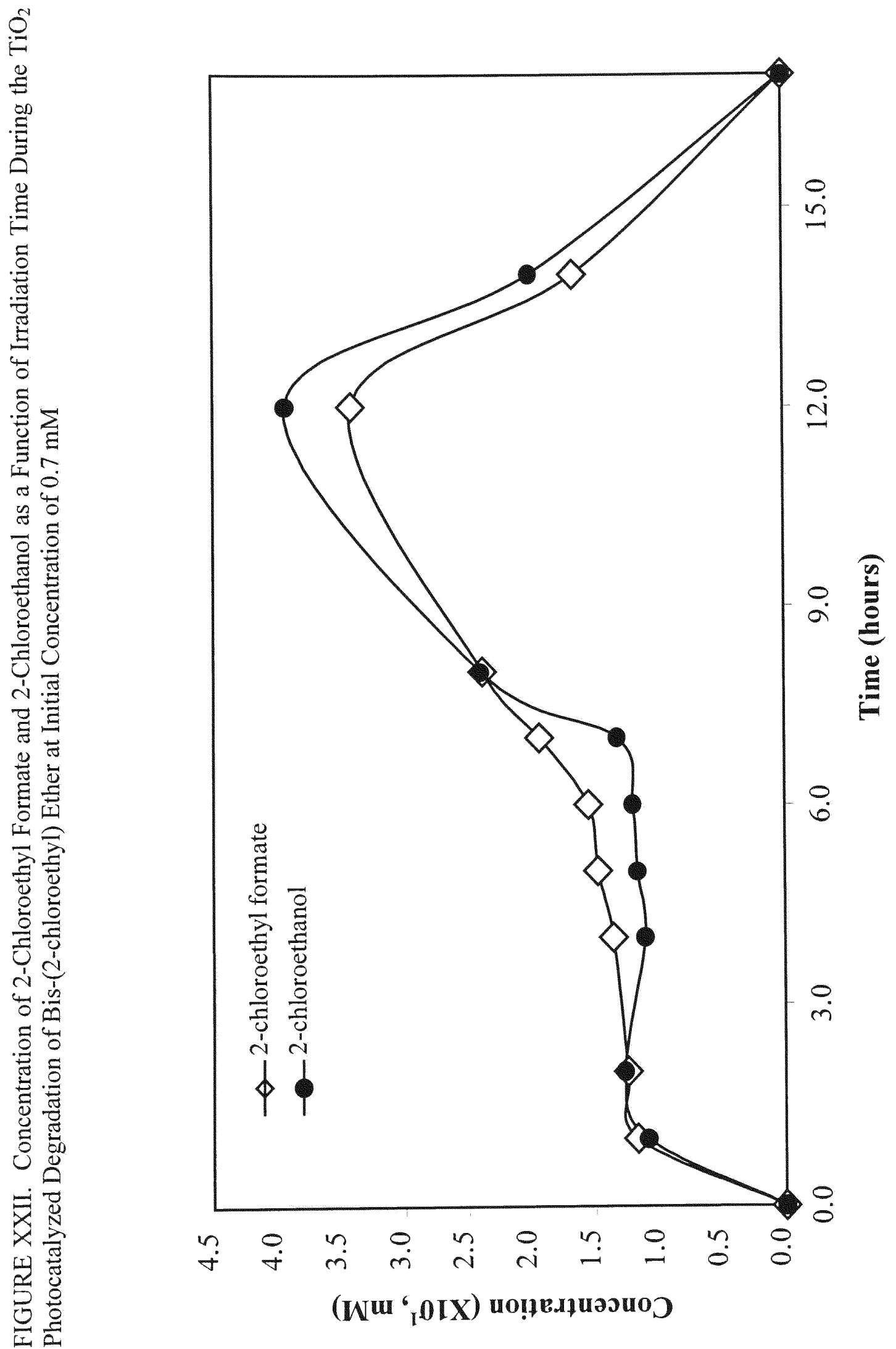
Titanium Dioxide photocatalysis of bis-(2-chloroethyl ether) yields two major reaction products, 2-chloroethyl formate, and 2-chloroethanol, identified by GC-FID analysis and comparison with authentic samples. The identification of 2-chloroethyl formate was further confirmed by GC-Head Space-Mass Spectroscopy. The rates of formation of both products are similar, with the concentration of 2-chloroethyl formate slightly higher during the irradiation (Figure XXII). Both products are formed during the first hour of irradiation, and their concentrations corresponded approximately to $16 \%$ of the starting ether concentration. With continuous irradiation the concentration was constant during the following 6 hours. After 7 hours, the rate of formation increased, and both products reached the maximum concentration at 12 hours of irradiation, followed by decreasing concentration until the products were not longer detected at 17 hours.<smiles>ClCCOCCCl</smiles>

bis (2-chloroethyl) ether

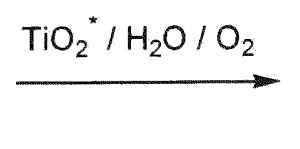

2-chloroethyl formate<smiles>O=COCCCl</smiles>

2-chloroethanol

From an initial concentration of $0.53 \mathrm{mM}$ of 1-chloro-2-propyl acetate a maximum concentration of approximately $0.02 \mathrm{mM}$ of chloroacetone was observed (Figure XIX). From a maximum concentration of approximately $0.13 \mathrm{mM}$ of 1-chloro-2-propyl acetate formed during the titanium dioxide photocatalytic degradation of bis-(2-chloroisopropyl) ether, chloroacetone is formed in a higher amount (approximately $0.03 \mathrm{mM}$ ), as shown in Figure XVII. This suggests that chloroacetone is formed from the $\mathrm{TiO}_{2}$ photocatalyzed 
oxidation of 1-chloro-2-propyl acetate and bis-(2-chloroisopropyl) ether. Based on these results, a mechanism for the hydroxyl radicals induced degradation of bis-(2chloroisopropyl) ether was proposed (Figure XXIII). Abstraction of the $\alpha$ hydrogen is likely the first step, which leads to the formation of a stabilized radical (1), due to orbital overlap of the non-paired electron with the oxygen non-bonding orbitals. Addition of oxygen, head to head termination and loss of $\mathrm{O}_{2}$, lead to the oxygen centered radical (oxyl radical, 2). Subsequent loss of $\cdot \mathrm{CH}_{2} \mathrm{Cl}(3)$ by $\beta$-fragmentation, leads to 1-chloro-2propyl acetate (4). Loss of radical (6) by $\beta$-fragmentation of the oxyl radical (2) leads to chloroacetone. Oxygen-centered radical (6) can undergo hydrogen shift leading to carbon-centered radical (7). This radical can lose $\bullet \mathrm{Cl}$ to lead the vinylic alcohol (8), which is in equilibrium with acetone. Although the formation of acetone was proposed by this mechanism, it was not investigated in our studies. 
FIGURE XXIII. Proposed Mechanism for the Degradation of Bis-(2-chloroisopro-pyl) Ether. Formation of 1-Chloro-2-Propyl Acetate and Chloroacetone

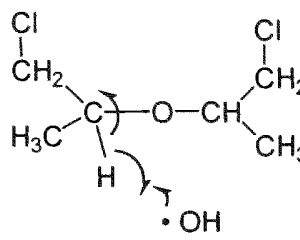<smiles>Oc1ccco1</smiles><smiles>CC(CCl)OC(C)(C)CCl</smiles><smiles>CCCO</smiles><smiles>CCOC(C)(CCl)OC(C)CCl</smiles><smiles>CCC(C)OC(C)(O)CCl</smiles><smiles>CCC(C)OC(C)(CCl)OOOC(C)(CCl)OC(C)CCl</smiles><smiles>CC(Cl)C(C)OC(C)(C)C(C)Cl</smiles><smiles>CC(C)Cl</smiles><smiles>CC(=O)OC(C)CCl</smiles><smiles>C=C(C)O</smiles>
$\underline{4}$

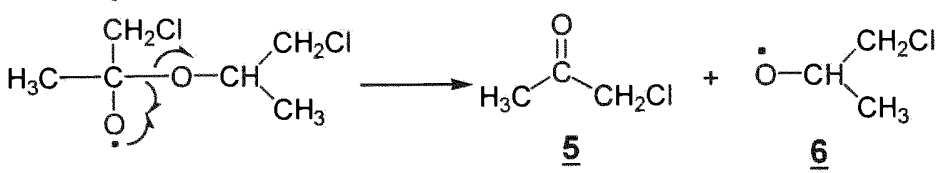

\section{$\underline{6}$}<smiles>CC(C)=O</smiles>

9

Based on the product studies, a mechanism was also proposed for the $\mathrm{TiO}_{2}$ photocatalytic degradation of 1-chloro-2-propyl acetate. Hydrogen abstraction to form a stabilized radical (10) (Figure XXIV), followed by the addition of one oxygen molecule, formation of the tetroxide (11), and loss of $\mathrm{O}_{2}$ are the sequence of steps leading the oxyl 
radical (12). Loss of acyl radical (13), by means of $\beta$-fragmentation, leads to the product chloroacetone. The acyl radical can further lead to carbon dioxide by losing methyl radical.

FIGURE XXIV. 1-Chloro-2-Propyl Acetate Photocatalyzed Degradation. Formation of Chloroacetone. Proposed Mechanism<smiles>CC(=O)OC(C)(CCl)CCCCO</smiles><smiles>CC(=O)CCl</smiles>

$+$<smiles>CCC1CCCC(=O)C1=O</smiles><smiles>CC(=O)OC(C)=CCl</smiles>

10<smiles>CC(=O)OC(C)([O+])CCl</smiles>
termination

\section{3}

Previous studies have also demonstrated the formation of chloroacetone during the titanium dioxide photocatalysis of bis-(2-chloroisopropyl) ether. Mechanisms have been proposed ${ }^{69}$, showing the formation of chloroacetone from the hydrolysis of hemiacetal, which is suggested to be one of the intermediate products in the haloether degradation. 
Our results indicated another possible pathway in the formation of chloroacetone, but the possibility of both pathways has not been eliminated.

Titanium dioxide induced degradation of bis-(2-chloroethyl) ether has been also rationalized. The proposed mechanism for the formation of one of the primary intermediates, 2-chloroethyl formate, is shown in Fig. XXV. Abstraction of the $\alpha$ hydrogen was proposed, followed by oxygen addition. Formation of the tetroxide (14), and loss of $\mathrm{O}_{2}$ to lead the oxygen centered (oxyl radical, 15), are the next proposed steps. Loss of $\cdot \mathrm{CH}_{2} \mathrm{Cl}$ (17), as final step, leads to 2-chloroethyl formate (16). Even though it has been postulated for primary and secondary oxyl radicals, the $1,2-\mathrm{H}$ shift prior to the $\beta$ fragmentation, this reaction pathway obeys that rule, and the loss of $\cdot \mathrm{CH}_{2} \mathrm{Cl}$ takes place faster than the hydrogen shift.

Another identified primary intermediate was 2-chloroethanol. The mechanism of its formation has been proposed in previous reports, ${ }^{69}$ where 2 -chloroethanol is formed by hydrolysis of hemiacetal, which could be one of the 2-chloroethyl ether degradation intermediates (Figure XXVI). 
FIGURE XXV. Formation of 2-Chloroethyl Formate During the $\mathrm{TiO}_{2}$ Photocatalysis of Bis-(2-chloroethyl) Ether. Proposed Mechanism

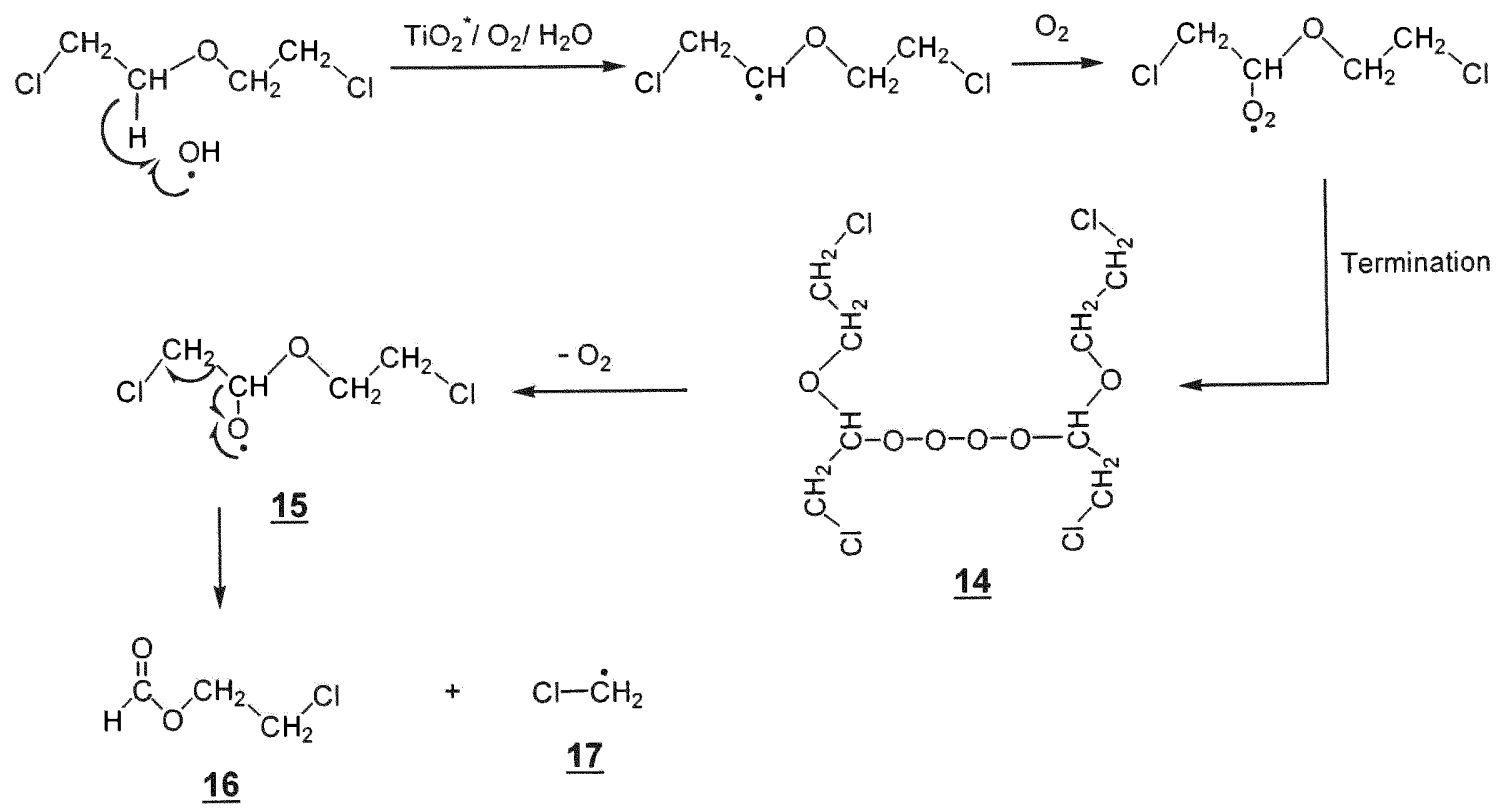

FIGURE XXVI. Formation of 2-Chloroethanol During the $\mathrm{TiO}_{2}$ Photocatalysis of Bis(2-chloroethyl) Ether. Proposed Mechanism

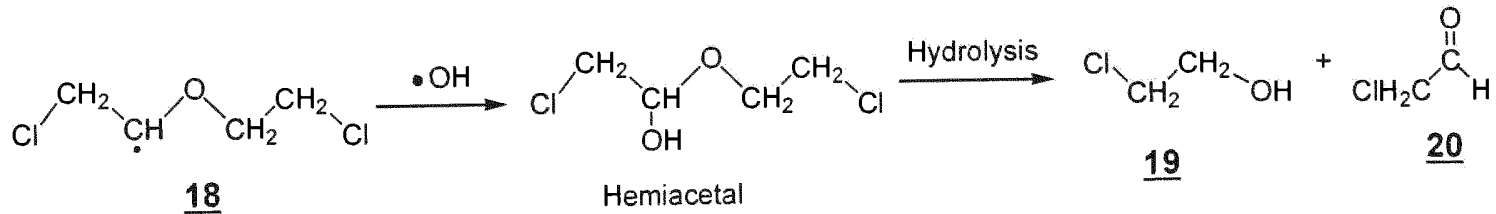




\subsection{CONCLUSIONS.}

As mentioned earlier, during previous studies of the titanium dioxide photocatalyzed degradation of bis-(2-chloroisopropyl) ether and bis-(2-chloroethyl) ether, some intermediate products had been identified. ${ }^{74}$ The complete investigation of the reaction pathways of these two chloroalkyl ethers during the $\mathrm{TiO}_{2}$-mediated photo-oxidation is crucial in determining whether or no advanced oxidation processes are useful in the complete mineralization of these pollutants, and their corresponding intermediate products.

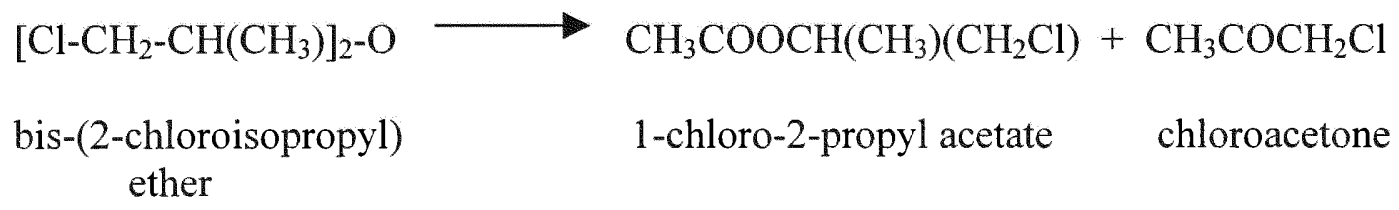

Equation 1 shows the products that were monitored in our study of titanium dioxide photocatalyzed degradation of bis-(2-chloroisopropyl) ether. Previous studies had confirmed the formation of 1-chloro-2-propanol and chloroacetone as intermediate products. ${ }^{74}$ The identification of 1-chloro-2-propyl acetate in our analysis was performed by GC-MS. The abstraction of hydrogen in $\alpha$ position with respect to oxygen in bis-(2chloroisopropyl) ether is expected, based on our understanding of the reactions of $\mathrm{OH} \bullet$ with organic substrates. Subsequent addition of oxygen, head to head termination, and loss of oxygen leading to the formation to the oxygen-centered radical are well known steps, and, as proposed in Figure XXIII, are the key in the formation of 1-chloro-2-propyl acetate and chloroacetone. 
In an attempt to achieve a more complete understanding of the reaction pathway, the $\mathrm{TiO}_{2}$ photo-induced oxidation of 1-chloro-2-propyl acetate was performed. Chloroacetone was identified as one of the intermediate products in this reaction (equation 2). 1-Chloro-2-propyl acetate is readily degraded by the titanium dioxide photo-induced oxidation as a result of hydrogen abstraction by $\mathrm{OH} \bullet$ present in the reaction media. Figure XXIV shows the proposed mechanism, where, once the carboncentered radical (10) is formed by $\mathrm{H} \bullet$ abstraction, the subsequent steps (addition of oxygen, termination, loss of oxygen, an loss of acyl radical), lead to chloroacetone. Based on the concentrations of chloroacetone monitored in reactions 1 and 2 , the direct formation of this intermediate from the degradation of bis-(2-chloroisopropyl) ether (equation 1) is also possible.

$\begin{array}{lcl}\mathrm{Cl}-\mathrm{CH}_{2}-\mathrm{CH}_{2}-\mathrm{O}-\mathrm{CH}_{2}-\mathrm{CH}_{2}-\mathrm{Cl} \longrightarrow & \mathrm{HCOOCH} \mathrm{CH}_{2} \mathrm{Cl}+ & \mathrm{Cl}-\mathrm{CH}_{2}-\mathrm{CH}_{2}-\mathrm{OH} \\ \text { Bis-(2-chloroethyl) ether } & \begin{array}{c}\text { 2-chloroethyl } \\ \text { formate }\end{array} & \text { 2-chloroethanol }\end{array}$

The formation of 2-chloroethanol, chloroacetaldehyde, and chloroacetic acid as intermediate products in the titanium dioxide photocatalyzed degradation of bis-(2chloroethyl) ether was confirmed in previous studies, and mechanisms were proposed for these transformations. ${ }^{74}$ The formation of 2-chloroethyl formate was monitored by GCFID and confirmed by GC-MS in our studies. A mechanism was proposed for the 
formation of this new product, as shown in Figure XXV. The $\alpha$-hydrogen abstraction is expected due to the formation to a relative stable carbon-centered radical. Previous studies have shown that this radical reacts with oxygen forming the corresponding peroxyl radical. The peroxyl radical undergoes head to head termination to form tetroxides, which subsequent lose oxygen leading to the corresponding oxyl radical (15). Further loss of the relative stable radical $\mathrm{Cl}-\mathrm{CH}_{2} \bullet$ leads to 2-chloroethyl formate. Our studies also showed that 2-chloroethyl formate is hydrolyzed in aqueous solution, and the rate of the hydrolysis increased at increasing temperatures, but the products of this transformation were not investigated.

In order to investigate the complete reaction pathways, as well as understand the mechanistic details involved in the titanium dioxide photocatalytic degradation of bis-(2chloroisopropyl) ether and bis-(2-chloroethyl) ether further studies are proposed. The study of the $\mathrm{TiO}_{2}$ photo-induced degradation of 2-chloroethyl formate is a key in order to investigate whether 2-chloroethanol is formed directly from bis-(2-chloroethyl) ether, or from 2-chloroethyl formate, which is an intermediate in the ether degradation. As we previously showed in chapter 2 , the titanium dioxide photocatalyzed oxidation of alcohols can lead to the corresponding aldehyde and carboxylic acid. The investigation of the photo-induced degradation of 2-chloroethanol is important in order to achieve a better understanding of the formation of chloroacetaldehyde and chloroacetic acid. 
1 Advanced Photochemical Oxidation Proceses. EPA Handbook, 1998.

2 Legrini, O.; Oliveros, E.; Braun, A.M., Chem. Rev. 1993, 93, 671.

3 Loraine, G. A.; Glaze, W. Destruction of Vapor Phase Halogenated Methanes by Means of Ultraviolet Photolysis. $47^{\text {th }}$ Purdue Industrial Waste Conference Proceedings. Lewis Publishers, Inc. Chelsea, Michigan.

4 CRC Handbook, 1985.

5 Cater and Others 1990; Dussert 1997.

6 Kang, J.; Hung, H.; Lin, A.; Hoffmann, M., Environ. Sci. Technol. 1999, 33, 3199.

7 (a) Ollis, D.F.; Pelizzetti, E.; Serpone, N., Environ. Sci. Technol. 1991, 25, 1523. (b) Serpone, N.; Pelizzetti, E., Eds., Photocatalysis: Fundamentals and Applications, Wiley: New York, 1989.

8 (a) Matthews, R. W., Pure \& Appl. Chem. 1992, 1285. (b) Bahnemann, D.; Bockelmann, D.; Goslich, R., Solar Energy Materials 1991, 24, 564.

9 Fox, M.; Dulay M., Chem. Rev. 1993, 93, 341.

10 Fujishima, A.; Rao, T.; Tryk, D., J. Photochem. Photobiol. Reviews 2000, 1, 1.

11 Gerisher, H.; Willing, F., Top Curr. Chem. 1976, 31.

12 Nozik, A. J., Ann. Rev. Phys. Chem. A 1978, 189.

13 Hoare, J.P.; Bard, A. J.; Dekker, M., Encyclopedia of Electrochemistry, New York: 1974, 191.

14 Lawless, D.; Serpone, N.; Meisel, D., J. Phys. Chem. 1991, 95, 5166.

15 Tunesi, S.; Anderson, M., J. Phys. Chem. 1991, 95, 3399.

16 Minero, C.; Cattozo, F.; Pelizzetti, E., Langmuir 1992, 8, 481.

17 Von Sonntag, C.; Schuchmann, H., Angew. Chem. Int. Ed. Engl. 1991, 30, 1229.

18 Schulte-Frohlinde, D.; Bothe E., Int. J. Radiat.Biolog. 1990, 58, 603.

19 Ames, B. N., Science 1983, 221, 1256. 
20 Schuchmann, M. N.; Schuchmann, H., von Sonntag, C.; J. Am. Chem. Soc.1990, 112, 403.

21 Das, S.; Schuchmann, H.; Schuchmann, P.; von Sonntag, C., Chem. Ber. 1987, 120, 319.

22 Schuchmann, M. N.; von Sonntag C., J. Am. Chem. Soc.1988, 110, 5698.

23 Bothe E.; Schulte-Frohlinde, D., Z. Naturforsh. 1980, 35, 1035.

24 Bothe E.; Schulte-Frohlinde, D.; von Sonntag, C., J. Chem. Soc.Perkin Trans. 1978, 2,416 .

25 Bothe E.; Schulte-Frohlinde, D., Z. Naturforsh. 1978, 33, 786.

26 Das, S.; Mieden, O. J.; Pan, X.; Repas, M.; Schuchmann, M. N.; Schuchmann, H.; von Sonntag, C.; Zegota, H.; Taylor, K. A.; Ward, J. F., von Sonntag, C. (Eds): Oxygen Radicals in Biology and Medicine, Plenum, New York 1988, 55.

27 Ilan, Y.; Rabani, J.; Henglein, A., J.Phys. Chem.1976, 80, 1558.

28 Bothe E.; Schulte-Frohlinde, D.; von Sonntag, C., Photochem. Photobiol.1978, 28, 639.

29 Schuchmann, M. N.; von Sonntag, C., J. Phys. Chem. 1982, 86, 1995.

30 Nonhebel, D.C.; Walton, J.C. : Free Radical Chemistry, Structure and Mechanism, University Press, Cambridge 1974, 405.

31 Bennett, J. E.; Howard, J.A., J. Am. Chem. Soc. 1973, 95, 4008.

32 Russell, G.A., J. Am. Chem. Soc. 1957, 79, 3871.

33 Ingold, K. U., Acc. Chem. Res. 1969, 2, 1.

34 Mendenhall, G.D; Quinga, E.M.Y., Int. J. Chem. Kinet. 1985, 17, 1187.

35 Bennett, J.E., J. Chem. Soc. Faraday Trans. 1990, 86, 3247.

36 Janata, E.; Veltwish, D., J. Chem. Soc. Perkin Trans. 1980, 2, 146.

37 Berdnikov V.M.; Bazhin, N.M.; Fedorov, V.K.; Polyakov, O.V., Kinet. Catal. (Engl. Transl.) $1972,13,986$.

38 Gilbert, B.C.; Holmes, R.G.; Laue, H.A.; Norman, R.O., J. Chem. Soc. Perkin Trans. $1976,2,1047$.

39 Batt, L., Int. Rev. Phys. Chem. 1987, 6, 53. 
40 Choo, K.Y.; Benson, S.W., Int. J. Chem. Kinet. 1981, 13, 833.

41 Walling, C.; Wagner, P.J., J. Am. Chem. Soc. 1964, 86, 3368.

42 Gilbert, B.C.; Marshall, P.D.; Norman, R.O.; Pineda, N.; Williams, P.S., J. Chem. Soc. Perkin Trans. 1981, 2, 1392.

43 Oxygenates in water: critical information and research needs. EPA, 1998.

44 Alexander, J.E.; Ferber, E.P.; Stahl, W.M, Fuel Reformulation 1994, 4,42.

45 Angle, C.R., J. Am. Med. Assoc. 1991, 266, 2985.

46 Chemical and Engineering News, Octuber 18, 1999, 49.

47 Chemical and Engineering News, May 8, 2000, 40.

48 Baehr, A.L; Ayers, M.A.(1997) Occurrence and movement of contaminants through the urban hydrologic cycle-FY97 workplan update [for NAWQA Comprehensive Urban Study]. West Trenton, NJ: U.S. Geological Survey, Long Island-New Jersey National Water-Quality Assessment Program: February 1.

49 Baehr, A.L.; Stackelberg, P.E.; Baker, R.J.; Kauffman, L.J.; Hopple, J.A.; Ayers, M.A. (1997) Design of a sampling network to determine the occurrence and movement of methyl tert-butyl ether and other organic compounds through the urban hydrologic cycle. In: American Chemical Society Division of Environmental Chemistry preprints of papers, $213^{\text {th }}$. San Francisco, CA: American Chemical Society; v. 37:400.

50 Landmeyer, J.E.; Chapelle, F.H.; Bradley, P.M.; Pankow, J.F.; Church, C.D.; Tratnyek, P.G. (1998) Fate of MTBE reletive to benzene in a gasoline-contaminated aquifer (1993-98). Ground Water Monit. Rem.

51 Speth,T.F.; Miltner,R.J., J. Am. Water Works Assoc. 1990, 82, 72.

52 Chen,C.T.; Tafuri, A.N.; Rahman, M; Foerst, M.B., J. Environ. Sci. Health 1998, 33, 987.

53 Stefafan, M.I.; Mack, J.; Bolton, J. R., Environ Sci. Thechnol. 2000, 34, 650.

54 Barreto, R.D.; Gray, K.A.; Anders, K., Wat. Res. 1995, 29, 1243.

55 Winstein, S.; Ingraham, L.L., J.Am. Chem. Soc. 1972, 74, 1160.

56 Piancatelli, G.; Scettri, A.; D'Auria, M., Synthesis 1982, 245. 
57 Rankin, K.N.; Liu, Q.; Hendry, J.; Yee, H.; Novereldin, N.A.; Lee, D.G., Tetrahedron Lett., 1998, 39, 1095.

58 Adam, W.; Blancafort, L., J. Am. Chem. Soc. 1996, 118, 4778.

59 Hoare, J.P.; Bard, A.J.; Dekker, M., Encyclopedia of Electrochemistry, N.Y., 1974, 191.

60 Lawless, D.; Serpone, N.; Meisel, D. J., Phys. Chem. 1991, 95, 5166.

61 Buxton, G. V.; Greenstock, C. L.; Helman, W. P.; Ross, A. B., J. Phys. Chem. Ref. Data 1988, 17, 513.

62 Von Sonntag, C.; Schuchmann, H., Angew. Chem. Int. Ed. Engl. 1991, 30, 1229.

63 Bennett, J.E.; Howard, J.A., J. Am. Chem. Soc. 1973, 95, 4008.

64 Summers, L., Chem. Rev. 1955, 55, 301.

65 Van Duuren, B.L., Cancer Res. 1975, 35, 2553.

66 Nelson, N., Ann. N.Y. Acad. Sci. 1976, 271, 81.

67 Ambient water quality criteria for chloroalkyl ethers. EPA, 1980.

68 Tou, J. C.; Kallos, G. J., Anal. Chem. 1974, 46, 1866.

69 Van Duuren, B.L., et al., J. Natl. Cancer Inst. 1972, 48, 1431.

70 Shackelford, W.M.; Keith, L. H., EPA 600/4-76-062. U.S. EPA, Athens, Georgia.

71 Kleopfer, R.D.; Fairless, B.J., Environ. Sci. Technol. 1972, 6, 1036.

72 Hannah, S. A.; Austern, B. M.; Erapl, A. E., J. Water Pollut. Control Fed. 1986, 58, 27.

73 Milano, J. C.; Bernat-Escallon, C.; Vernet, J. L., Environmental Technology Letters $1989,10,291$.

74 Mabjish, S. R., Titanium dioxide photocatalysis of haloethers: a mechanistic study, M.Sc. Thesis, Florida International University, 1998.

75 Vershueren, K. Handbook of Environmental Data on Organic Chemicals, Van Nostrand/Reinhold, New York, N.Y. 1977.

76 Leo, A.; Hansch, C.; Elkins, D., Chem. Rev. 1971, 7l, 525.

77 Hofle, G.; Steglich, W.; Vorbruggen, H., Angew. Chem. Int. Ed. Engl. 1978, 17, 114. 
78 Werner, W., J. Chem. Research 1980, 2769.

79 L. A., Cort; R. G., Pearson, J. Chem. Soc.1960, 1682. 
APPENDICES 
Appendix I. Standardization Curve for MTBE. Analysis by GC-Head Space-FID. Conditions Provided on Section 2.3.3.3

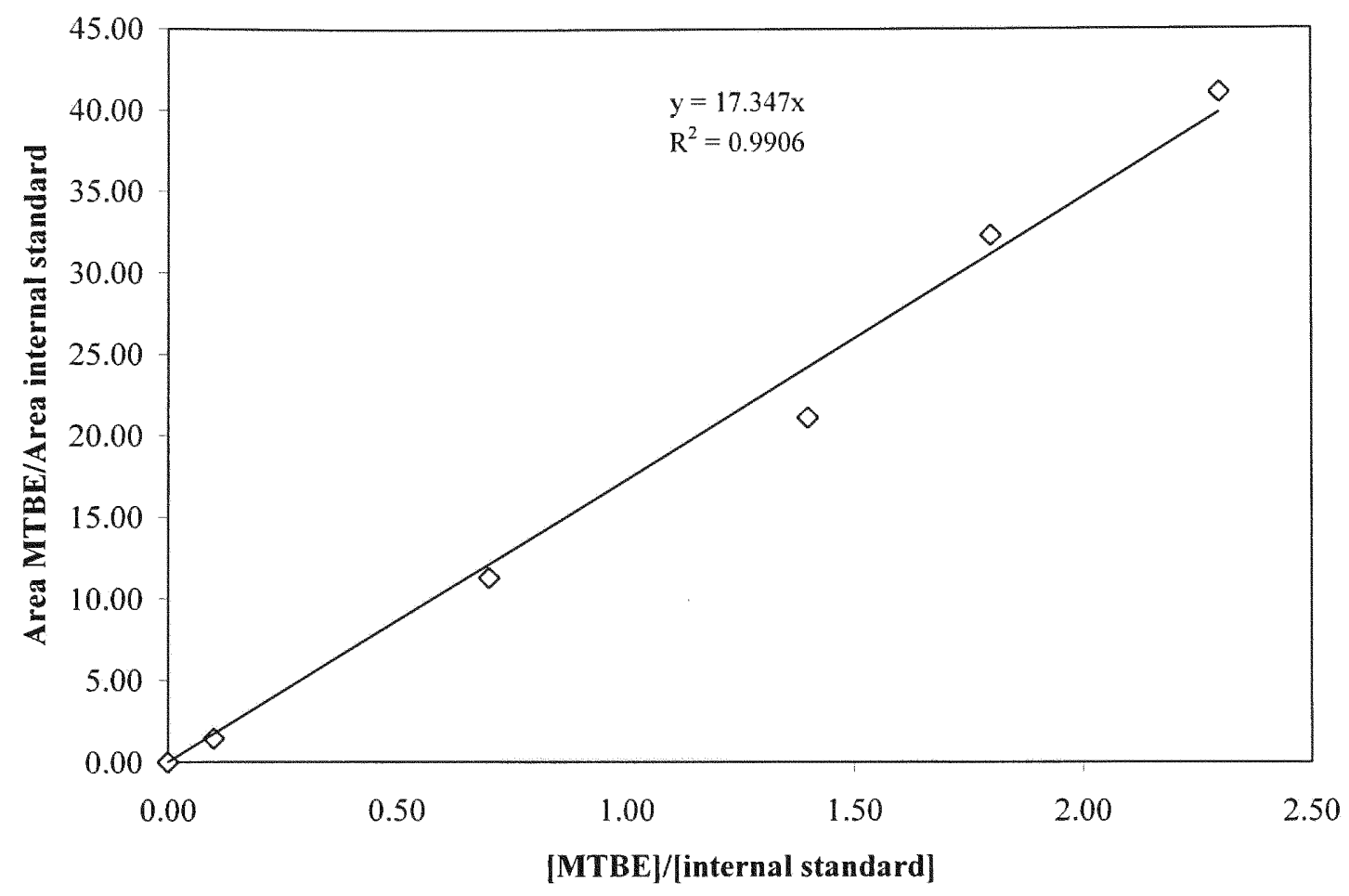


Appendix II. Standardization Curve for 2-Methoxy-2-Methylpropanal. Analysis by GCHead Space-FID. Conditions Described on Section 2.3.3.3

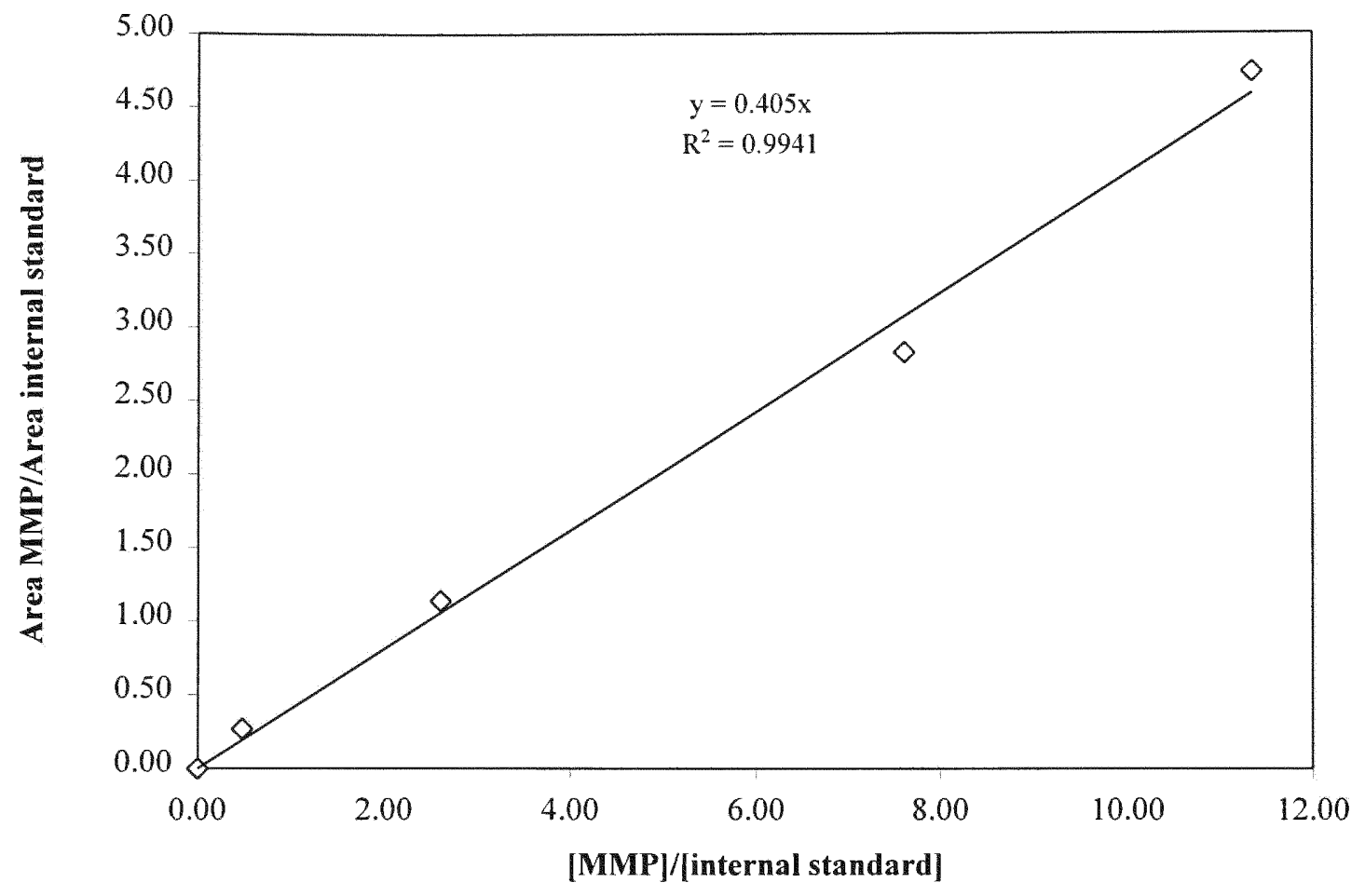


Appendix III. Standardization Curve by GC-Head Space-FID for 2-Methoxy-2Methylpropanol. Conditions Provided on Section 2.3.3.3

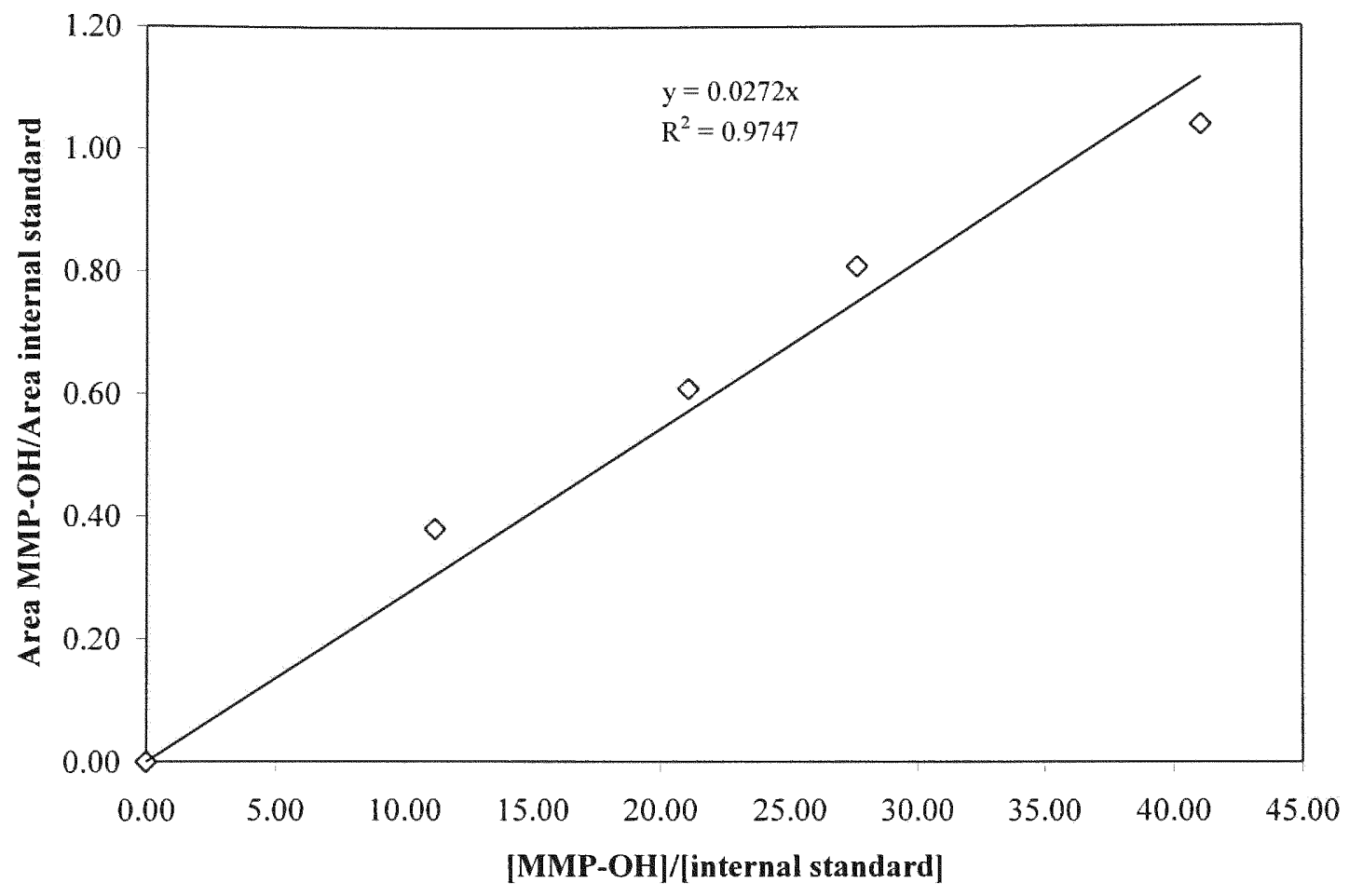


Appendix IV. Standardization Curve for Acetone Using GC-Head Space-FID. Conditions Described on Section 2.3.3.3

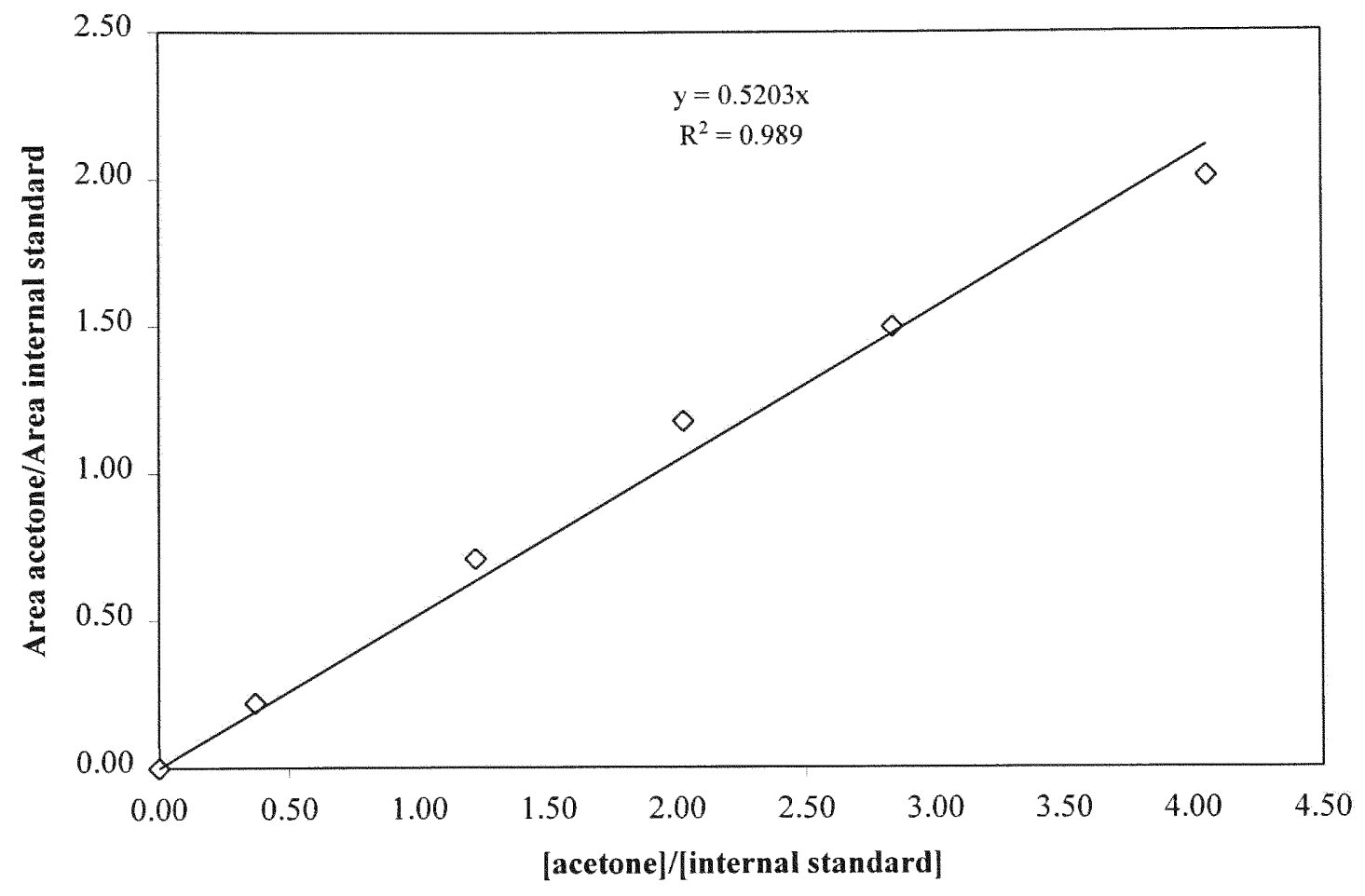


Appendix V. Standardization Curve for Methyl Acetate. Analysis by GC-Head SpaceFID. Conditions Provided on Section 2.3.3.3

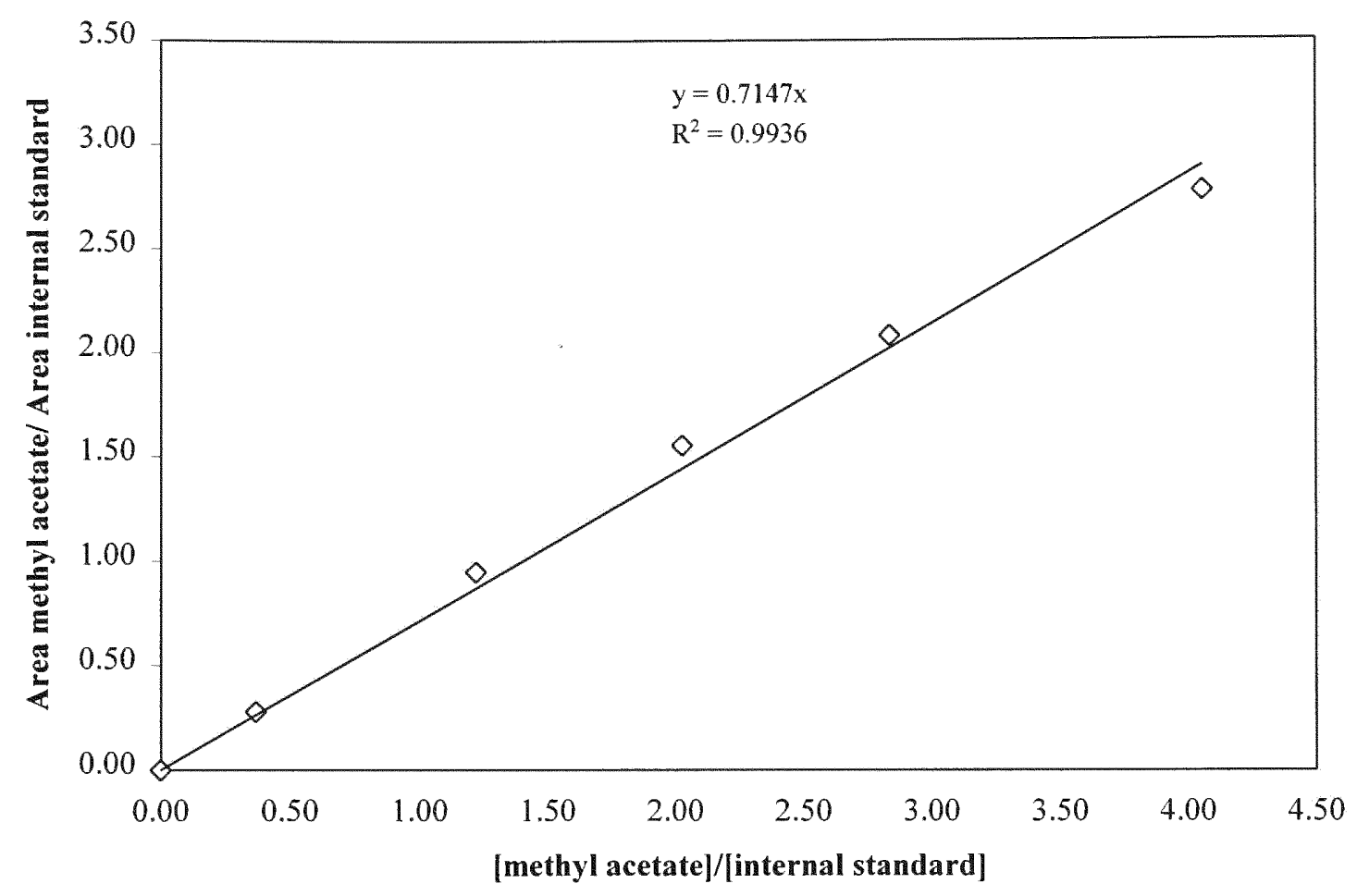


Appendix VI. Standardization Curve for 2-Methoxy-2-Methylpropanoic Acid. Analysis by Ion Chromatography. Conditions Described on Section 2.3.3.3

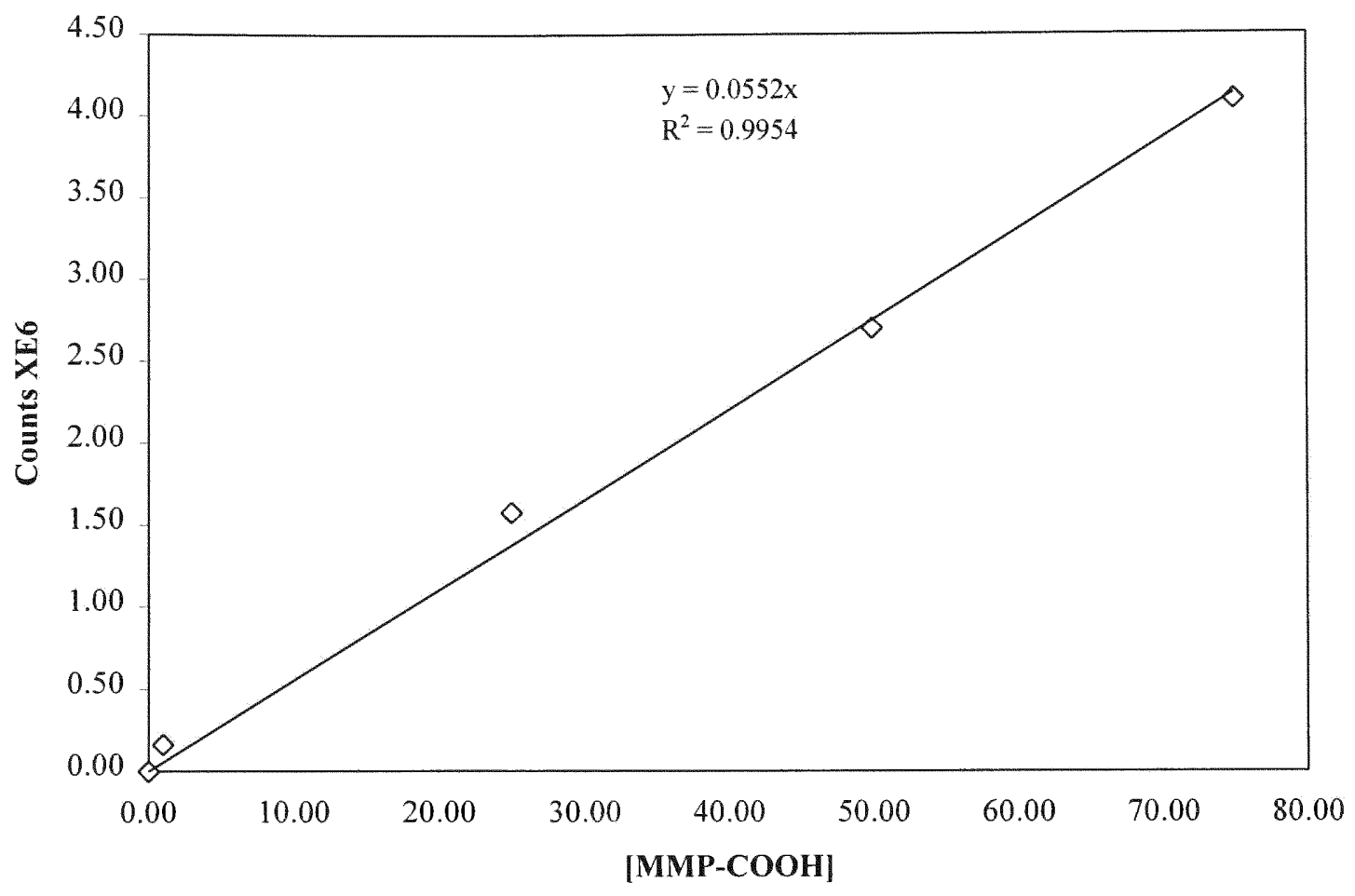


Appendix VII. Standardization Curve for 2-Methoxy-2-Methylpropanol Using the Conditions as Described on Section 2.3.3.2.

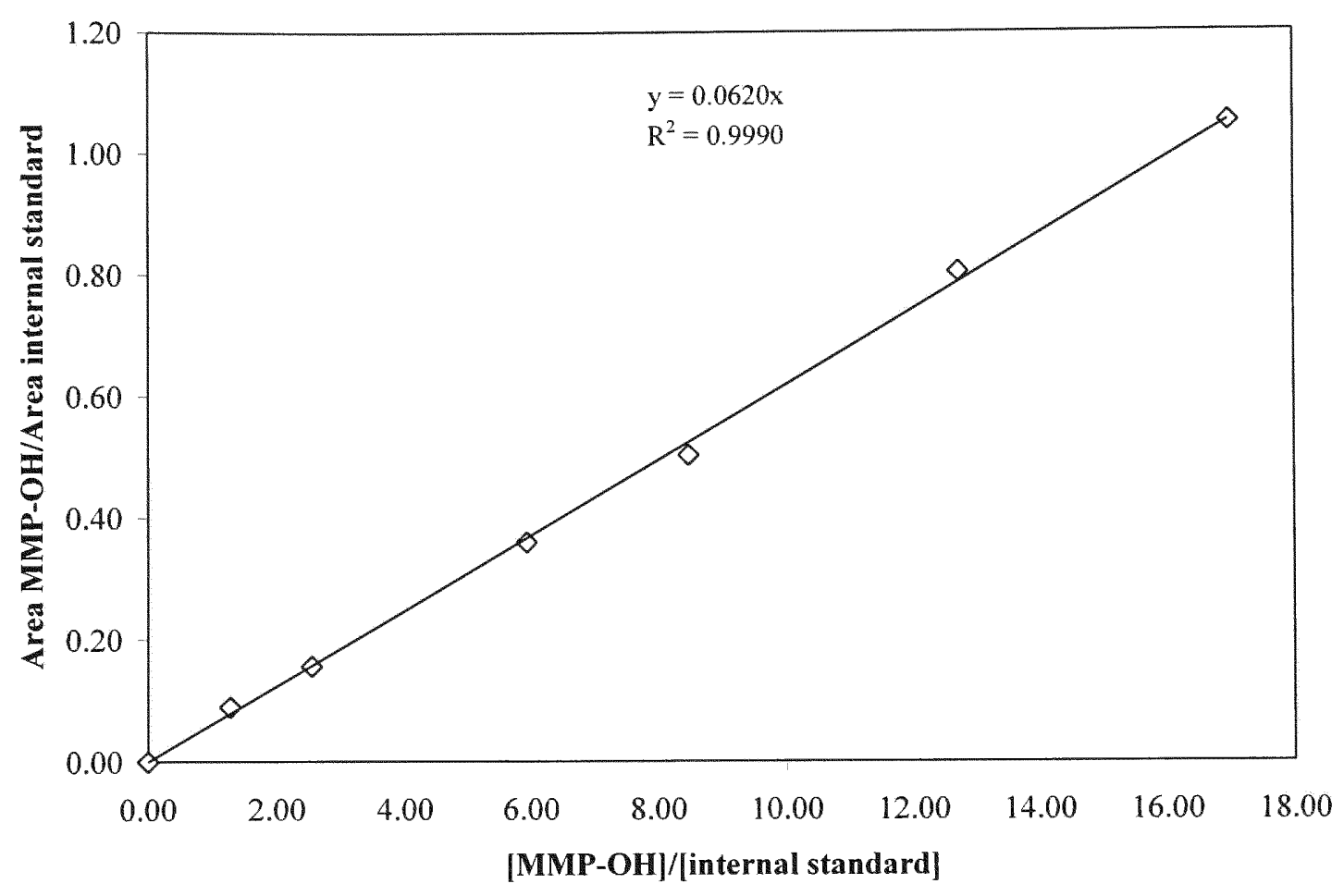


Appendix VIII. Standardization Curve for 2-Methoxy-2-Methylpropanal Using the Conditions as Described on Section 2.3.3.2

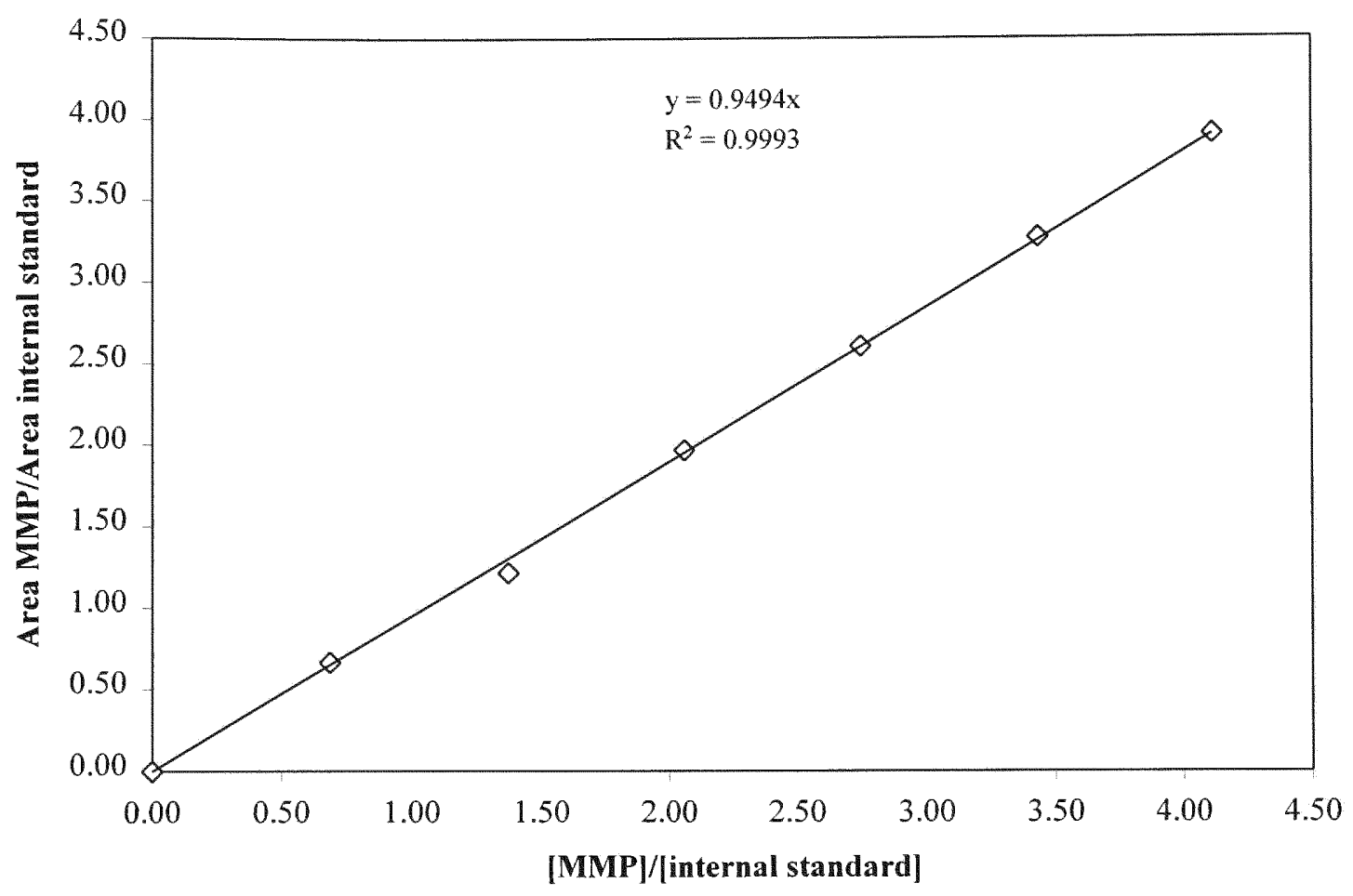


Appendix IX. Standardization Curve for Acetone. Conditions as Described on Section 2.3.3.2

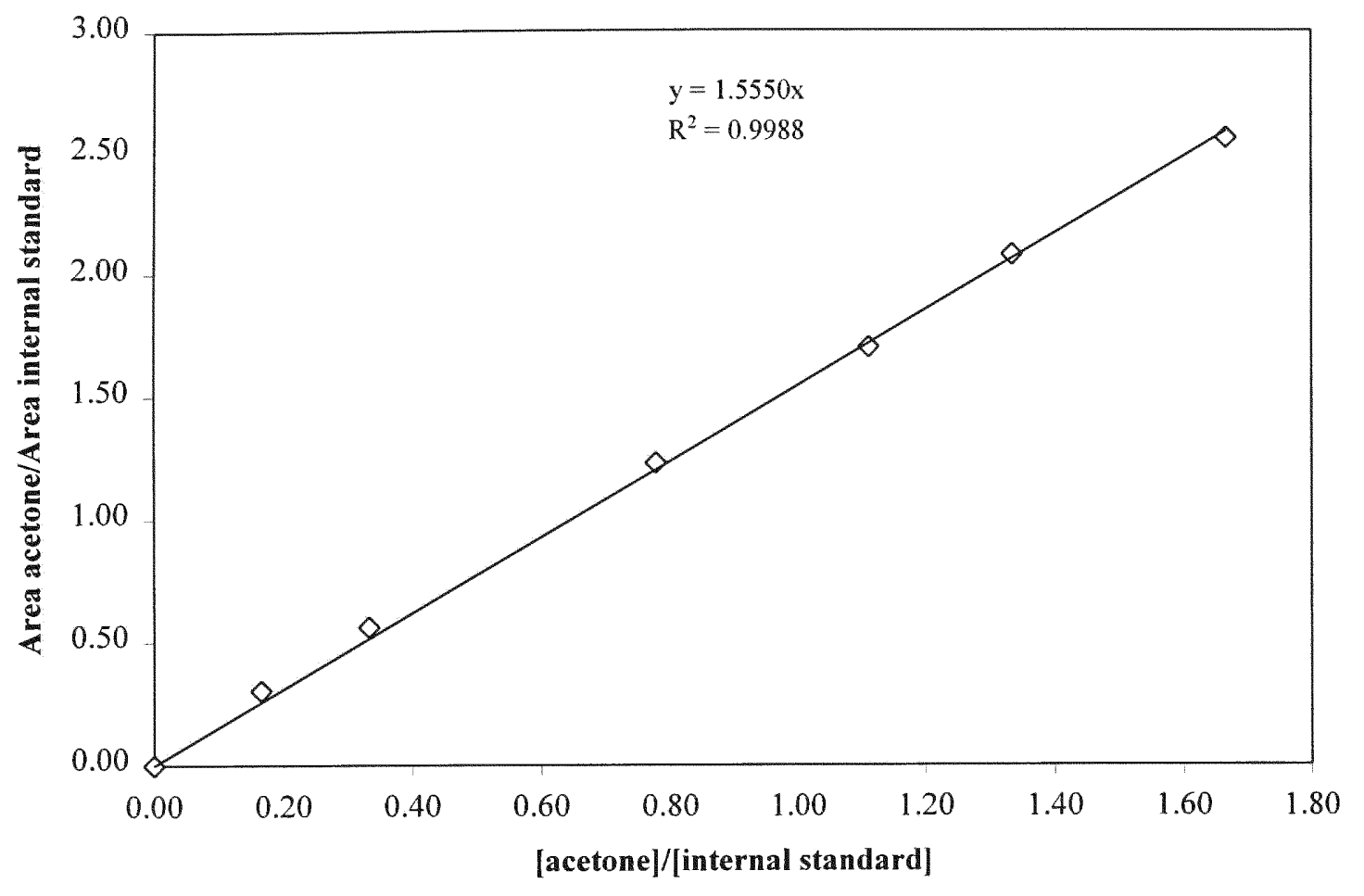


Appendix X. Standardization Curve for Methyl Acetate. Conditions Provided on Section 2.3.3.2

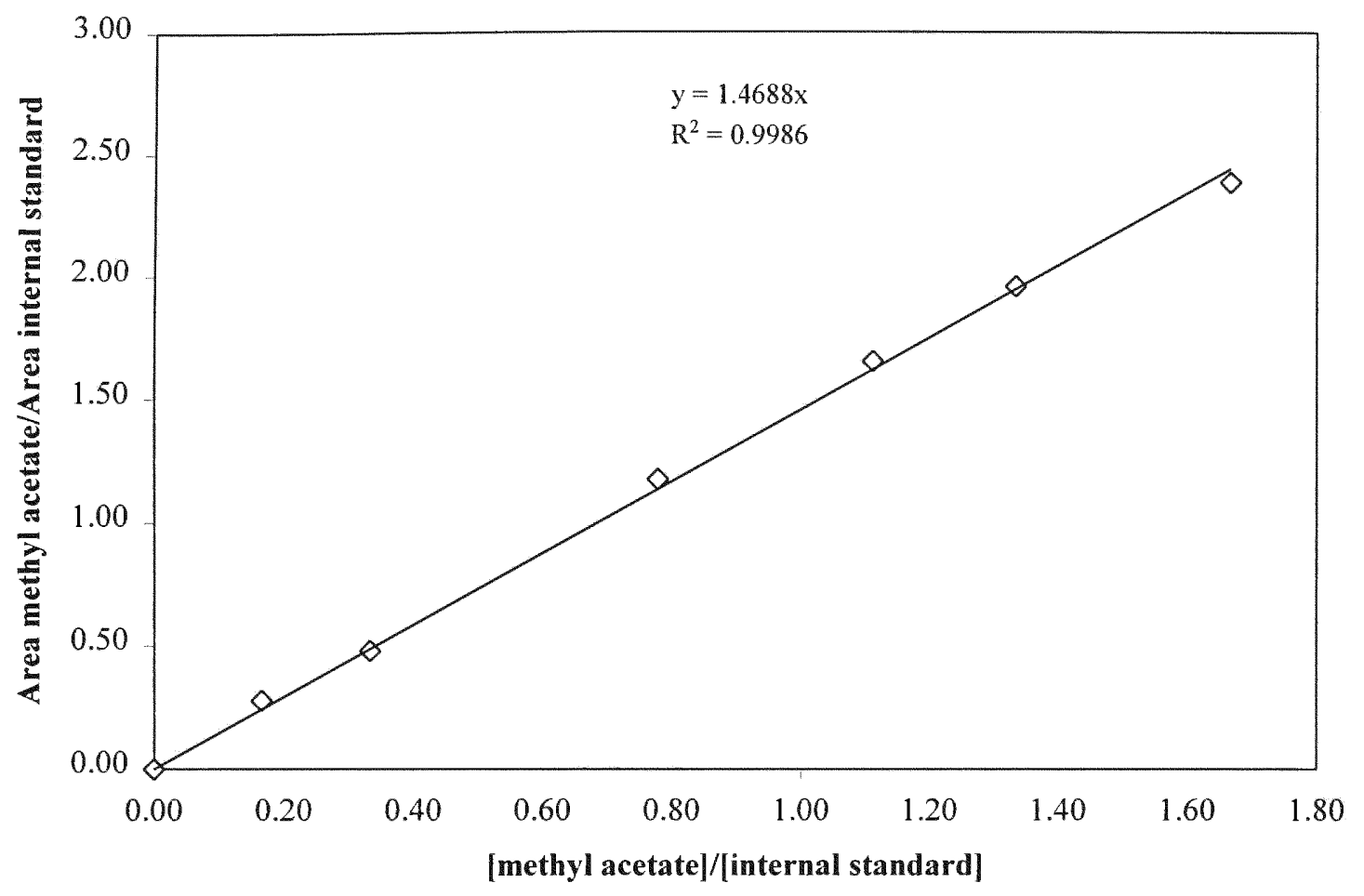


Appendix XI. Standardization Curve for 2-Methoxy-2-Methylpropanal. Conditions Described on Section 2.3.3.1

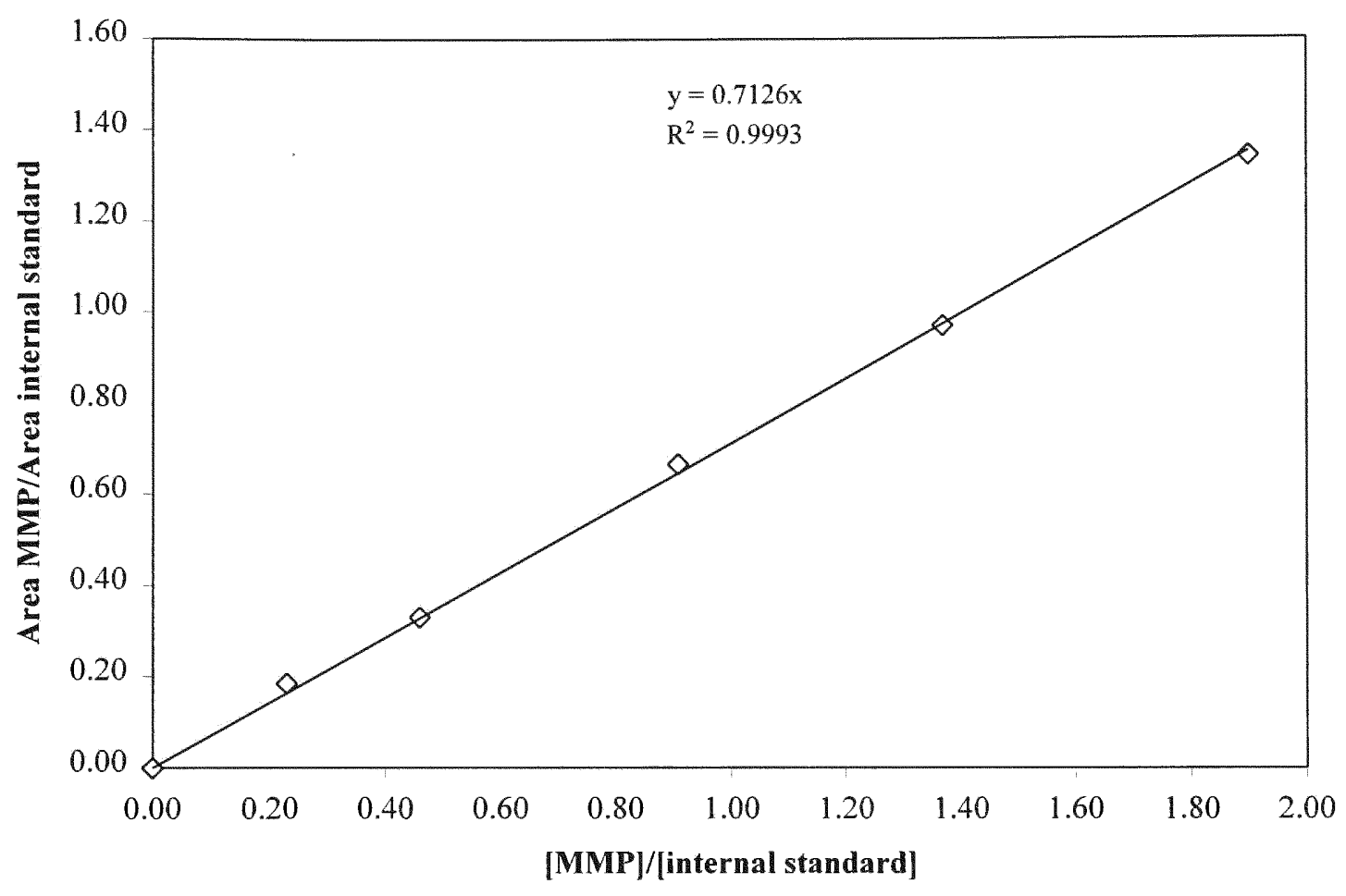


Appendix XII. Standardization Curve for Acetone. Conditions Provided on Section 2.3.3.1

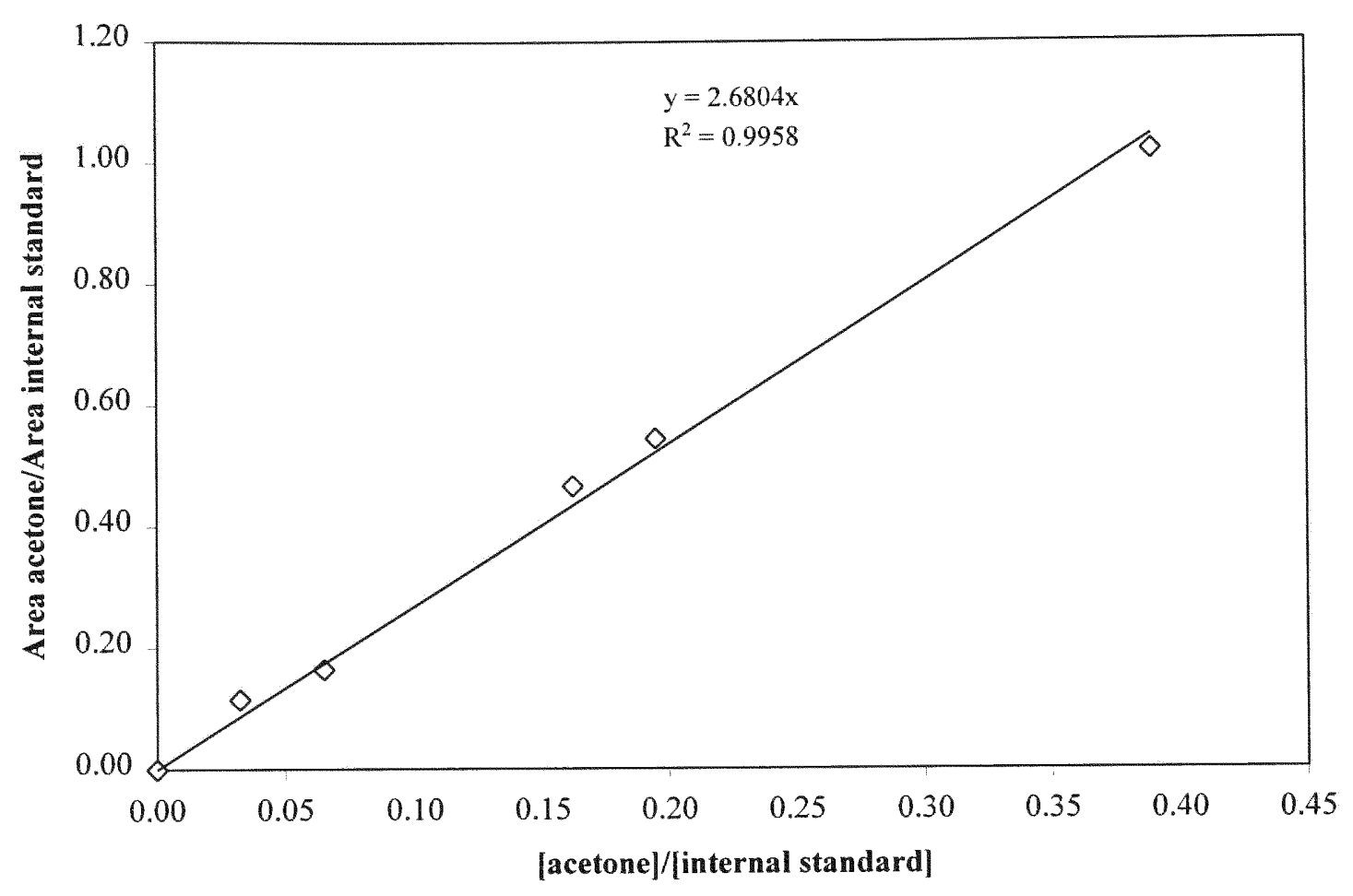


Appendix XIII. Standardization Curve for Methyl Acetate Using the Conditions Described on Section 2.3.3.1

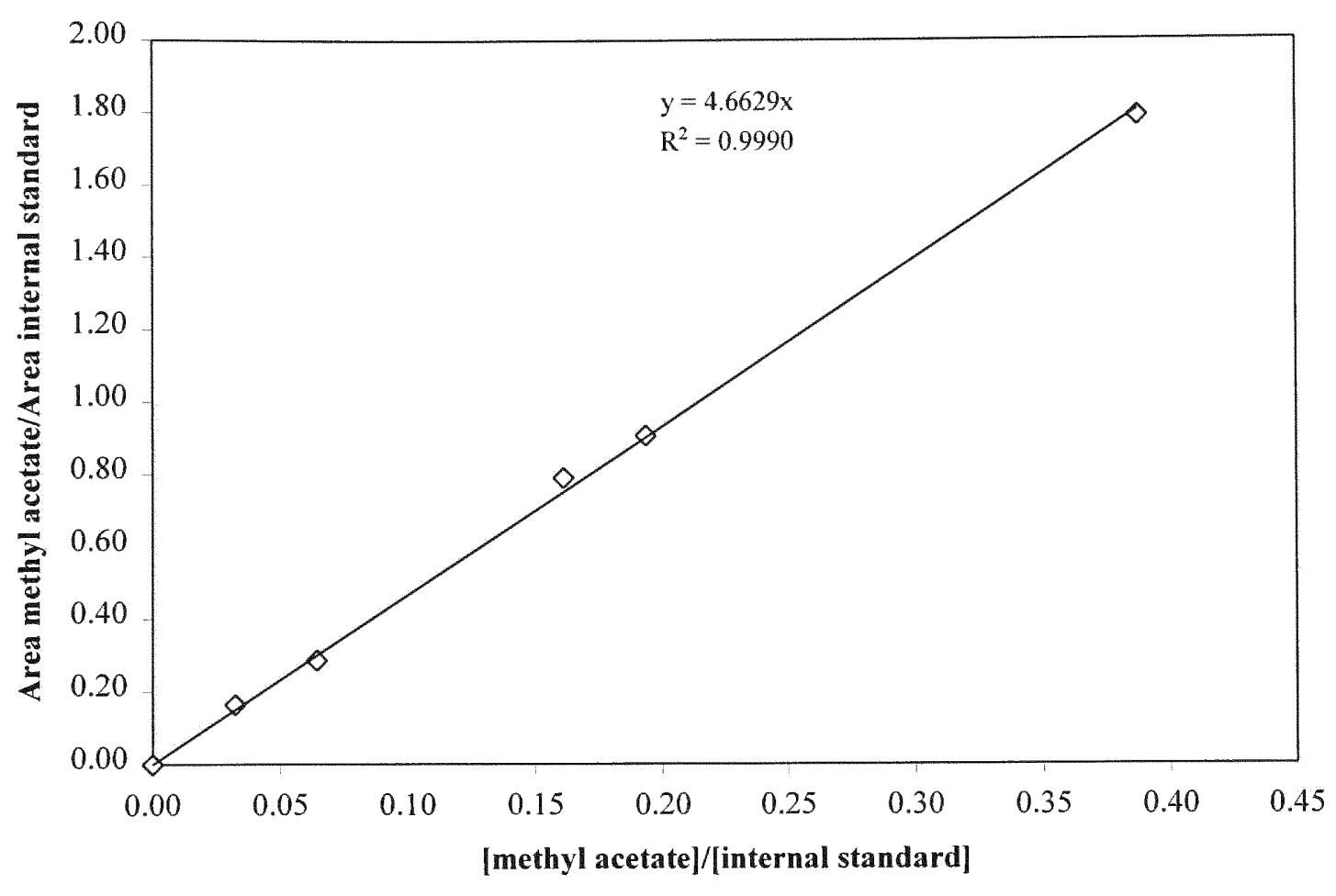


Appendix XIV. Standardization Curve for Bis-(2-chloroisopropyl) Ether. Conditions Provided on Section 3.3.3.1

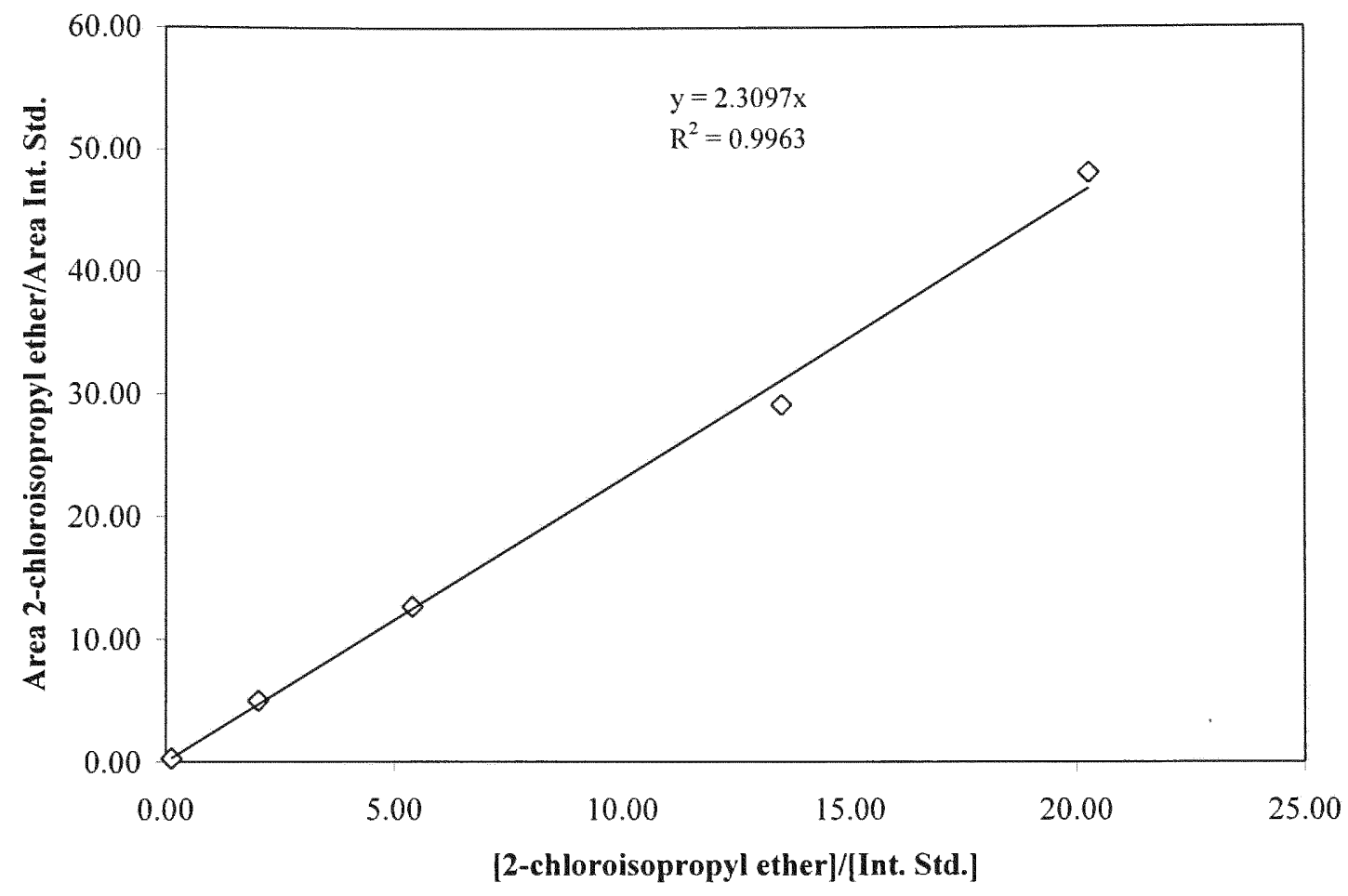


Appendix XV. Standardization Curve for 1-Chloro-2-Propyl Acetate. Conditions as Described on Section 3.3.3.1

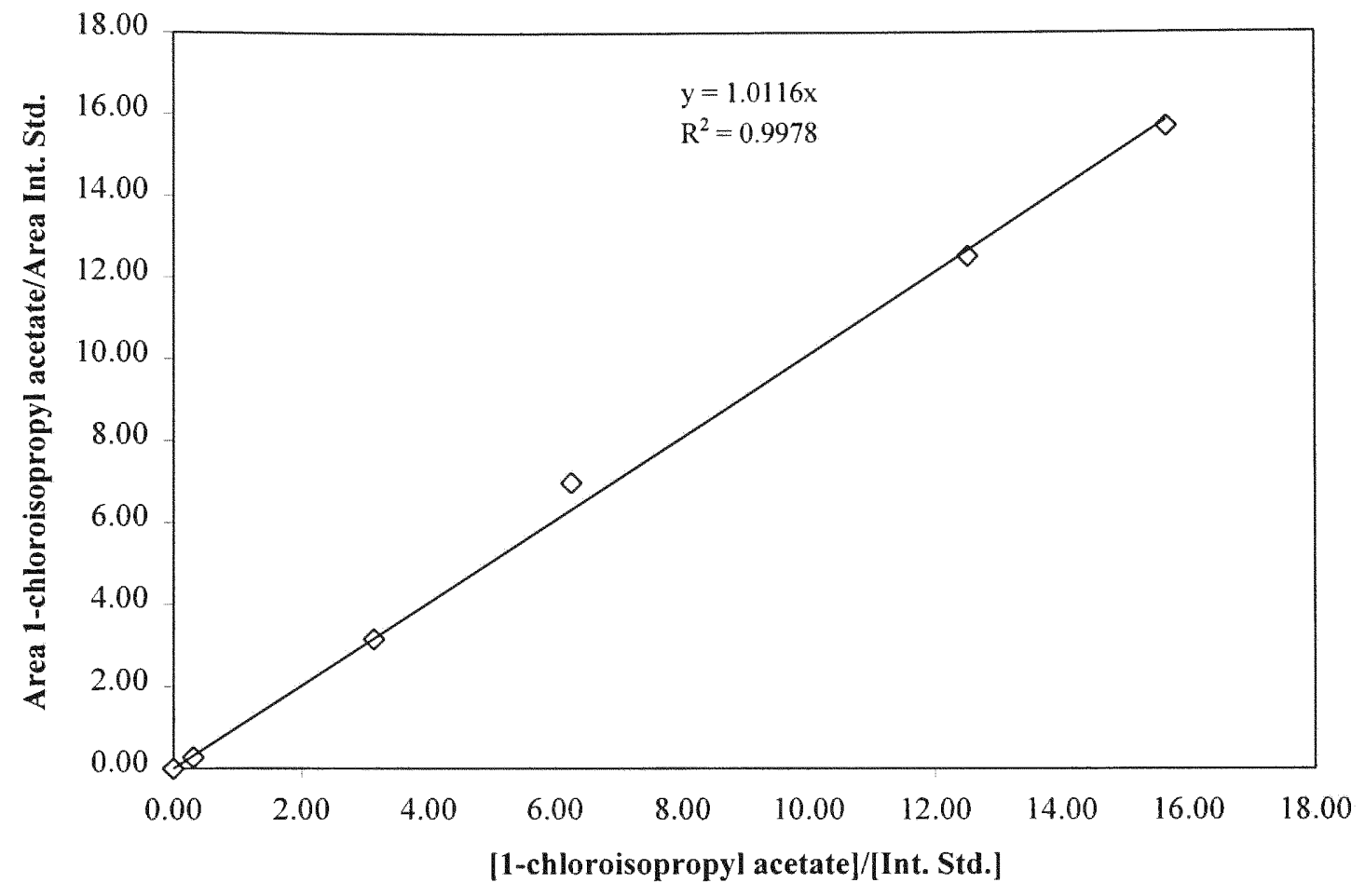


Appendix XVI. Standardization Curve for Chloroacetone. Conditions as Described on Section 3.3.3.1

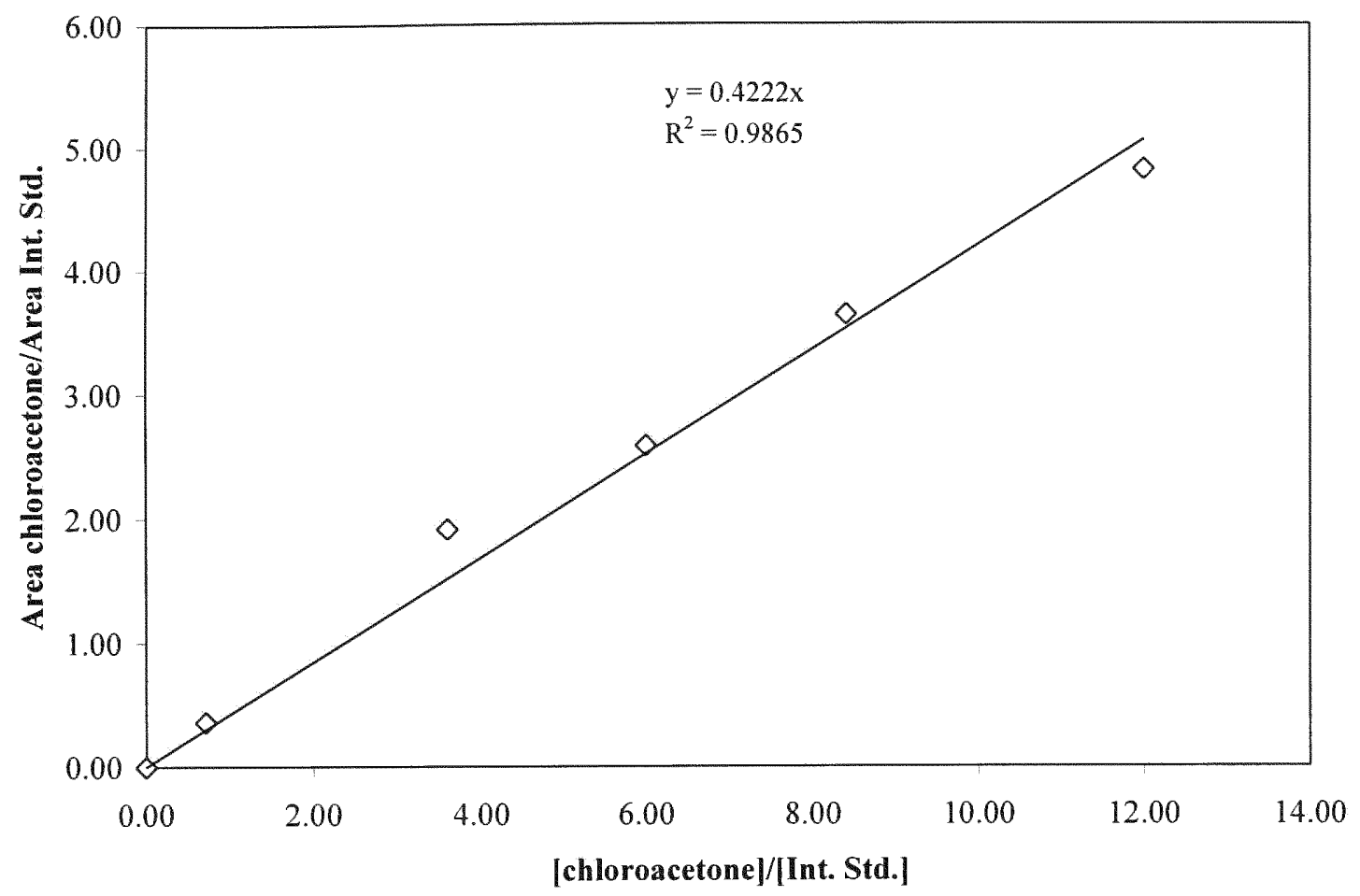


Appendix XVII. Standardization Curve for Bis-(2-chloroethyl) Ether. Conditions Described on Section 3.3.3.2

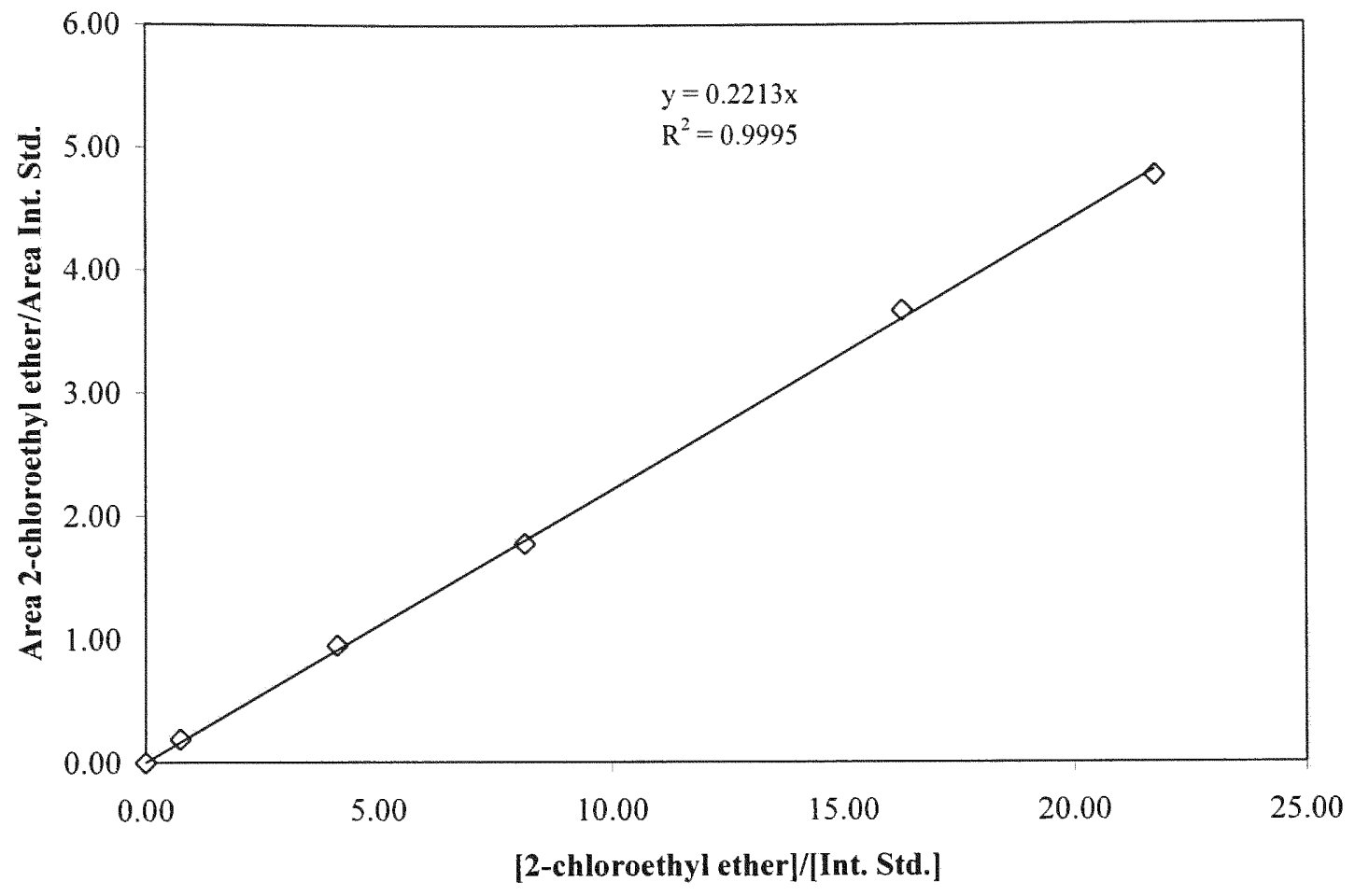


Appendix XVIII. Standardization Curve for 2-Chloroethyl Formate. Conditions as Described on Section 3.3.3.2

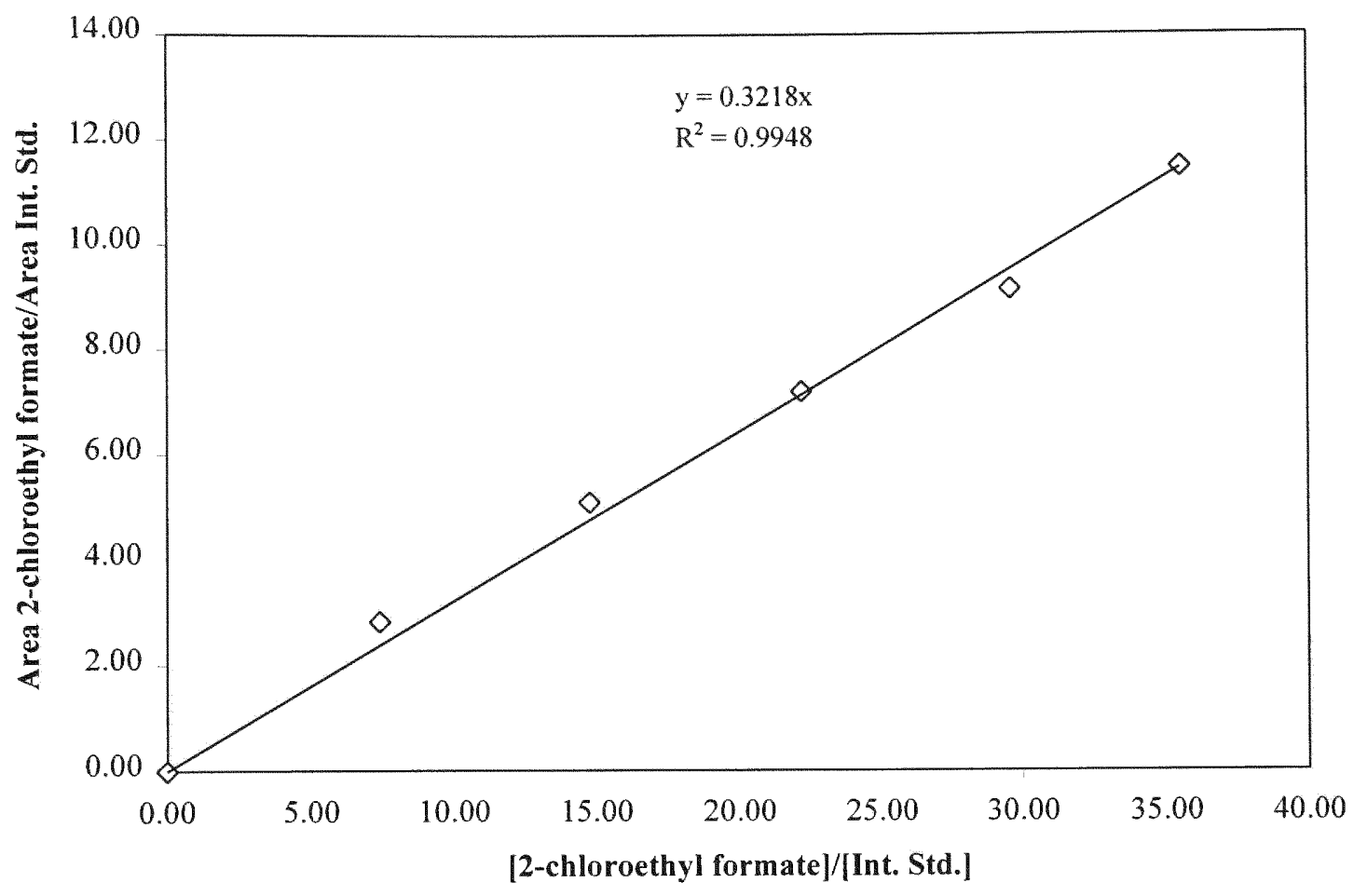


Appendix XIX. Standardization Curve for 2-Chloroethanol Using the Conditions as Described on Section 3.3.3.2

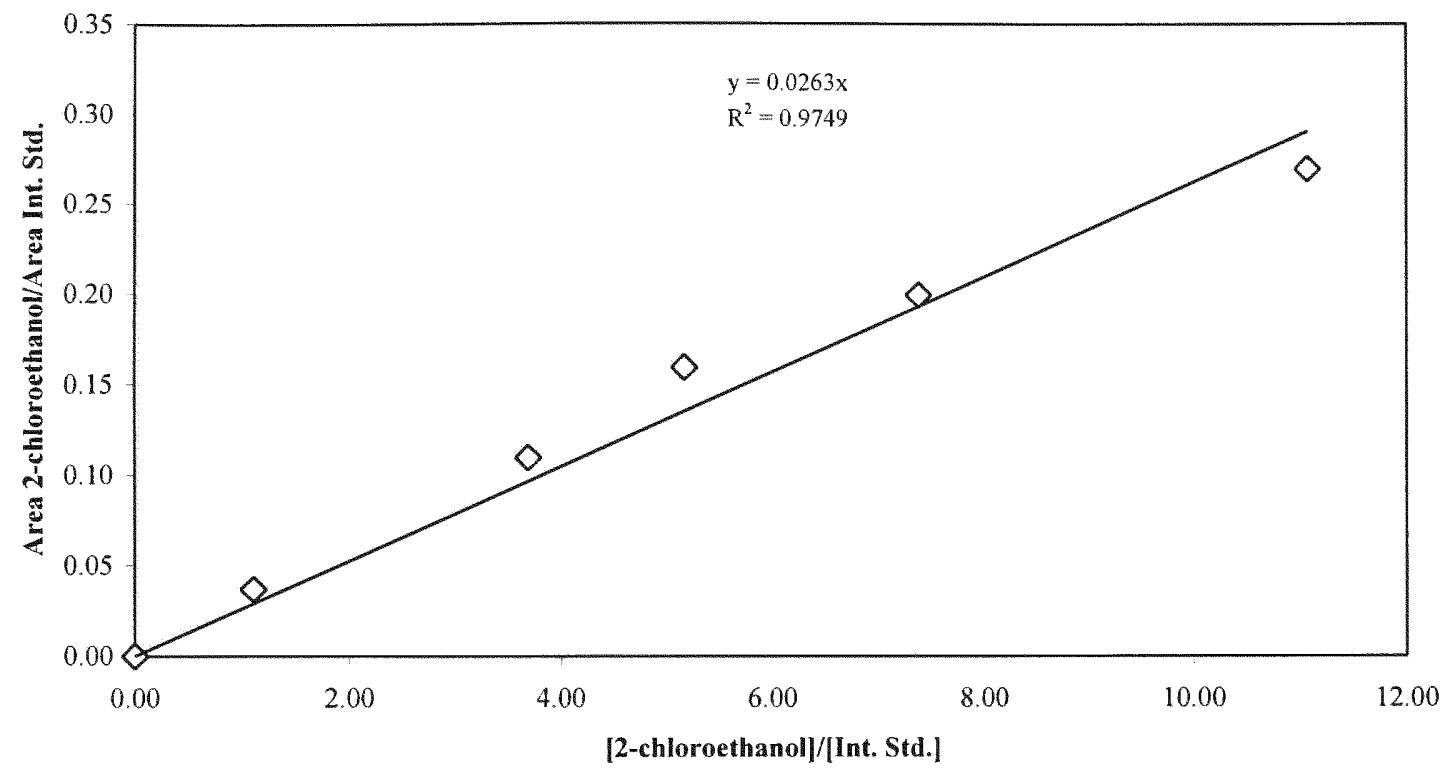




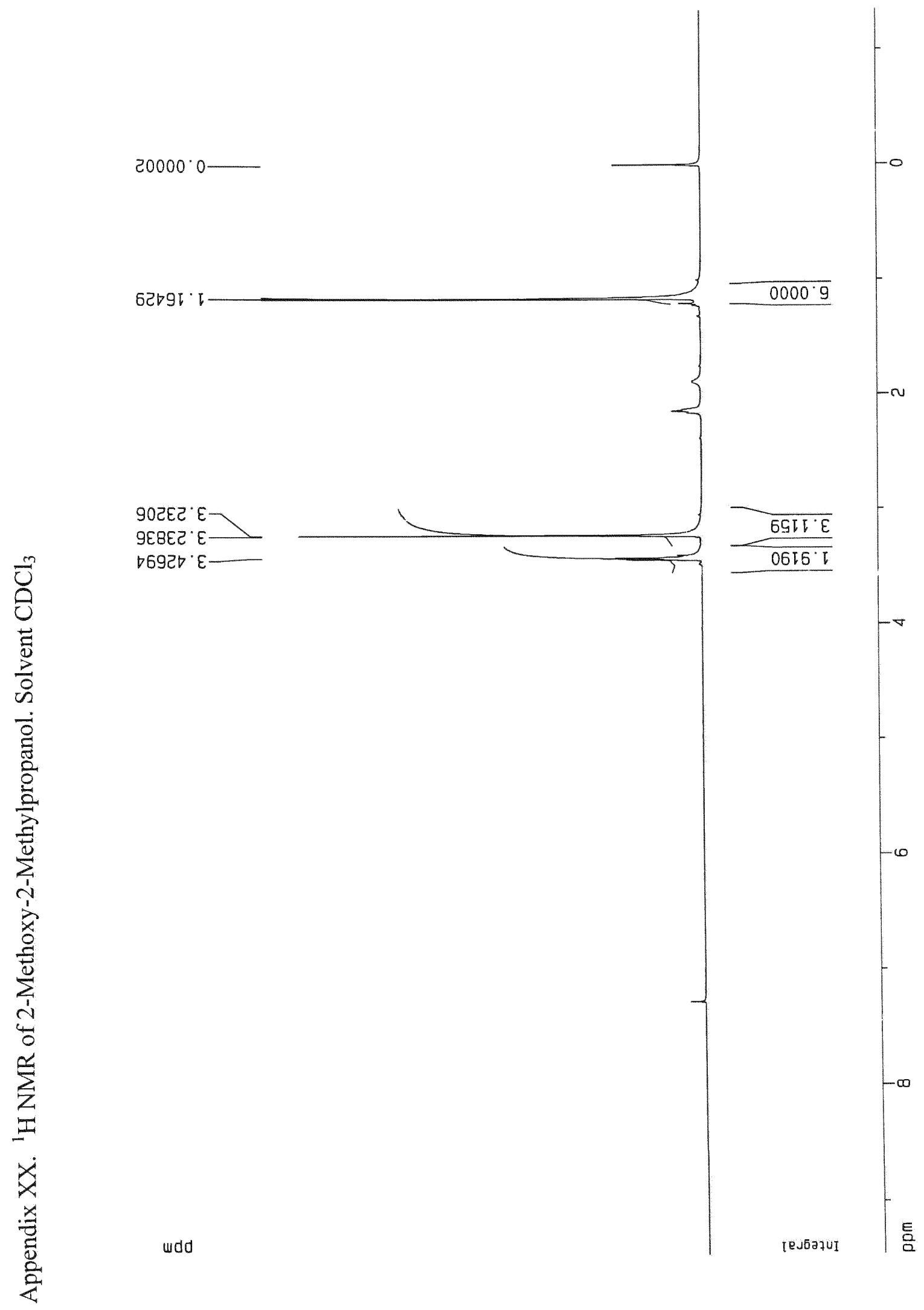




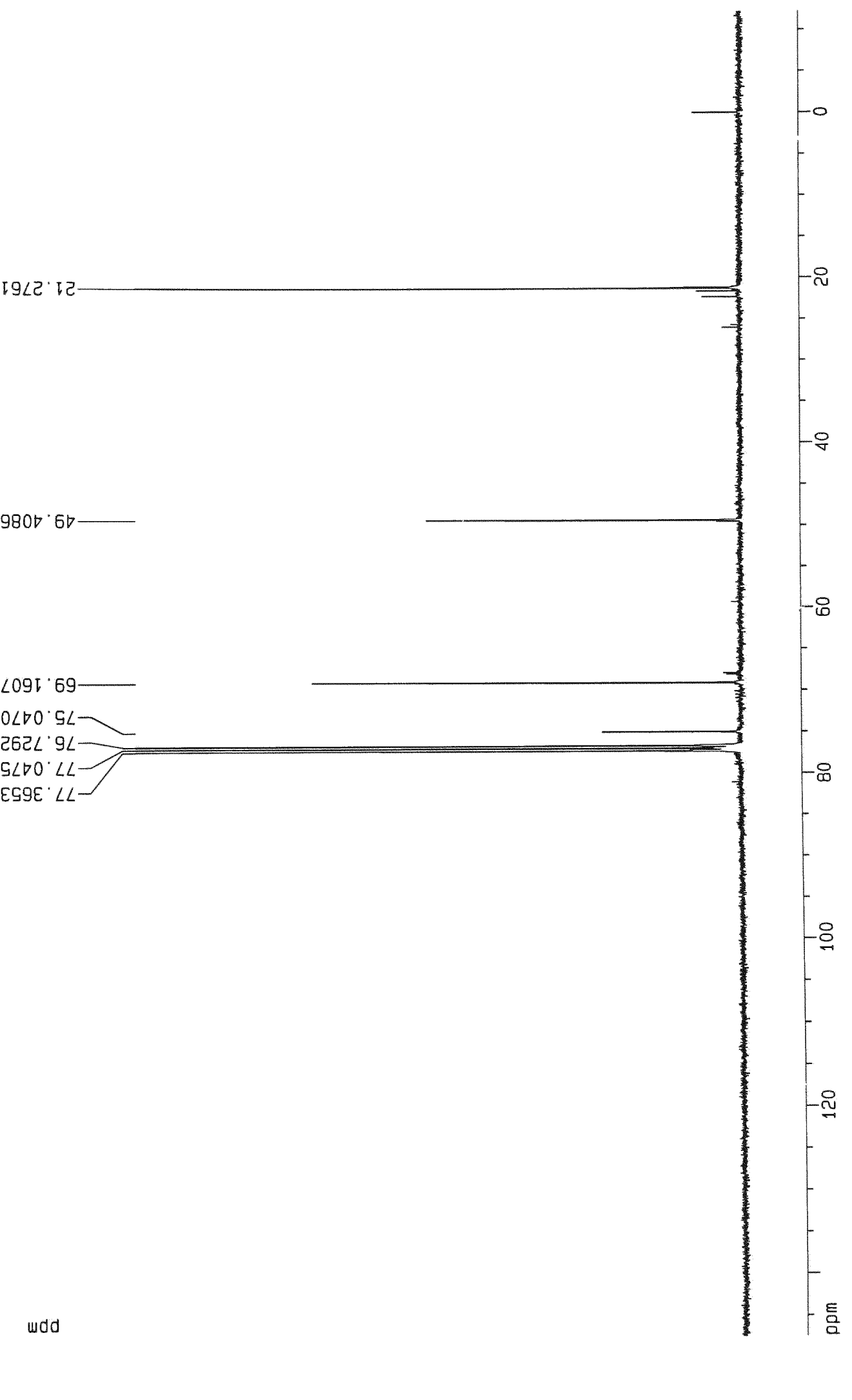




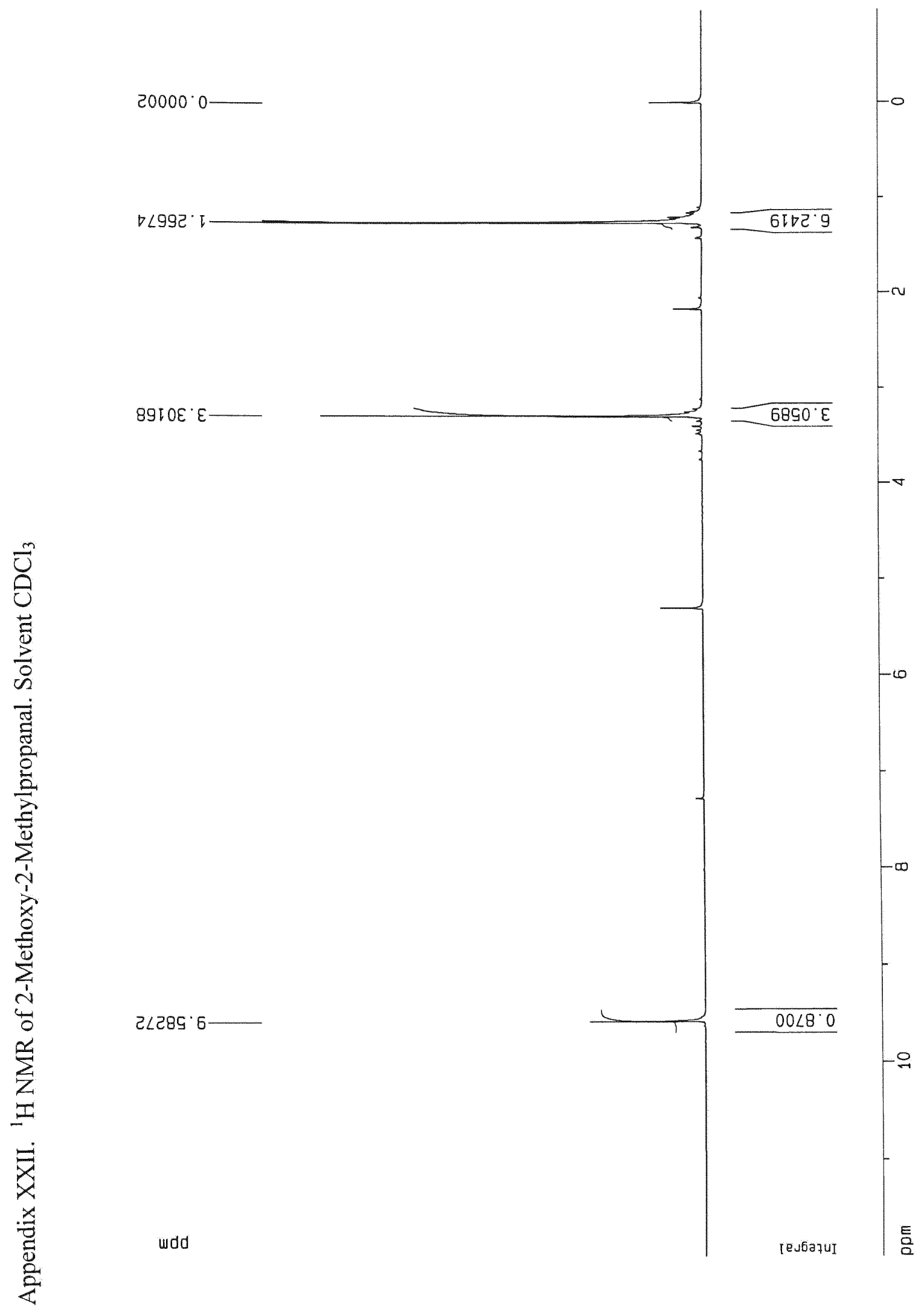




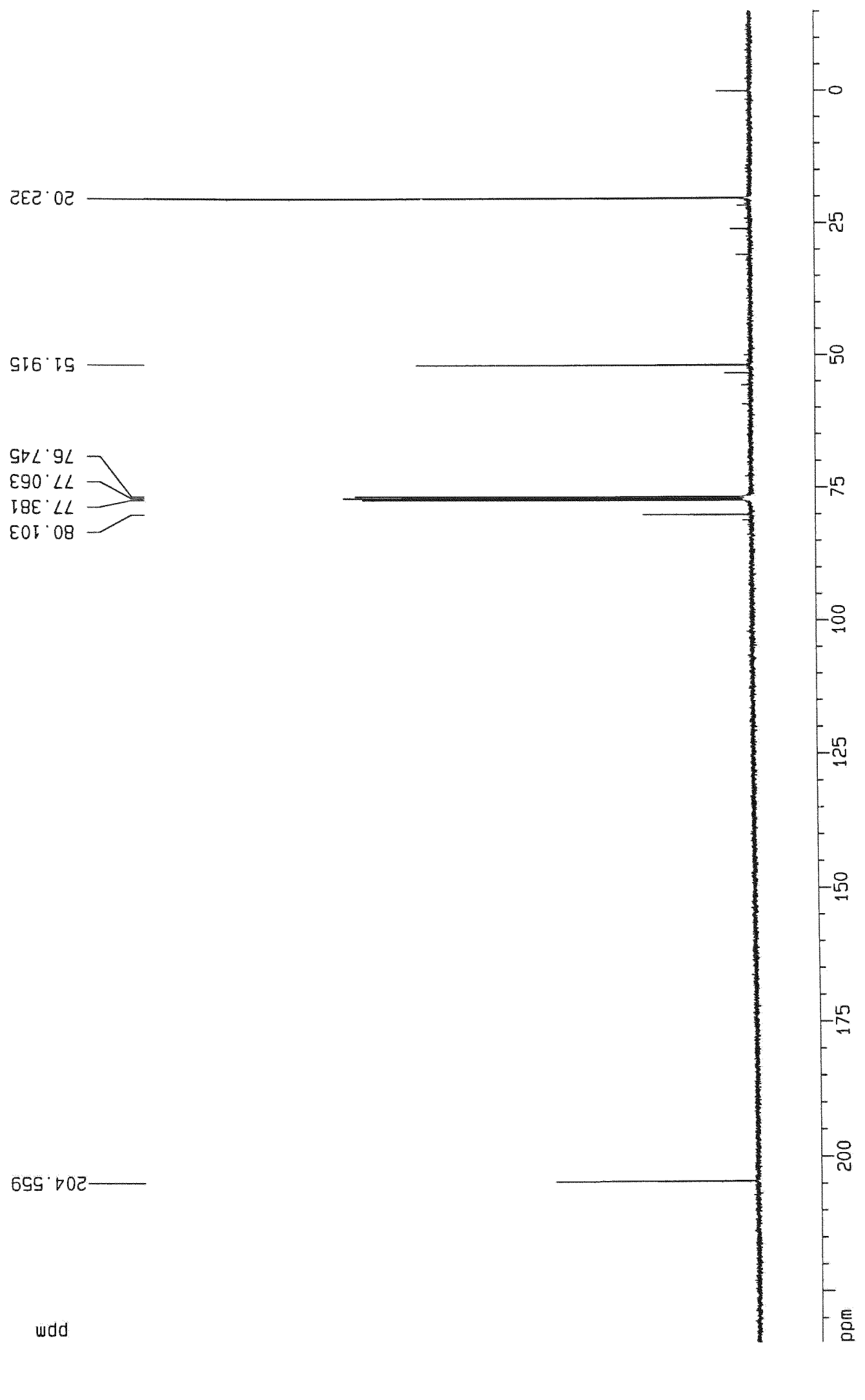




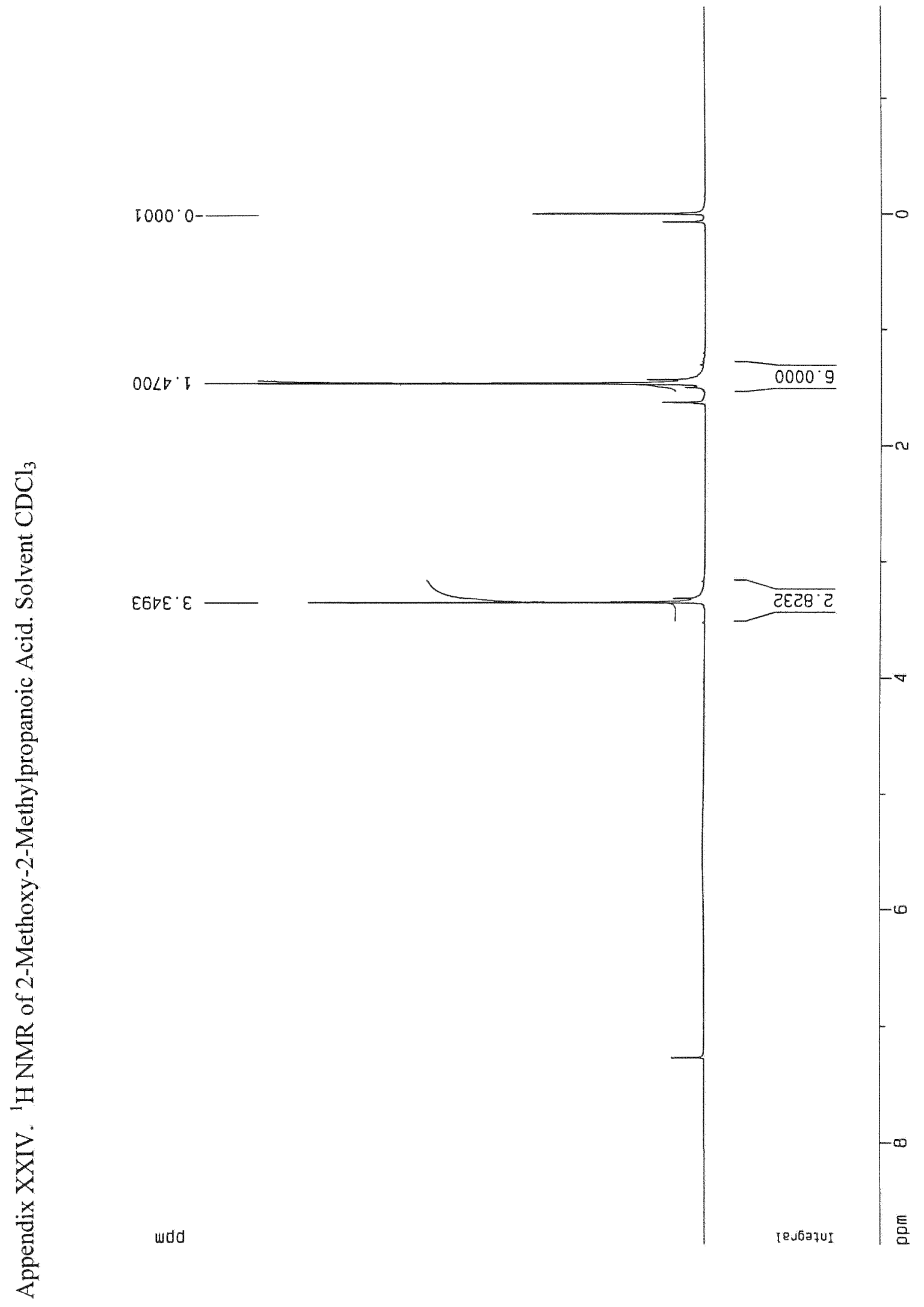




$$
000^{\circ} 0
$$

$90 D^{\circ} E 2$

8E6 $\varepsilon 己$

$98 \varepsilon^{\circ} \nabla z$

$\angle 28^{\circ}$.

0

$\varepsilon I L ' 9 L$

IEO $L$

$\angle D E^{\circ} \angle L$

$\angle 29^{\circ} \angle L$

폰

$\frac{1}{8}$

过

.$\frac{0}{8}$

ำ

응

营

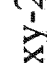

온

$\sum_{i}^{\infty}$

त.

$\sum_{z}^{\beta}$

U

3

递

$\varepsilon 8 E^{\circ} 8 \angle \square-$

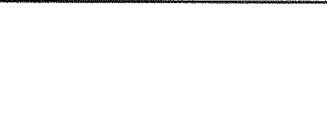




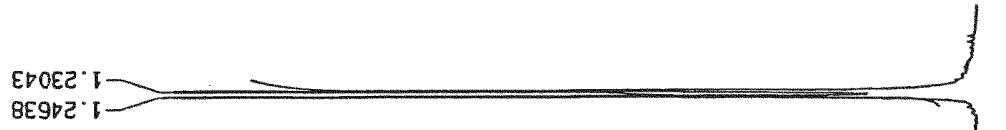

BE9be' I

$2062 \sigma^{\circ} \cdot$

E0sto $>$

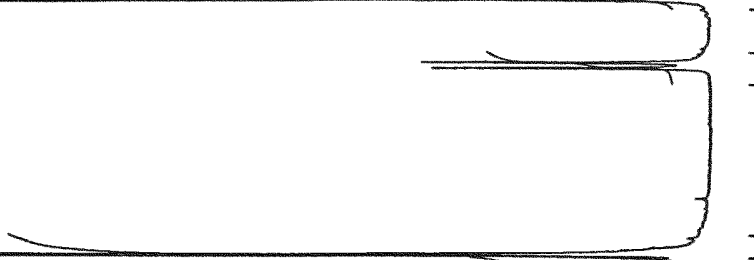

$0000 \bar{\varepsilon}$

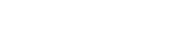

$90486 \cdot 1$
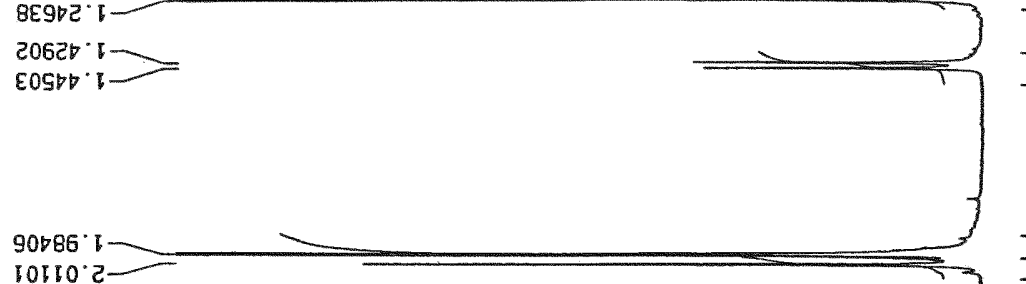

$\stackrel{9}{\Xi}$

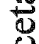

4

है

ॄี

0

$\frac{\pi}{0}$

Z

II
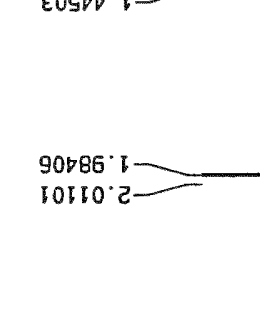

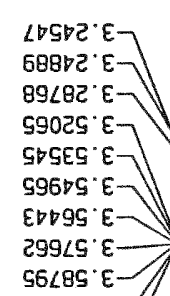

E9S09 $\mathrm{E}-$

S69.9. $\mathrm{E}$

$\angle 2860^{\circ} \mathrm{O}$

BटSOL 15

द82 1०

टट6 I 10

$$
\text { ट6951 }
$$

ด $9191^{\circ} \mathrm{C}$

$S \angle 9 \angle 1 \circ)$

\section{L'}
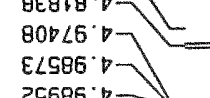

$$
\text { टद686 } \%
$$$$
\text { แ } 100^{\circ} \mathrm{G}
$$$$
00500^{\circ} \mathrm{S}
$$$$
09910.5-
$$

wdd

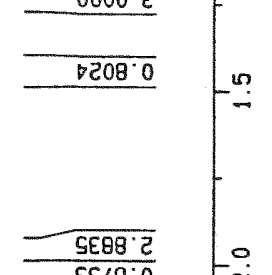

$\therefore \widehat{\Omega}$

$\sum \Xi$

$2 \ldots$

$\frac{7}{8}$

o

है है 


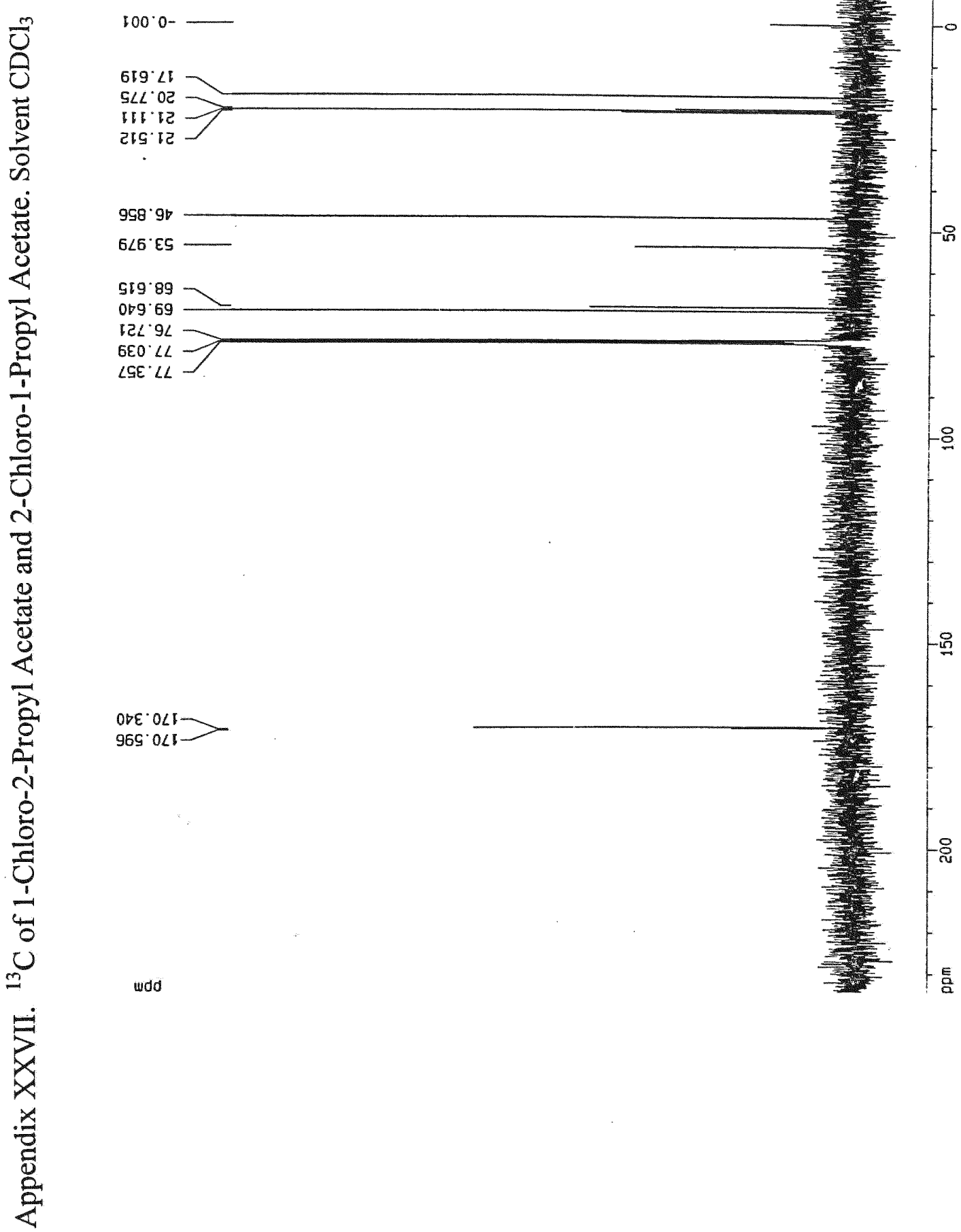




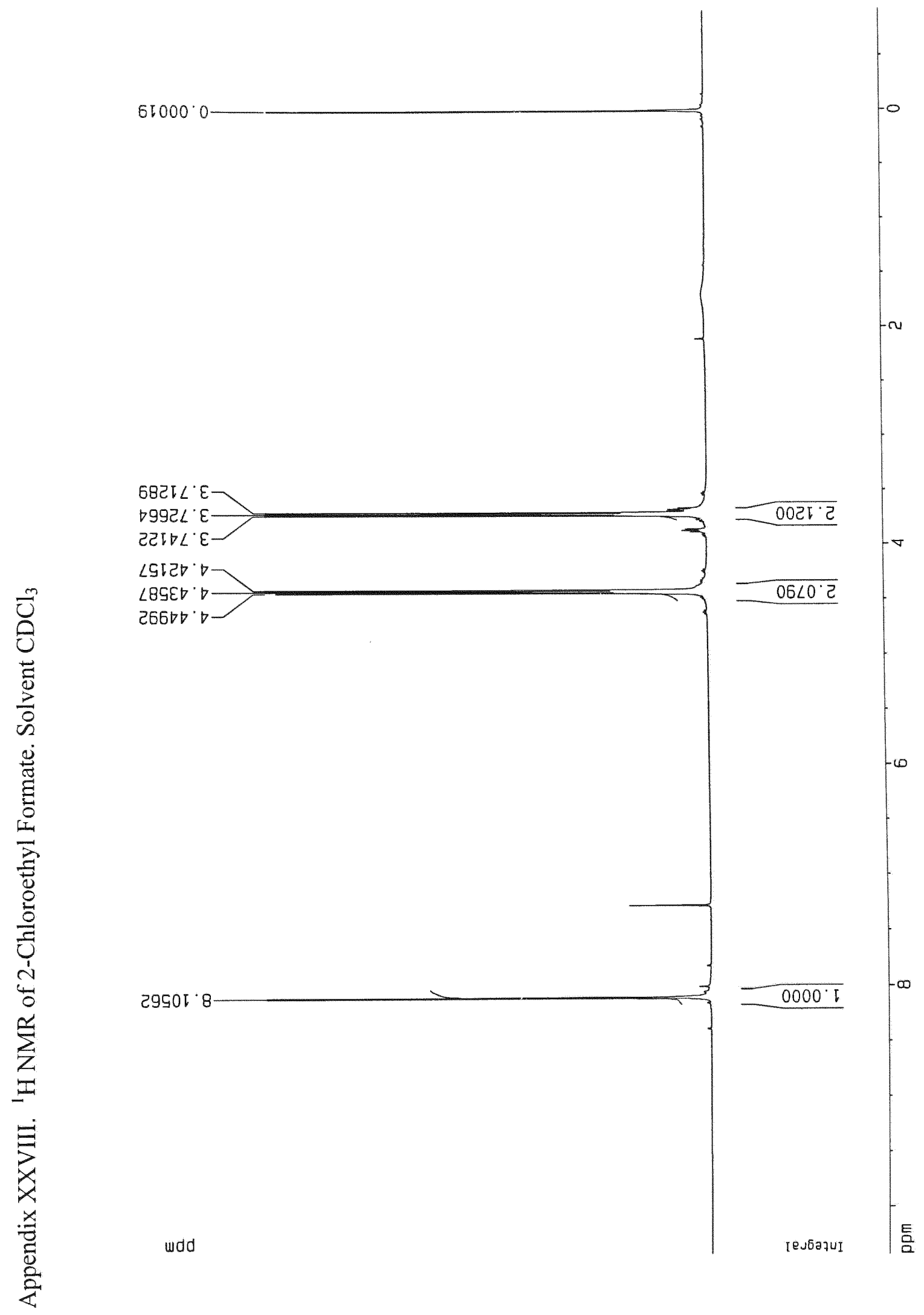




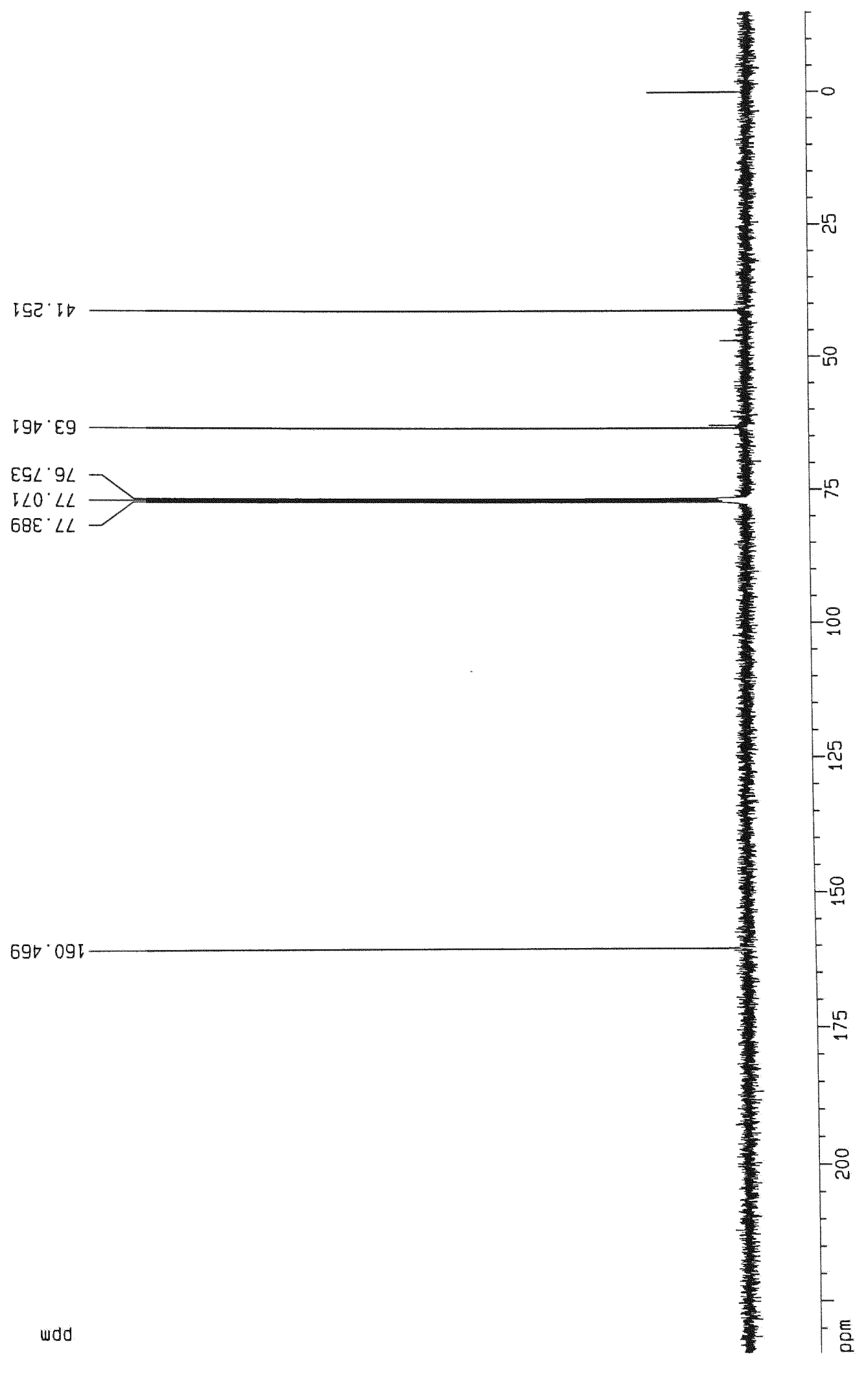


Appendix XXX. GC-MSD Analysis of Bis-(2-chloroisopropyl) Ether. Standards Mixture. Retention Times 16.79 min: n-Butanol; $18.47 \mathrm{~min}$ : Chloroacetone; $19.62 \mathrm{~min}$ : 1-Chloro-2-Propanol; 32.45 min 1-Chloro-2-Propyl Acetate; $32.58 \mathrm{~min}$ : 2-Chloro-1Propyl Acetate; 36.13 min: Bis-(2-chloroisopropyl) Ether

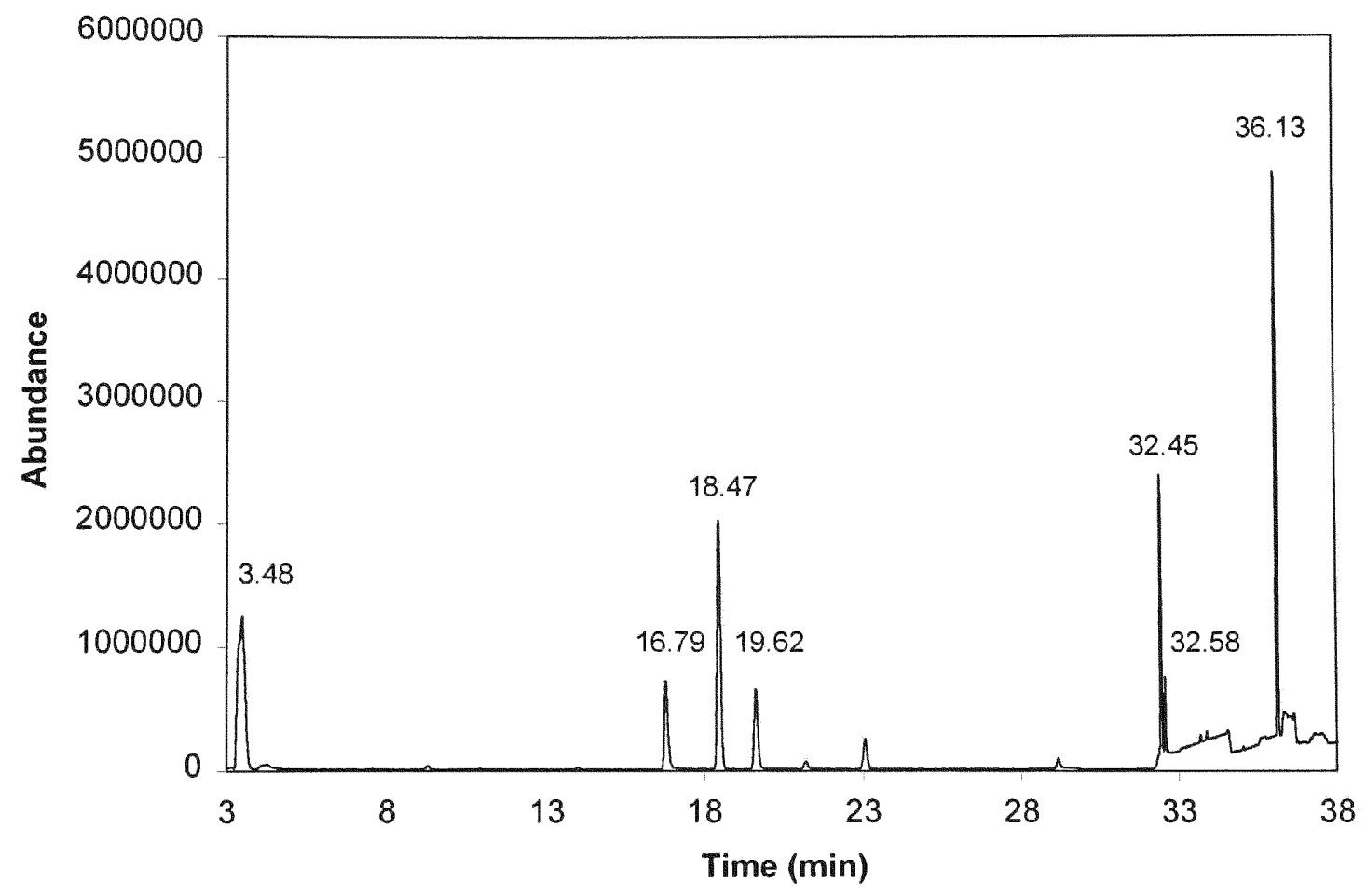


Appendix XXXI. Mass Spectra of 1-Chloro-2-Propyl Acetate Standard. Analysis Done by GC-Head Space-MSD

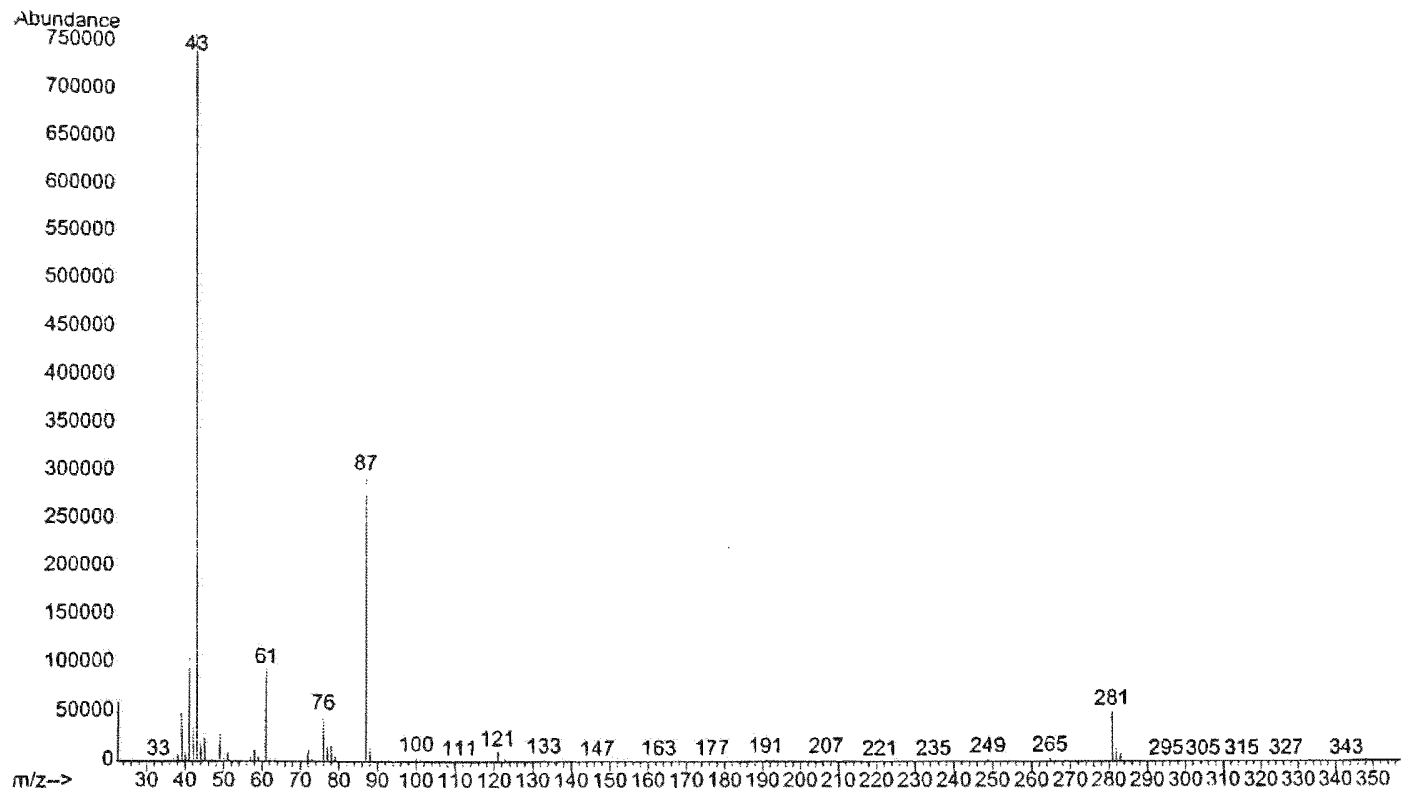


Appendix XXXII. Titanium Dioxide Photocatalyzed Degradation of Bis-(2chloroisopropyl) Ether (180 min Reaction). GC-Head Space-MSD Analysis. Retention Times 32.45 min: 1-Chloro-2-Propyl Acetate; $36.13 \mathrm{~min}$ : Bis-(2-chloroisopropyl) Ether

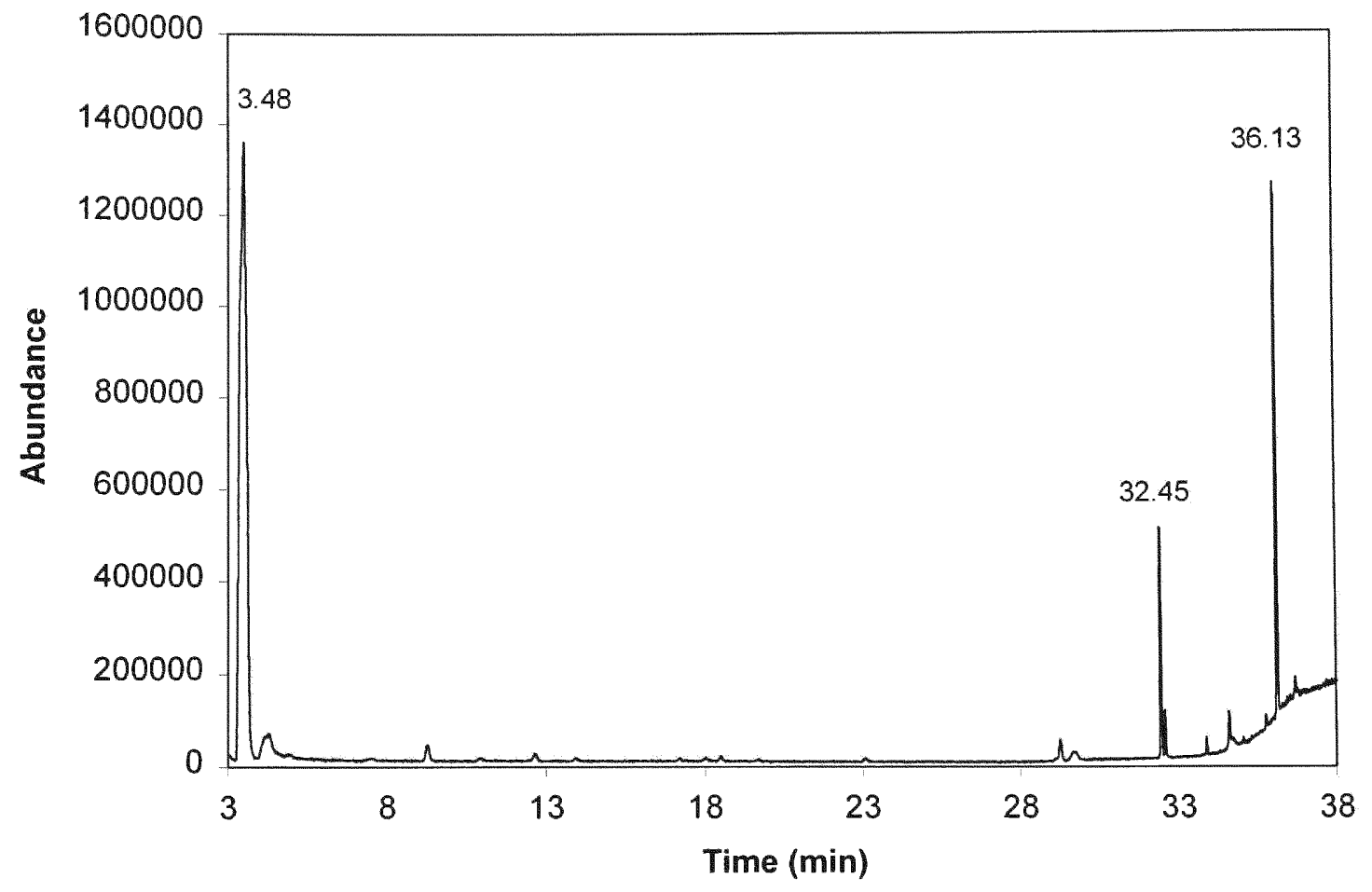


Appendix XXXIII. Mass Spectra of 1-Chloro-2-Propyl Acetate Formed During the Titanium Dioxide Photocatalyzed Degradation of Bis-(2-chloroisopropyl) Ether (180 min Reaction). GC-Head Space-MSD Analysis

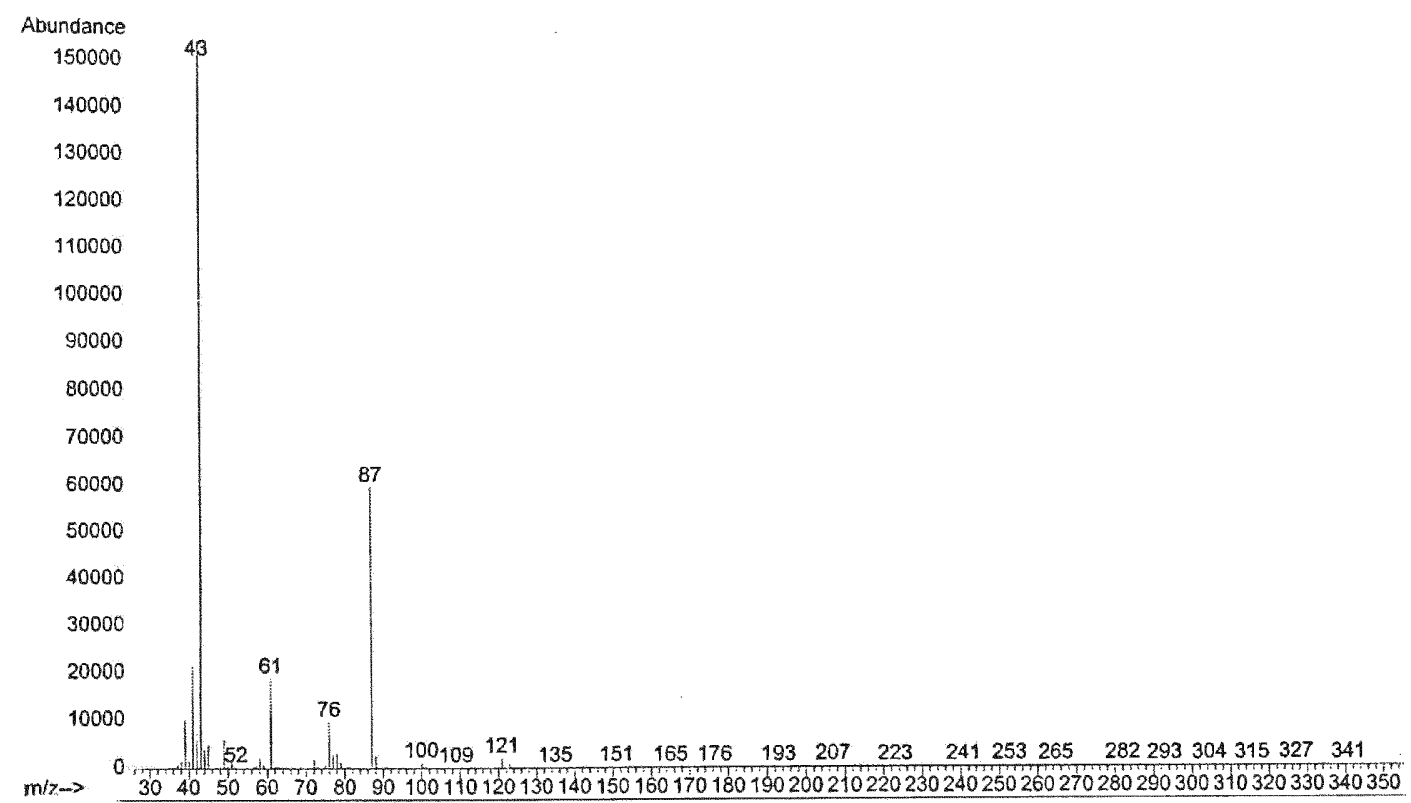


Appendix XXIV GC-Head Space MSD Analysis of Bis-(2-chloroethyl) Ether. Standards Mixture. GC-Head Space-MSD Analysis. Retention Times 4.94 min: Chloroacetaldehyde; 6.70 min: 2-Chloroethanol; $8.53 \mathrm{~min}$ : 2-Chloroethyl Formate; $13.78 \mathrm{~min}$ : Bis-(2chloroethyl) Ether

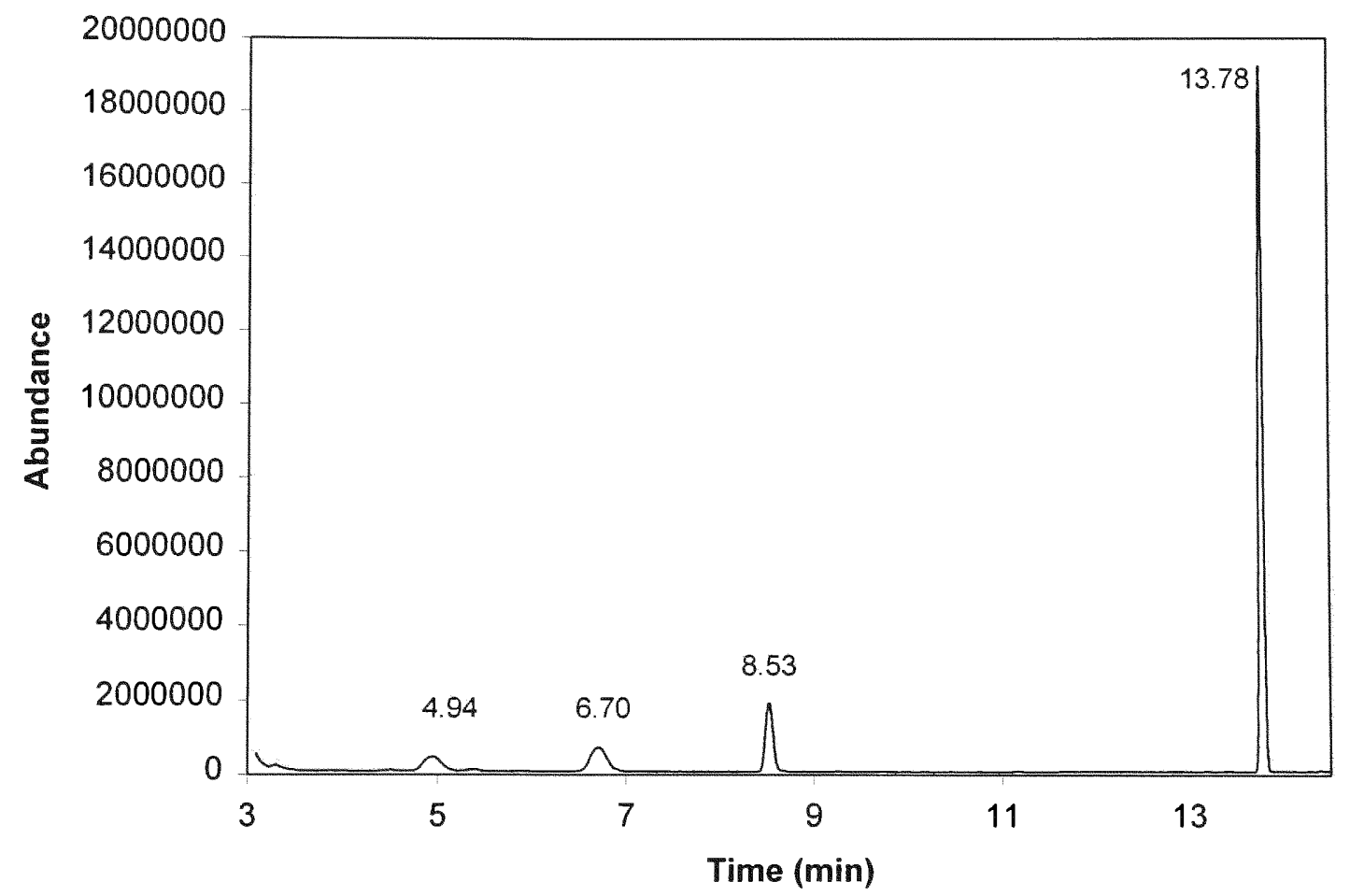


Appendix XXXV. Mass Spectra of 2-Chloroethyl Formate Standard by GC-Head Space MSD Analysis

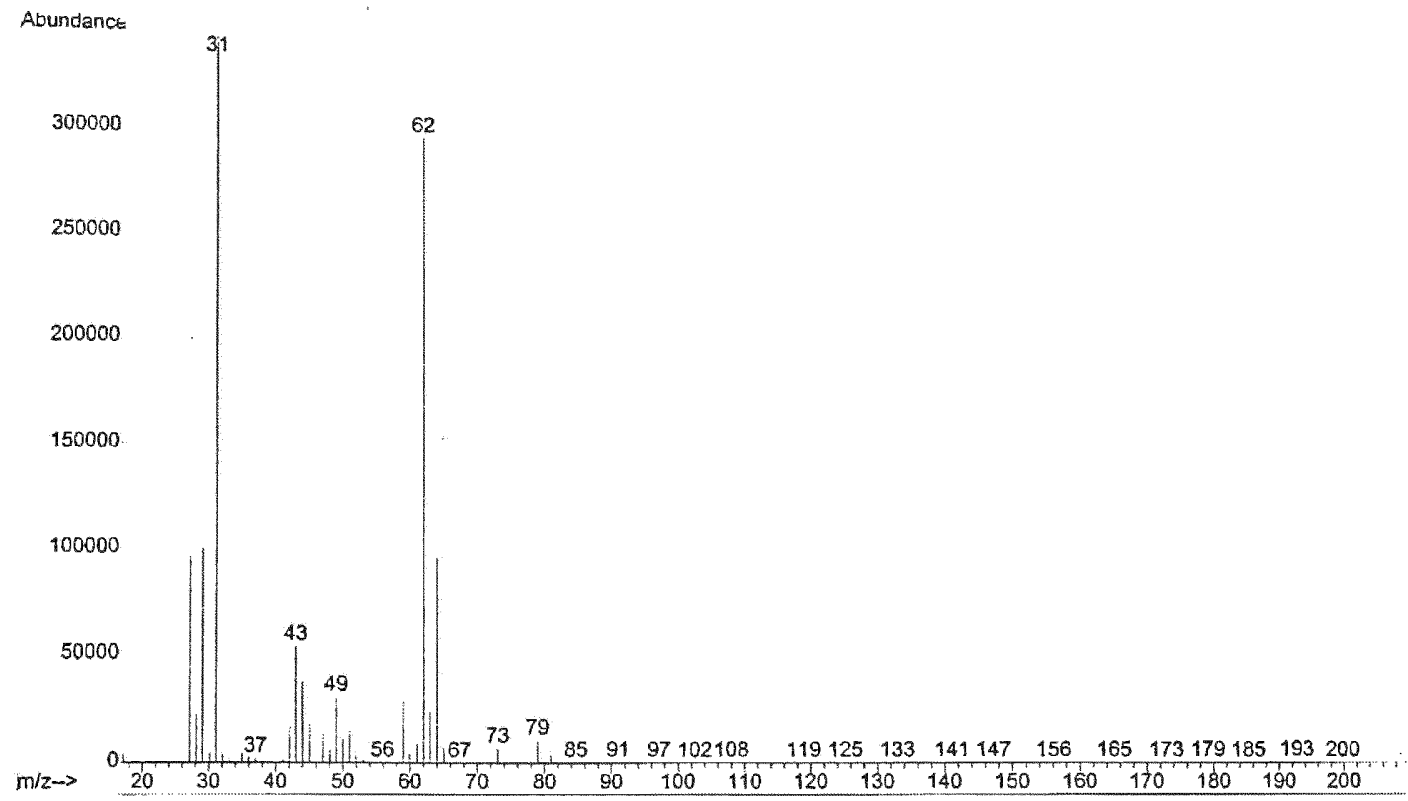


Appendix XXXVI. TiO 2 Photocatalytic Degradation of Bis-(2-chloroethyl) Ether. GCHead Space-MSD Analysis. Sample at 5 Hours of Irradiation. Retention Times: 6.70 min: 2-Chloroethanol; $8.53 \mathrm{~min}$ : 2-Chloroethyl Formate; $13.78 \mathrm{~min}$ : Bis-(2-chloroethyl) Ether

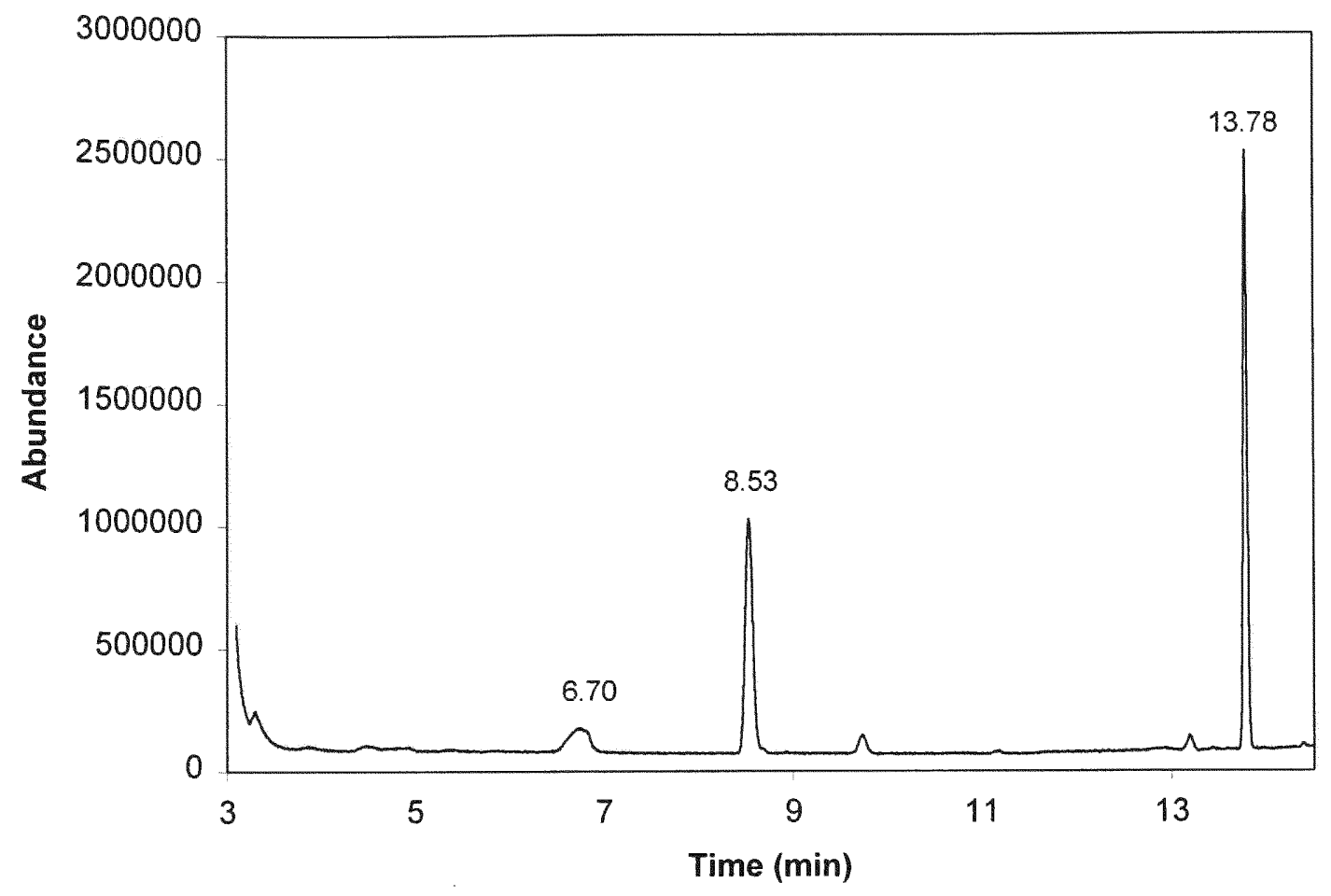


Appendix XXXVII. Mass Spectra of 2-Chloroethyl Formate Formed During the Titanium Dioxide Photocatalytic Degradation of Bis-(2-chloroethyl) Ether (5 Hours Reaction)

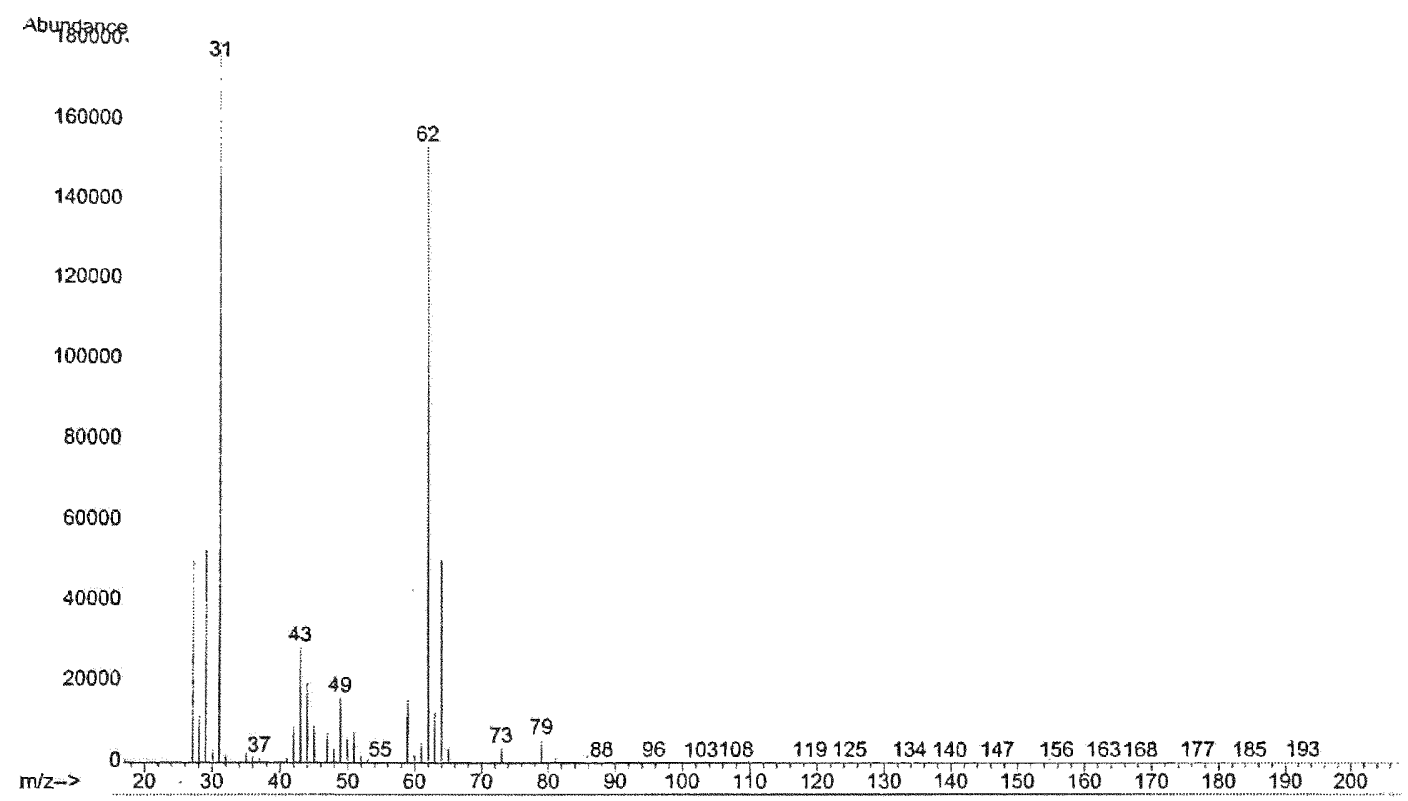

